\title{
Sinking, fast and slow: Bifurcating beta in financial and behavioral space
}

\section{Chen, James Ming}

- ReCeIved: I maY 2015

- accepted: 16 august 2015

\section{Abstract}

Modern portfolio theory accords symmetrical treatment to all deviations from expected return, positive or negative. This assumption is vulnerable on both descriptive and behavioral grounds. Many of the predictive flaws in contemporary finance stem from mathematically elegant but empirically flawed Gaussian models. In reality, returns are skewed. The presumption that returns and volatility are symmetrical also defies human behavior. Losing hurts worse than winning feels good; investors do not react equally to upside gain and downside loss. Moreover, correlation tightening during bear markets, not offset by changes in correlation during bull markets, suggests that standard diversification strategies may erode upside returns without providing adequate protection during times of stress. This article outlines mathematical tools for calculating volatility, variance, covariance, correlation, and beta, not merely across the entire spectrum of returns, but also on either side of mean returns. It pays special attention to beta. Beta is a composite measure that reflects changes in volatility and in correlation as returns move across either side of their expected value. Beta's separate components address the distinct managerial concerns arising from loss aversion (or upside speculation) and from changes in correlation under different market conditions. Bifurcating beta in financial space describes both phenomena and anticipates the behavioral response to volatility and correlation in falling markets - problems appropriately described as sinking, fast and slow.

\section{Keywords:}

Beta, downside risk, volatility, correlation, skewness, capital asset pricing model, CAPM, asset pricing, statistical moments, behavioral finance. 


\section{Desplomes rápidos y lentos: La bifurcación de la beta en el espacio financiero y conductual}

Chen, James Ming

\section{Resumen}

La teoría moderna de carteras confiere un tratamiento simétrico a toda desviación del rendimiento esperado, positiva o negativa. Este supuesto resulta vulnerable tanto empírica como conductualmente. Muchas de las imperfecciones predictivas de las finanzas modernas tienen su origen en el uso de modelos gaussianos que, aunque matemáticamente elegantes, son empíricamente erróneos. En realidad, los rendimientos son asimétricos. Más aún, la presunción de simetría tanto en los rendimientos como en la volatilidad contradice el comportamiento humano. El dolor que produce perder es superior al placer que conlleva ganar: los inversionistas no reaccionan igual ante las ganancias que ante las pérdidas. Más aún, la correlación elevada en la parte bajista del mercado, no compensada por cambios en la correlación en los periodos alcistas, sugiere que las estrategias estándar de diversificación erosionan los rendimientos positivos sin proporcionar una protección adecuada en los periodos negativos.

Este artículo describe las herramientas matemáticas necesarias para calcular volatilidad, varianza, covarianza, correlación y beta, no solo a lo largo del espectro total de retornos sino también a cada lado de su media. Se presta una especial atención a la beta, una medida compuesta que refleja cambios en volatilidad y correlación cuando los rendimientos varían por encima y por debajo del valor esperado. Los distintos componentes de la beta hacen referencia a las diferentes cuestiones que preocupan a los inversionistas, que surgen de la aversión a las pérdidas (o de la especulación en mercados alcistas) y de cambios en la correlación ante distintas condiciones de mercado. La bifurcación de la beta en el espacio financiero describe ambos fenómenos y anticipa la respuesta conductual a la volatilidad y la correlación en mercados bajistas -problemas consecuentemente descritos como desplomes, rápidos y lentos-.

\section{Palabras clave:}

Beta, riesgo de caída, volatilidad, correlación, asimetría, modelo de valoración del precio de los activos financieros, CAPM, valoración de activos, momentos estadísticos, finanzas conductuales. 


\section{Seduced by symmetry, smarter by half}

The capital asset pricing model (CAPM) remains the dominant paradigm in financial risk management - at least among practitioners, if not among scholars. Despite evidence that beta is not positively related to returns on stock, ${ }^{1}$ to say nothing of beta's failure to account for macroeconomic ${ }^{2}$ and idiosyncratic ${ }^{3}$ factors affecting security prices and returns, many investment professionals continue to rely on the CAPM. ${ }^{4}$ Even Eugene Fama, beta's leading nemesis, has conceded that "market professionals (and academics) still think about risk in terms of market $\beta$." "It takes a better theory to kill an existing theory," and the financial profession has "yet to see [a] better theory." 6 The spectacle is almost cartoonish:

In spite of the lack of empirical support, the CAPM is still the preferred model for classroom use in ... finance courses. In a way it reminds us of cartoon characters like Wile E. Coyote who have the ability to come back to original shape after being blown to pieces .... Maybe the CAPM survives because (a) the empirical support for other asset-pricing models is no better, (b) the theory behind the CAPM has an intuitive appeal that other models lack, and (c) the economic importance of the empirical evidence against the CAPM ... is ambiguous. ${ }^{7}$

The inconclusive attack on the capital asset pricing model also threatens the larger framework of modern portfolio theory, a broader branch of mathematical finance from which the CAPM is derived. In a 2012 issue of AESTIMATIO, the IEB International Journal of Finance, Harry Markowitz staged a stirring defense of modern portfolio theory over more mathematically comprehensive models, citing "economically significant difficulties in cost and convenience": "The only inputs required for a mean-variance analysis are the means, variances, and covariances of the [relevant] securities or asset classes." Modern portfolio theory, however, remains vulnerable in its symmetrical treatment of all deviations from expected return, positive or negative. This assumption is vulnerable on both descriptive and behavioral grounds. Many of the predictive flaws in contemporary finance stem from its reliance on the mathemat-

\footnotetext{
' See Eugene F. Fama \& Kenneth R. French, The Cross-Section of Expected Stock Returns, 47 J. FiN. 427 (I992); see also Marc R. Reinganum, A New Empirical Perspective on the CAPM, 16 FIN. \& QUANT.ANALYSIS 439 (1981); Seha M.Tinic \& Richard R.West, Risk and Return:January vs. the Rest of the Year, I 3 J. FIN. ECON. 56 I (1983).

${ }^{2}$ See Nai-Fu Chen, Richard Roll \& Stephen A. Ross, Economic Forces and the Stock Market, 59 J. Bus. 383 (1986).

${ }^{3}$ See Josef Lakonishok \& Alan C. Shapiro, Stock Returns, Beta,Variance, and Size:An Empirical Analysis, 40 FIN.ANALYSTS J. 36 (I 986 ).

${ }^{4}$ See Haim Levy, The CAPM Is Alive and Well:A Review and Synthesis, I6 EuR. Fin. MGMT. 43 (2009).

${ }^{5}$ Eugene F. Fama, Efficient Capital Markets: II, 46 J. FiN. I575, 1593 (I99I); accord Glenn N. Pettengill, Sridhar Sundaram \& Ike Mathur, The Conditional Relation Between Beta and Returns, 30 J. FIN. \& QUANT.ANALYSIS I0I, 102 (1995).As recently as 200I, more than two-thirds of financial practitioners in the United States used the classical CAPM formulation of beta as their basic measure of systematic risk. See John R. Graham \& Campbell R. Harvey, The Theory and Practice of Corporate Finance: Evidence from the Field, $60 \mathrm{~J}$. Fin. EcoN. 187 (200I). A 2004 survey reported that $45 \%$ of European financial practitioners relied on the CAPM. See Dirk Brounen,Abe Dejong \& Kees G. Koedijk, Corporate Finance in Europe: Confronting Theory with Practice, 33 FIN. MGMT. 7 I (2004).

${ }^{6}$ Tim Koller, Marc Goedhart \& David Wessels, Valuaiton: Measuring and Managing the Value of Companies 261 (5th ed. 20I0).

${ }^{7}$ Ravi Jagannathan \& Zhenyu Wang, The Conditional CAPM and the Cross-Section of Expected Returns, 5I J. FIN. 3, 4 (I996) (footnote omitted).

${ }^{8}$ Harry Markowitz, The "Great Confusion" Concerning MPT, 4 AESTIMATIO 8, I 4 (20I2). See generally Harry Markowitz, Mean-Variance Approximations to Expected Utility, 234 Eur.J. Operational ResearCH 346 (20l4); Harry M. Markowitz \& ErikVan Dijk, Single-Period Mean-Variance Analysis in a Changing World, 59 Fin.ANALYSTS J. 30 (2003).
} 
ically elegant but practically unrealistic construction of "beautifully Platonic models on a Gaussian base." ${ }^{9}$ Much of the edifice of contemporary mathematical finance - from the capital asset pricing model to the Black-Scholes model of option pricing, ${ }^{10}$ Merton's distance-to-default model of credit risk, ${ }^{11}$ the original RiskMetrics specification of valueat-risk, ${ }^{12}$ and the Gaussian copula ${ }^{13}$ - traces its origins to the Gaussian "normal" distribution. ${ }^{14}$ In reality, returns are skewed ${ }^{15}$ and exhibit heavier than normal tails. ${ }^{16}$

The presumption that returns and volatility are symmetrical also defies intuitive and quantitative understandings of human behavior. Investors do not regard excess gains to be as troubling as failures to meet a targeted level of returns - if indeed they object at all when returns exceed expectations. ${ }^{17}$ Most investors fear potential losses more than they covet potential gains. ${ }^{18}$ Fear of future shortfalls and attendant disappointment motivates precautionary savings. ${ }^{19}$ As the Supreme Court of the United States recognized in 1936, decades before the rise of prospect theory, "[t]hreat of loss, not hope of gain, is the essence of economic coercion." ${ }^{20}$ In even simpler words drawn from the lowest literary registers of the American South, "[l]osing hurts worse than winning feels good." 21 Behavioral limits on investor rationality drive momentum in short-run stock prices $^{22}$ and persistent overreaction to market events over the long run. ${ }^{23}$

Asymmetry in financial returns raises a managerial concern distinct from volatility, variance, or any other measure of dispersion. Correlations among asset classes rise as markets decline. ${ }^{24}$ In unruly markets, the only thing that rises is

\footnotetext{
9 Nassim Nicholas Taleb, The Black SWAN:The Impact of THe Highly Improbable 279 (2007).

${ }^{10}$ See Fischer Black \& Myron Scholes, The Pricing of Options and Corporate Liabilities, 81 J. PoL. EcoN. 637 (1973); Robert C. Merton, The Theory of Rational Option Pricing, 4 BeLL J. ECON. I4I (1973).

" See Robert C. Merton, On the Pricing of Corporate Debt:The Risk Structure of Interest Rates, 29 J. Fin. 449 (1974).

${ }^{12}$ See Jorge Mina \& Jerry Yi XiaO. Return to RiskMetrics:The Evolution OF A Standard (200I); Jeremy Berkowitz \& James O’Brien, How Accurate Are Value-at-Risk Models at Commercial Banks?, 57 J. Fin. 1093 (2002).

${ }^{13}$ See Roger B. Nelsen,AN Introduction to Copulas (1999); David X. Liu, On Default Correlation:A Copula Function Approach, 9:4 J. FiXed InCOMe 43 (2000).

14 See generally Benoit B. Mandelbrot,The (Mis)BehaVior of Markets:A Fractal VIeW of RISK, Ruin, ANd ReWARd (2004).

15 See, e.g., John Y. Campbell, Andrew W. Lo \& A. Craig MacKinlay, The Econometrics of Financial Markets 17, 81 , I72, 498 (1997); Felipe M. Aparicio \& Javier Estrada, Empirical Distributions of Stock Returns: European Securities Markets, 1990-95, 7 EUR.J. Fin. I (200I); Geert Bekaert, Claude Erb, Campbell R. Harvey \& Tadas Viskanta, Distributional Characteristics of Emerging Market Returns and Asset Allocation, 24:2 J. PORTFOLIO MGMT. I02 (Winter 1998); Pornchai Chunhachinda, Krishnan Dandepani, Shahid Hamid \&Arun J. Prakash, Portfolio Selection and Skewness: Evidence from International Stock Markets, 21 J. BANKING \& FiN. 143 (1997);Amado Peiró, Skewness in Financial Returns, 23 J. BANKING \& Fin. 847 (I999).

${ }^{16}$ See, e.g., Stanley J. Kon, Models of Stock Returns - A Comparison, 39 J. FinANCE I47 (I 984); Harry M. Markowitz \& Nilufer Usmen, The Likelihood of Various Stock Market Return Distributions, Part I:Principles of Inference, I3 J. RISK \& UNCERTAINTY 207 (1996); Harry M. Markowitz \& Nilufer Usmen, The Likelihood of Various Stock Market Return Distributions, Part 2: Empirical Results, 13 J. RISK \& UNCERTAINTY 22I (1996); Terence C. Mills, Modelling Skewness and Kurtosis in the London Stock Exchange FT-SE Index Return Distributions, 44 STATISTICIAN 323 (1995).

${ }_{17}$ See, e.g., Ralph O. Swalm, Utility Theory — Insights into Risk Taking, 44 Harv. Bus. Rev. 123 (1966).

${ }^{18}$ See, e.g., Daniel Kahneman \& Amos Tversky, Prospect Theory:AnAnalysis of Decision under Risk, 47 EconOMETRICA 263 (I979); Paul Slovic, Psychological Study of Human Judgment: Implications for Investment Decision Making, 27 J. FIN. 779 (1972).

${ }^{19}$ See Miles Kimball, Precautionary Saving in the Small and in the Large, 58 ECONOMETRICA 53 (1990).

${ }^{20}$ United States v. Butler, 297 U.S. I, 82 (1936).

${ }^{21}$ Lewis Grizzard, Gettin' It ON:A Down-Home Treasury 72 (1990). Lewis Grizzard (1946-94) was a humor columnist for the Atlanta JournalConstitution.

${ }^{22}$ See Mark M. Carhart, On Persistence in Mutual Fund Performance, 52 J. Fin. 57 (1997); Mark Grinblatt, Sheridan Titman \& Russ Wermers, Momentum Investment Strategies, Portfolio Performance, and Herding:A Study of Mutual Fund Behavior, 85 AM. EcoN. Rev. I088 (1995); Narasimhan Jegadeesh \& Sheridan Titman, Returns to Buying Winners and Selling Losers: Implications for Market Efficiency, 48 J. FIN. 65 (1993).

${ }^{23}$ See Werner F.M. DeBondt \& Richard H.Thaler, Does the Stock Market Overreact?, 40 J. FiN. 557 (1985).

${ }^{24}$ See, e.g., Rob Bauer, Roul Haerden \& Roderick Molenaar, Asset Allocation in Stable and Unstable Times, I3:3 J. INVESTING 72 (Fall 2004 ); Malcolm P. Baker \& Jeffrey Wurgler, Comovement and Predictable Relations Between Bonds and the Cross-Section of Stocks, 2 Rev.AsSET PrICING STUD. 57 (20I2).
} 
correlation. ${ }^{25} \mathrm{Or}$, in a play on the words of a more elegant Southern writer, everything that crashes must converge. ${ }^{26}$ Even under ideal conditions, risk reduction through portfolio diversification poses a formidable challenge. Long-term positive correlation between stocks and bonds undermines the effectiveness of diversification. ${ }^{27}$ Increases in correlation during bear markets, not matched by corresponding increases in correlation during bull markets, suggest that standard diversification strategies may erode upside returns without providing adequate protection during times of stress. ${ }^{28}$ Ironically, rising correlations in falling markets imperil the very portfolios that are designed to weather variability in normal markets. ${ }^{29}$

This article propounds a comprehensive set of mathematical tools for calculating volatility, variance, covariance, correlation, the coefficient of determination (or $r$ squared), and beta, not merely across the entire spectrum of returns, but also on either side of the asset-specific or market-wide mean (or, for that matter, any other benchmark). Full elaboration of partial second moments in the distribution of returns facilitates the calculation of overall, upside, and downside variants of the measures most often used to evaluate portfolio risk. The relationship between risk measures on either side of the relevant benchmark can be described in simple mathematical terms.

The development of single-sided risk measures does more than supplement the standard toolkit of portfolio theory, a craft already under pressure to predict asset prices and to anticipate (if not entirely neutralize) investor psychology. Devising distinct measures of upside and downside volatility, covariance, and correlation facilitates the testing of hypotheses reflecting market and behavioral factors that may change when returns cross above or below critical thresholds. Complete mathematical specification ensures that these measures are both theoretically consilient and empirically computable. Risk measures with clear physical interpretations provide readily understandable, easily quantifiable, and statistically verifiable support or contradiction for intuitions about risk management and portfolio design.

To name just one possibility, the explicit specification of upside volatility, covariance, and correlation would support research into the risks that lurk when returns exceed investor expectations. A considerable literature examines downside risk. This

\footnotetext{
${ }^{25}$ See, e.g., John Drzik, Richard J. Herring \& Francis X. Diebold, The New Role of Risk Management: Rebuilding the Model, Knowledge@Wharton, http://knowledge.wharton.upenn.edu/article.cfm?articleid=2268 (June 24, 2009).

${ }^{26}$ Cf. Flannery O'CONNOR, EVERYTHing That RISES Must CONVERGE (1965).

${ }^{27}$ See John Y. Campbell \& John Ammer, What Moves the Stock and Bond Markets? A Variance Decomposition for Long-Term Asset Returns, 48 J. Fin. 3 (1993); cf. Robert Dubois, Asset Price Trend Theory: Reframing Portfolio Theory from the Ground Up, 16:3 J.WEALTH MgMT. II, I2-I3, (Winter 20I3) (distinguishing between "risk moderation" through the reduction of "both positive and negative variance" and "risk containment" through "limit[s] [on] negative portfolio variance," such as "loss-contingent exits").

${ }^{28}$ See François Longin \& Bruno Solnik, Extreme Correlation of International Equity Markets, 56 J. FiN. 649, 650-5I, 669-70 (200I).

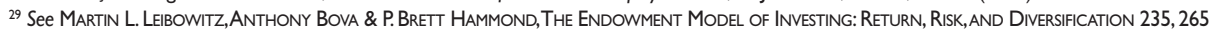
(20I0).
} 
article's method for decomposing the elements of upside and downside risk, however, should be sufficiently supple to address the financial variant of what Tennessee Williams called "the catastrophe of success": ${ }^{30}$ how investors and institutions shred their investment plans in the presence (or even the mere anticipation) of upside gain.

Other uses for properly measured upside volatility abound. For instance, one source promotes upside semideviation as a measure of active portfolio managers' performance that, unlike the information ratio, does not punish performance exceeding a benchmark rate of return. ${ }^{31}$ Another source encourages portfolio managers to combine stocks with relatively low downside beta (to temper exposure to declining markets) and stocks with relatively high upside beta (to capture potential gains in rising markets). ${ }^{32}$

Of particular interest is beta. ${ }^{33}$ Within the conventional formulation of the capital asset pricing model, beta supplies the basic measure of investment risk: "Stocks with betas greater than one are more volatile than the market and are known as aggressive stocks. In contrast, stocks with betas less than one are less volatile ... and are known as defensive stocks." ${ }^{34}$ Even in 2015, beta as a measure of systematic risk "remains the most explanatory element of the risk premium in most asset pricing models." 35 According to historians and philosophers of science, "the eminence of a scientist" can be measured "by the length of time that he holds up progress in his field." 36 By that standard, beta's dead hand still grips mathematical finance. For all of opprobrium and disqualifying evidence adduced against "standard deviation and its variations" (including beta) as measures of risk "in ... non-normal distributions," "relatively little effort has been made" to devise "a better risk measure that might resolve ... dispute[s]" over the vitality of the CAPM. ${ }^{37}$ Even today, "the concept of beta risk" arguably remains "the single most important contribution of academic researchers to the financial community." 38

\footnotetext{
${ }^{30}$ See Tennessee Williams, The Catastrophe of Success, in N.Y.Times, Nov. 30, 1947, reprinted in TenNessee WiLliams, The GLAss MenAGERIE 99 (Robert Bray introd., 1999).

${ }^{31}$ See FrankA. Sortino, Robert van der Meer \& Auke Plantinga, The Dutch Triangle,J. PoRTFOLIO MGMT., Fall 1999, at 50."The information ratio is the ratio of the expected annual residual return to the annual volatility of the residual return." RICHARD C. GRINOLD \& RONALD N. KAHN, ACTIVE Portfolio Management:A Quantitative Approach for Producing Superior Returns ANd Controluing Risk 5 (2d ed. I999). In other words, the information ratio is expected active return divided by tracking error, where active return is the difference between realized returns and benchmark return, and tracking error is the standard deviation of the active return. See generally id. at 109-46.

${ }^{32}$ See James Chong, Shaun Pfeiffer \& G. Michael Phillips, Can Dual Beta Filtering Improve Investor Performance?, 10 J. PERSONAL FIN. 63,74 (20I0).

${ }^{33}$ See generally, e.g., Seth Klarman \& Joseph Williams, Beta, 5 J. Fin. EcoN. 117 (I99I); Jay Shanken, On the Estimation of Beta Pricing Models, 5 Rev. Fin. STUD. I (1992).

${ }^{34}$ William F. Sharpe, Gordon J.Alexander \& JefFrey W. Bailey, INVESTMents I83 (6th ed. 1998).

${ }^{35}$ M.A. Bellelah, M.O. Bellelah, H. Ben Ameur \& R. Ben Hafsia, Does the Equity Premium Puzzle Persisist During Financial Crisis? The Case of the French Equity Market, Research in Int'l Bus. \& Fin. (preprint proof posted 4 March 20I5, at page I4).Available at http://dx.doi.org/10.1016/j.ribaf.2015.02.018

${ }^{36}$ J.E. LOVELOCK, GAIA:A NeW LOOK AT LIFE ON EARTH 70 (I979); see also EDWARD O.WILSON, CONSILIENCE:THE UNITY OF KNOWLEDGE I82-83 (I998) ("[P]rogress in a scientific discipline can be measured by how quickly its founders are forgotten."); $f$. A.N.WHITEHEAD, THE AIMS OF EDUCATION AND OTHER ESSAYS 162 (1929) (“A science which hesitates to forget its founders is lost.").

${ }^{37}$ Guy Kaplanski, Traditional Beta, Downside Risk Beta and Market Risk Premiums, 44 Q. Rev. Econ. \& Fin. 636, 637 (2004).

${ }^{38}$ Louis K.C. Chan \& Josef Lakonishok, Are Reports of Beta's Death Premature?, I9:4 J. PORTFOLIO MGMT. 5I, 51 (Summer 1993); see also Jagannathan \& Wang, supra note 7, at 4 ("The CAPM is widely viewed as one of the two or three major contributions of academic research to financial managers during the postwar era.").
} 
Considerable scholarship has responded to Fama and French's declaration in 1992 that "the relation between $\beta$ and average return ... is weak, perhaps nonexistent." 39 One line of scholarship, which now dominates financial literature, pursues the small size and book-to-market ratio factors that Fama and French identified as the most significant deviations from the conventional CAPM. ${ }^{40}$ Another line of scholarship, however, has sought to rehabilitate beta by emphasizing single-sided beta as an improvement on the standard measure that Fama and French discredited. ${ }^{41}$ This article seeks to extend that mission. If indeed "there is a conditional relationship between beta and returns," especially if single-sided beta provides "a good indicator of how stocks react in periods of down market[s]," then "beta may still have a useful role to play." 42

"[E]ven if beta is less efficient than alternative measures of systematic risk or is ... incomplete," it may still "be justified as a measure of risk." 43 This relatively modest goal nevertheless demands rigorous work. Rejecting "the mean variance CAPM" in favor of a more "satisfactory description of market equilibrium poses what statistical science calls type I and type II errors. ${ }^{44}$ On one hand, "the persistence of [pricing] anomalies over time" in beta ${ }^{45}$ and the conventional CAPM "may be related to the possibility that useless factors appear to be priced." On the other hand, "pricing anomalies" may be "due to omitted factors. ${ }^{46}$ Even Eugene Fama and Kenneth French concede that it remains entirely "possible that the apparent empirical failures of the CAPM are due to bad proxies for the market portfolio," so that "the true market is mean-variance efficient," even if "the proxies used in empirical tests are not." ${ }^{47}$

To put the point bluntly: "A systematic relationship" of some sort "must exist between beta and [cross-sectional] returns for beta to be a useful measure of risk." 48 Beta's scientific salvation may lie in the calculation and evaluation of its upside and downside components. More precisely, mathematical finance should calculate single-sided beta based on whether returns on a security, an asset class, a portfolio, or a market benchmark have fallen short of, matched, or exceeded mean return (or, for that matter, any other target rate). So measured, this methodological warhorse may unearth

\footnotetext{
${ }^{39}$ Fama \& French, supra note I, at 464.

${ }^{40}$ See, e.g., Kent Daniel \& Sheridan Titman, Evidence on the Characteristics of Cross-Sectional Variation in Stock Returns, 52 J. FiN. I (I997); Eugene Fama \& Kenneth R. French, Size and Book-to-Market Factors in Earnings and Returns, 50 J. FIN. I3I (1995).

${ }^{41}$ See, e.g., Fischer Black, Beta and Return, 20:I J. PoRTFolio MGMT. 8 (Fall 1993); Chan \& Lakonishok, supra note 38; Kevin Grundy \& Burton G. Malkiel, Reports of Beta's Death Have Been Greatly Exaggerated, $22: 3$ J. PoRTFOLIO MGMT. 36 (Spring 1996).

${ }^{42}$ Jonathan Fletcher, An Examination of the Cross-Sectional Relationship of Beta and Return: UK Evidence, 49 J. EcoN. \& Bus. 211 , 220 (I997).

${ }^{43}$ Pettengill, Sundaram \& Mathur, supra note 5, at 102.

${ }^{44}$ Giovanni Barone Adesi, Patrick Gagliardini \& Giovanni Urga, Testing Asset Pricing Models with Coskewness, 22 J. Bus. \& EcON. STAT. 474, 474 (2004). On type I and type II errors, see generally ROXY PECK \& JAY L. DeVORE, STATISTICS:THE EXPLORATION AND ANALYSIS OF DATA $464-65$ (20I I); DAVID Sheskin, Handbook of Parametric and Nonparametric Statistical Procedures 54 (2004).

45 Barone Adesi, Galiardini \& Urga, supra note 44, at 474.

${ }^{46} \mathrm{Id}$.

${ }^{47}$ Eugene F. Fama \& Kenneth R. French, The CAPM Is Wanted Dead or Alive, 5 I J. FiN. 1947, 1956 (1996); accord Kaplanski, supra note 37 , at 637.

${ }^{48}$ Pettengill, Sundaram \& Mathur, supra note 5, at 105.
} 
previously unrecognized insights into volatility and correlation toward either extreme of the distribution of returns. ${ }^{49}$

As correlated relative volatility, beta contains two components. Beta is a composite measure that reports both the ratio of asset-specific to market-wide volatility and the correlation between that asset and the market as a whole. The computation of beta, varying according to market conditions, permits the evaluation of beta, in its conventional CAPM formulation, as distinct components that reflect changes in volatility and in correlation as returns move across either side of their expected value. These components address, respectively, the distinct managerial concerns arising from loss aversion (or upside speculation) and from changes in correlation under different market conditions. Breaking beta down into upside and downside components, and further into components reflecting changes in volatility versus correlation with broader market conditions, enables us to better quantify the behavioral and systematic aspects of dynamic markets. This dichotomy reflects what Daniel Kahneman describes as the two modes of human thought, the "fast" heuristics of human behavior and the "slow" processing of rational evidence. ${ }^{50}$ In the context of downside risk, single-sided beta most fully describes financial sinking, fast and slow.

This article concludes with an anticipatory glance at skewness and coskewness in financial returns. After all, "semivariance combines into one measure the information provided by two statistics, variance and skewness, thus making it possible to use a one-factor model." 51 The question is whether a one-factor model relying on semivariance or any of its derivatives, including single-sided beta, should give way on grounds of accuracy and validity to more complex measurements. One strain within the literature contends that skewness and coskewness outperform downside beta in reflecting the cross-section of financial returns. At a minimum, however, single-sided beta and other measures derived from partial second moments of financial distributions are compatible with methodologies emphasizing higher-order moments. Indeed, full elaboration of single-sided beta represents a vital step in reestablishing the CAPM on a four-moment basis. Before abandoning the two-moment model that has sustained portfolio management for decades, we should extract all of the information that remains embedded within the second moment. Through this article's modest, easily implemented improvements in the measurement of volatility, covariance, and correlation, that information can sharpen the mathematical interpretation of financial returns.

\footnotetext{
${ }^{49}$ Nurjannah, Don U.A. Galadegera \& Robert Brooks, Conditional Relation Between Systematic Risk and Returns in the Conventional and Downside Frameworks: Evidence from the Indonesian Market, 3 J. EMERGING MKT. FIN. 27I, 274 (20I2).

50 See generally DANIEL KAHNEMAN, THINKING, FAST AND SLOW 19-105 (201 I).

${ }^{51}$ Javier Estrada, Systematic Risk in Emerging Markets:The D-CAPM, 3 EMERGING MKTS. Rev. 365, 366 (2002).
} 


\section{Diving to be deeper: ${ }^{52}$ a history of downside risk measures}

The danger in assuming symmetry in the distribution of returns is neither new nor mysterious. Many of the architects of modern portfolio theory nevertheless adopted this statistical shortcut in grudging acceptance of that era's computational limitations. ${ }^{53}$ Harry Markowitz's theoretical call "for calculating the covariances of every security" initially posed a "monumental" barrier to practical implementation: under the constraints on computing power during the 1960s, "[c]alculating a single portfolio could eat up tens of thousands of dollars in computer time." ${ }^{24}$ As William Sharpe noted in 1964: "Under certain conditions the [mean-variance analysis] can be shown to lead to unsatisfactory predictions of [investor] behavior. Markowitz suggests that a model based on the semivariance would be preferable; in light of the formidable computational problems, however, he bases his analysis on the mean and the standard deviation." 55 Other economists confirmed the feasibility and theoretical superiority of Markowitz's unimplemented semivariance measure. ${ }^{56}$ Business leaders agreed: A 1969 survey revealing an "emphasis on downside risk" by executives in diverse industries "indicate[d] that their concept of risk [was] better described by semi-variance than by ordinary variance." ${ }^{57}$ Institutional investors have likewise indicated that their definition of risk hinges not on raw variability in returns, but on avoidance of loss. ${ }^{58}$

Traditional, two-tailed measurements of risk-adjusted performance, particularly the Sharpe ratio, ${ }^{59}$ give dangerous guidance during bear markets because they implicitly assume that returns are normally distributed and because they effectively treat upside and downside volatility as equal constituents of risk. ${ }^{60}$ Roy's safety-first criterion, announced in 1952, consciously sought to minimize the probability that an investor would realize actual returns $\left(R_{a}\right)$ below some minimally acceptable baseline $\left(R_{b}\right){ }^{61}$

\footnotetext{
${ }^{52}$ Cf. SinÉAd LoHan, Diving to Be Deeper, on No Mermaid (1998).

${ }^{53}$ See, e.g., Fred D. Arditti, Risk and the Required Return in Equity, 22 J. FiN. 19 (1967) (analyzing the relationship between expected return and skewnewss in the distribution of returns); Merton H. Miller \& Myron S. Scholes, Rates of Return with Relation to Risk: A Reexamination of Some Recent Findings, in STUDIES IN THE THEORY OF CAPITAL MARKETS 47 (Michael C. Jensen ed., 1 1972) (subjecting one capital asset pricing model to testing in response to asymmetry in the distribution of returns).

${ }^{54}$ Justin Fox, The Myth of the Rational Market:A History of Risk, ReWard, and Delusion on Wall Street 86 (2009).

${ }^{55}$ William F. Sharpe, Capital Asset Prices: A Theory of Market Equilibrium Under Conditions of Risk, 19 J. Fin. 425, 428 n.8 (I964). Markowitz considered five alternatives to variance as a measure of risk: expected value of loss, the probability of loss, expected absolute deviation, maximum expected loss, and semivariance. See Harry M. MarkowitZ, Portfolio Selection 188-94, $287-97$ (1959); James C.T. Mao, Models of Capital Budgeting: E-VVs. E-S, 4 J. FIN. \& QUANT.ANALYSIS 657 (1970).

${ }^{56}$ See James P. Quirk \& Rubin Saposnik, Admissibility and Measurable Utility Functions, 29 Rev. Econ. STUD. 140 (1962). Markowitz eventually implemented a version of mean-semivariance optimization in 1993. See Harry Markowitz, Peter Todd, Ganlin Xu \& Yuji Yamane, Computation of Mean-Semivariance Efficient Sets by the Critical Line Algorithm, 45 AnNAls OPER. ReSEARCH 307 (1993).

${ }^{57}$ James C.T. Mao, Survey of Capital Budgeting:Theory and Practice, 25 J. FiN. 349, 354 (1970).

${ }^{58}$ See Philip L. Cooley, A Multidimensional Analysis of Institutional Investor Perception of Risk, 32 J. FIN. 67 (I977).

${ }^{59}$ See William F. Sharpe, Mutual Fund Performance, 39 J. Bus. I 19, 123 (1966) (proposing a measure of "reward to variability" that treated standard deviation as its measure of risk);William F. Sharpe, Adjusting for Risk in Portfolio Performance Measurement. I:2 J. PorTfOLIO MGMT. 29 (Winter I975) (same).

${ }^{60}$ See James S.Ang \& Jess H. Chua, Composite Measures for the Evaluation of Investing Performance, I4 J. FIN. \& QUANT.ANALYSIS 36I (I 979 ); Robert C. Klemkosky, The Bias in Composite Performance Measures, 8 J. Fin. \& QUANT.ANAlYsIs 505 (1973); Hendrik Scholz, Refinements to the Sharpe Ratio: Comparing Alternatives for Bear Markets, 7 J.AsSet MGMT. 347 (2007).

${ }^{61}$ See Arthur D. Roy, Safety First and the Holding of Assets, 20 EconOMETRICA 43I (1952).
} 
Formally, a portfolio manager should minimize $P\left(R_{a}<R_{b}\right)$. Roy's safety-first criterion very modestly substitutes the minimally acceptable baseline for the risk-free rate of the Sharpe ratio. It directs a manager to maximize $\frac{E-d}{\sigma}$, where $E$ is the expected return and $d$ represents "some disastrous level of return." 62

Markowitz has described Roy's safety-first criterion as one of the "two papers published in 1952" that opened the "era of modern portfolio theory." ${ }^{63}$ William Baumol later demonstrated that Roy's criterion could be satisfied by minimizing $E-k \sigma .{ }^{64}$ The quantity $E-k \sigma$, which exploits ordinary definitions of mean, standard deviation, and standard score $(x=\mu+z \sigma)$, was alleged to be "a more reasonable measure of risk than $\sigma$ itself." ${ }^{65}$ Consistent with modern portfolio theory's focus on events near the mean, Markowitz and Baumol conditioned their reconciliation of Roy's safety-first criterion with the assumption that $k$ would be pegged at " 2 or 3. " 66

In retrospect, Roy's safety-first criterion and its emphasis on avoidance of catastrophic loss foreshadowed later economists' concern with minimizing downside risk. Roy identified a distinction noted in early literature on mathematical finance and subsequently highlighted by behavioral economics: whereas small-scale financial decisions may seek "some target rate of return," larger commitments "involve[] the danger of insolvency." 67 "Most investors perceive a low probability of a large loss to be far more risky than a high probability of a small loss, even when the expected losses are the same." ${ }^{68}$ Although this perception does represent a departure from perfect rationality and the economic assumptions underlying the efficient capital markets hypothesis, it is more realistic to model financial markets with awareness of this nearly universal human heuristic.

The measures of semivariance, semideviation, semicovariance, semicodeviation, and single-sided beta of specific interest to this article may be traced to a 1974 article by William Hogan and James Warren. ${ }^{69}$ Hogan and Warren offered a downside risk measure whose point of reference was the risk-free return. Formally, they defined downside covariance between an asset and the market as a whole as the expected value of the difference between the return on an asset and the risk-free rate, times the

\footnotetext{
62 Harky M. Markowitz, Mean-Variance Analysis in Portfolio Choice and Capital Markets 37 (1987).

${ }^{63}$ Id. The other paper was Harry M. Markowitz, Foundations of Portfolio Theory, 46 J. FIN. 469, 469-70 (I99I). Other sources trace the origins of portfolio selection to Helen Makower \& Jacob Marschak, Assets, Prices and Monetary Theory, 5 EconomICA 26I (1938) and Jacob Marschak, Money and the Theory of Assets, 6 EconometricA 31 I (1938). See Fox, supra note 54, at 347.

${ }^{64}$ See William J. Baumol, An Expected Gain-Confidence Limit Criterion for Portfolio Selection, 10 MGMT. SCI. 174 (I963).

${ }^{65}$ MarkoWItZ, MeAN-VARIANCE ANALYSIS, supra note 62, at 38.

${ }^{66}$ Id.

${ }^{67}$ Mao, supra note 57 , at 354 .

${ }^{68}$ Leslie A. Balzer, Investment Risk: A Unified Approach to Upside and Downside Returns, in MANAGING DownsIDE RISK IN FINANCIAL MARKETS:THEORY, PrACTICE AND IMPLEMENTATION I03, II5 (FrankA. Sortino \& Stephen E. Satchell eds., 200I).

${ }^{69}$ William W. Hogan \& James M.Warren, Toward the Development of an Equilibrium Capital-Market Model Based on Semivariance, 9 J. FIN. \& QUANT. ANALYSIS I (1974).
} 
difference between the return on the market portfolio and the risk-free rate, conditioned on the failure of the market-wide return to meet the risk-free return: ${ }^{70}$

$$
\sigma_{-}(a, m)=\left\langle\left(x_{a}-x_{f}\right) \cdot\left(x_{m}-x_{f} \mid x_{m}<x_{f}\right)\right\rangle
$$

where \langle\rangle is the expectation operator. In more operationally comprehensible terms, this second term of this definition may be rendered in terms of a minimum operator:

$$
\sigma_{-}(a, m)=\left\langle\left(x_{a}-x_{f}\right) \cdot \min \left(x_{m}-x_{f}, 0\right)\right\rangle
$$

Three years later, in 1977, Vijay Bawa and Eric Lindenberg developed a generalized mean-lower partial moment framework that treated both the conventional capital asset pricing model and Hogan and Warren's variant as special cases. ${ }^{71}$ Bawa and Lindenberg's formulation retained a distinctive trait of Hogan and Warren's risk measure - the assumption that returns on an asset in excess of the risk-free rate affirmatively reduce risk when market-wide returns fall below the risk-free rate: $x_{a}>x_{f} \cap x_{m}<x_{f}{ }^{72}$

In 1989, W.V. Harlow and Ramesh Rao generalized Bawa and Lindenberg's mean-lower partial moment framework even further. ${ }^{73}$ Their approach subsumed Hogan and Warren, Bawa and Lindenberg, and conventional CAPM. ${ }^{74}$ Harlow and Rao greatly enhanced the flexibility of one-sided risk measures. ${ }^{75}$ Among other things, they embedded their measure of conditional variance within a generalized framework calculating risk according to mean lower partial moments. ${ }^{76}$ Of immediate interest is Harlow and Rao's embrace of the mean market-wide return, rather than the risk-free rate, as the baseline for measuring risk: ${ }^{77}$

$$
\sigma_{-}(a, m)=\left\langle\left(x_{a}-\mu_{a}\right) \cdot\left(x_{m}-\mu_{m} \mid x_{m}<\mu_{m}\right)\right\rangle
$$

In 2002, Javier Estrada performed the final step in specifying conditional covariance on the downside of expected return as the product of two conditional shortfalls: that of returns on an asset relative to its mean, as well as the shortfall of the market-wide portfolio relative to expected market-wide returns: ${ }^{78}$

$$
\sigma_{-}(a, m)=\left\langle\left(x_{a}-\mu_{a} \mid x_{a}<\mu_{a}\right) \cdot\left(x_{m}-\mu_{m} \mid x_{m}<\mu_{m}\right)\right\rangle
$$

\footnotetext{
${ }^{70}$ See id. at 5 \& n. 2 .

71 SeeVijay S. Bawa \& Eric B. Lindenberg, Capital Market Equilibrium in a Mean-Lower Partial Moment Framework, 5 J. FIN. ECON. I89, I9I, I98 (I977).

72 See id. at 197; Hogan \&Warren, supra note 69, at I0; cf. Estrada, Systematic Risk in Emerging Markets, supra note 5I, at 370.

${ }^{73}$ See W.V. Harlow \& Ramesh K.S. Rao, Asset Pricing in a Generalized Mean-Lower Partial Moment Framework:Theory and Evidence, 24 J. Fin. \& QUANT. ANALYSIS 285 (1989).

${ }^{74}$ See id. at 29I (demonstrating how a second-order mean-lower partial moment model assuming normally distributed returns and adopting the risk-free rate as the target return yields the conventional capital asset pricing model).

75 See David Nawrocki, A Brief History of Downside Risk Measures, 8). INVESTING 9, (1999) (characterizing Harlow and Rao's breakthrough as catapulting work on semivariance from "silent black and white film" to "wide screen Technicolor film with digital surround sound").

${ }^{76}$ See Harlow \& Rao, supra note 73, at 286-92. On lower partial moments, compare Vijay S. Bawa, Optimal Rules for Ordering Uncertain Prospects, 2 J. Fin. ECON. 95 (1975) with Peter C. Fishburn, Mean-RiskAnalysis with RiskAssociated with Below-Target Returns, 67 AM. EcoN. Rev. II6 (I 977). See generally Bruce J. Feibel, InVestment Performance Measurement I55-64 (2003); Stephen E. Satchell, Lower Partial-Moment Capital Asset Pricing Models: A Re-Examination, in MANAGING DoWnside RISK IN FINANCIAL MARKeTS, supra note 68, at I56.

${ }^{77}$ Compare Harlow \& Rao, supra note 73, at 286 with Estrada, Systematic Risk in Emerging Markets, supra note 5I, at 369.

${ }^{78}$ See Estrada, Systematic Risk in Emerging Markets, supra note 51, at 368.
} 
Alone among the measures described here, Estrada's definition of downside covariance satisfies the reflexive property that characterizes ordinary variance: the covariance of returns on a specific asset and market-wide returns is equal to the covariance of market-wide returns and returns on the specific asset. ${ }^{79}$ In other words, Estrada alone treats covariance between an asset or portfolio under study and the marketwide benchmark as equivalent to covariance between the benchmark and the subject of study: $\operatorname{cov}(a, m)=\operatorname{cov}(a, m)$. Other specifications of semicovariance create the "problematic" suggestion "that covariance between securities $i$ and $j$ is different from" covariance "between securities $j$ and $i$." 80

\section{Both sides now: ${ }^{81}$}

\section{the full financial toolkit of partial second moments}

\subsection{Traditional CAPM specifications of volatility, variance, covariance, correlation, and beta}

I begin with a brief recitation of traditional specifications of volatility, variance, covariance, and beta - the statistics that form the basis of the CAPM and related branches of mathematical finance. ${ }^{82}$ Mean, variance, and standard deviation are formally defined in terms of mathematical moments. The $n$th moment of a distribution $f(x)$ about the value $\tau$ is defined as: ${ }^{83}$

$$
\mu_{n}=\int_{-\infty}^{\infty}(x-\tau)^{n} f(x) d x
$$

If $\tau$ is defined as $\mu$, the mean or the first raw moment, then the second moment of $f(x)$ about $\mu$ is the second central moment, or the variance $\left(\sigma^{2}\right)$ :

$$
\begin{gathered}
\mu_{1}^{\prime}=\int_{-\infty}^{\infty} x^{1} f(x) d x=\mu \\
\mu_{2}=\int_{-\infty}^{\infty}(x-\mu)^{2} f(x) d x=\sigma^{2}
\end{gathered}
$$

\footnotetext{
${ }^{79}$ See id. at 369-70 \& n.2; Javier Estrada, Mean-Semivariance Behavior:Downside Risk and Capital Asset Pricing, 16 INT'L ReV. Econ. \& FiN. 169,174 (2007); Hsin-Jung Tsai, Ming-Chi Chen \& Chih-Yuan Yang, A Time-Varying Perspective on the CAPM and Downside Betas, 29 INT'L Rev. Econ. \& FiN. 440, 44I (20I4).

${ }^{80}$ Don U.A. Galagedera, An Alternative Perspective on the Relationship Between Downside Beta and CAPM Beta, 8 EMERGING MkTs. Rev. 4, 7 (2007). For fuller mathematical elaboration of Estrada's measure alongside those of Bawa \& Lindenberg, supra note 71, and Harlow \& Rao, supra note 73, see Galagedera, supra, at 6-7, 17-19.

${ }^{81}$ C. JONI MITCHELL, Both Sides Now, on CLOUdS (1969).

${ }^{82}$ See, e.g., Fischer Black, Capital Market Equilibrium with Restricted Borrowing, 45 J. Bus. 444 (1972); Fischer Black, Michael C. Jensen \& Myron S. Scholes, The Capital Asset Pricing Model: Some Empirical Tests, in StUdies IN THE THeORY of CAPITAL MARKETS, supra note 53, at 79; John Lintner, Security Prices, Risk and Maximal Gains from Diversification, 20 J. FIN. 587 (1965); John Lintner, The Valuation of Risk Assets and the Selection of Risky Investments in Stock Portfolios and Capital Budgets, 73 Rev. Econ. \& STATS. 13 (1965); Jan Mossin, Equilibrium in a Capital Asset Market, 34 ECONOMEtRICA 768 (1966);William F. Sharpe, Capital Asset Prices:A Theory of Market Equilibrium Under Conditions of Risk, 19 J. Fin. 425 (I964); Jack L. Treynor, Toward a Theory of Market Value of Risky Assets, in Asset Pricing and Portfolio Performance: Models, Strategy and PerFORMANCE Metrics 15 (Robert A. Korajczyk ed., 1999). See generally Eugene F. Fama \& Kenneth R. French, The Capital Asset Pricing Model: Theory and Evidence, 18:3 J. ECON. PERSPS. 25 (Summer 2004).

${ }^{83}$ See generally William H. Press, Brian P. Flannery, Saul A. Teukolsky \& William T.Vetterling, Numerical Recipes in Fortran 77:The Art of SCIENTIFIC COMPUTING 604-09 (2d ed. 1992) ("§ I4.I: Moments of a Distribution: Mean,Variance, Skewness, and So Forth.”).
} 
Standard deviation, or financial volatility, is defined as the positive square root of variance:

$$
\sigma=\sqrt{\sigma^{2}}=\sqrt{\int_{-\infty}^{\infty}(x-\mu)^{2} f(x) d x}
$$

Since portfolios are typically constructed with multiple assets or asset classes, it is useful to speak of covariance between returns on an asset (class) and market-wide returns:

$$
\sigma(a, m)=\operatorname{cov}(a, m)=E\left[\left(x_{a}-\mu_{a}\right)\left(x_{m}-\mu_{m}\right)\right]=\left\langle\left(x_{a}-\mu_{a}\right)\left(x_{m}-\mu_{m}\right)\right\rangle
$$

where $a$ indicates the asset (class), $m$ indicates the market as a whole, $x_{p}$ indicates returns on either the asset-specific or the market-wide portfolio $(p \in\{a, m\})$, and $\mu_{p}$ indicates mean returns on either portfolio. For compactness in notation, I shall henceforth use angle brackets, \langle\rangle , to express the expectation operator, or mean:

$$
\langle f(x)\rangle=E[f(x)]=\mu_{f(x)}
$$

The variance of a single distribution can be understood as a special case of covariance, where the two variables are identical:

$$
\sigma(p, p)=\sigma_{p}^{2}=\operatorname{cov}(p, p)=\left\langle\left(x_{p}-\mu_{p}\right)\left(x_{p}-\mu_{p}\right)\right\rangle=\left\langle\left(x_{p}-\mu_{p}\right)^{2}\right\rangle
$$

In like fashion, we can restate our definition of volatility as the square root of variance:

$$
\sigma_{p}=\sqrt{\left\langle\left(x_{p}-\mu_{p}\right)^{2}\right\rangle}
$$

Normalizing covariance according to the product of asset-specific and market-wide volatility yields the correlation between those returns:

$$
\rho(a, m)=\frac{\operatorname{cov}(a, m)}{\sigma_{a} \sigma_{m}}=\frac{\left\langle\left(x_{a}-\mu_{b}\right)\left(x_{m}-\mu_{m}\right)\right\rangle}{\sqrt{\left\langle\left(x_{a}-\mu_{b}\right)^{2}\right\rangle\left\langle\left(x_{m}-\mu_{m}\right)^{2}\right\rangle}}
$$

Squaring correlation yields the coefficient of determination, more popularly known as $R^{2}$, or $r$-squared:

$$
r^{2}=\rho(a, m)^{2}=\frac{\left\langle\left(x_{a}-\mu_{b}\right)\left(x_{m}-\mu_{m}\right)\right\rangle^{2}}{\left\langle\left(x_{a}-\mu_{b}\right)^{2}\right\rangle\left\langle\left(x_{m}-\mu_{m}\right)^{2}\right\rangle}
$$

The product of (1) the ratio of asset-specific volatility to market-wide volatility and (2) the correlation between returns on that asset and market-wide returns is the beta of that asset: 


$$
\beta_{a}=\frac{\sigma_{a}}{\sigma_{m}} \rho(a, m)=\frac{\sigma_{a}}{\sigma_{m}} \cdot \frac{\operatorname{cov}(a, m)}{\sigma_{a} \sigma_{m}}=\frac{\operatorname{cov}(a, m)}{\sigma_{m}^{2}}=\frac{\left\langle\left(x_{a}-\mu_{a}\right)\left(x_{m}-\mu_{m}\right)\right\rangle}{\left\langle\left(x_{m}-\mu_{m}\right)^{2}\right\rangle}
$$

When beta is broken down into these components, it is readily understood as correlated relative volatility. ${ }^{84}$

For discrete distributions, all of the foregoing measures can be easily computed:

$$
\begin{aligned}
& \sigma_{p}=\sqrt{\frac{1}{n} \sum_{i=1}^{n}\left(x_{p, i}-\mu_{p}\right)^{2}} \\
& \sigma_{p}^{2}=\frac{1}{n} \sum_{i=1}^{n}\left(x_{p, i}-\mu_{p}\right)^{2} \\
& \operatorname{cov}(a, m)=\frac{1}{n} \sum_{i=1}^{n}\left(x_{a, i}-\mu_{a}\right)\left(x_{m, i}-\mu_{m}\right) \\
& \rho(a, m)=\frac{\frac{1}{n} \sum_{i=1}^{n}\left(x_{a, i}-\mu_{a}\right)\left(x_{m, i}-\mu_{m}\right)}{\sqrt{\frac{1}{n} \sum_{i=1}^{n}\left(x_{a, i}-\mu_{a}\right)^{2}} \sqrt{\frac{1}{n} \sum_{i=1}^{n}\left(x_{m, i}-\mu_{m}\right)^{2}}} \\
& =\frac{\sum_{i=1}^{n}\left(x_{a, i}-\mu_{a}\right)\left(x_{m, i}-\mu_{m}\right)}{\sqrt{\sum_{i=1}^{n}\left(x_{a, i}-\mu_{a}\right)^{2} \sum_{i=1}^{n}\left(x_{m, i}-\mu_{m}\right)^{2}}} \\
& r^{2}=\frac{\left[\sum_{i=1}^{n}\left(x_{a, i}-\mu_{a}\right)\left(x_{m, i}-\mu_{m}\right)\right]^{2}}{\sum_{i=1}^{n}\left(x_{a, i}-\mu_{a}\right)^{2} \sum_{i=1}^{n}\left(x_{m, i}-\mu_{m}\right)^{2}} \\
& \beta_{a}=\frac{\frac{1}{n} \sum_{i=1}^{n}\left(x_{a, i}-\mu_{a}\right)\left(x_{m, i}-\mu_{m}\right)}{\frac{1}{n} \sum_{i=1}^{n}\left(x_{m, i}-\mu_{m}\right)^{2}}=\frac{\sum_{i=1}^{n}\left(x_{a, i}-\mu_{a}\right)\left(x_{m, i}-\mu_{m}\right)}{\sum_{i=1}^{n}\left(x_{m, i}-\mu_{m}\right)^{2}}
\end{aligned}
$$

\subsection{Deriving semideviation and semivariance from upper and lower partial moments}

The upper and lower partial second moments of financial distributions enable the calculation of conditional, one-sided versions of deviation, variance, covariance, correlation, and beta. I rely on the downside risk framework devised by Javier Estrada. ${ }^{85}$ Specifically, I adopt Estrada's organizational logic, if not his precise notation. ${ }^{86}$ Among other advantages, Estrada's mathematically cogent retention of the symmetry of covari-

\footnotetext{
${ }^{84}$ See LIEBOWITZ, BOVA \& HAMMOND, supra note 29, at 14 (defining beta as "the correlation between the asset (or portfolio return and the market

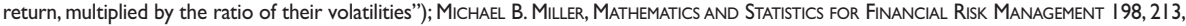
292 (2d ed. 2014) (defining beta as the product of correlation between the returns on two assets and the ratio of their volatilities); SHANNON P. Pratt \& Roger J. Grabowski, Cost of Capital:Applications AND Examples 305-06 (4th ed. 20I0).

${ }^{85}$ See Estrada, Downside Risk and Capital Asset Pricing, supra note 79, at 172; Estrada, Systematic Risk in Emerging Markets, supra note 51, at 368-69.

${ }^{86}$ See Estrada, Downside Risk and Capital Asset Pricing, supra note 79, at I7I; Estrada, Systematic Risk in Emerging Markets, supra note 5 I, at 367.
} 
ance between specific assets and the market-wide portfolio, $\operatorname{cov}(a, m)=\operatorname{cov}(a, m)$, enables the application of trigonometric shortcuts that will be outlined in part IV of this paper.

I hasten to note, however, that other specifications of semivariance may also be adapted to the approach I outline below. Despite its theoretical advantages, Estrada's approach has not unequivocally outperformed its rivals. Indeed, several studies have found stronger empirical support for specifications proposed by Estrada's rivals than for Estrada's model. ${ }^{87}$ Absent conclusive evidence that the contributions of Hogan and Warren, Bawa and Lindenberg, and Harlow and Rao have been superseded, we should retain these alternative formulations. Among other things, we may elect to set the target rate of return at the risk-free rate, thereby exploiting a source of flexibility inherent in Harlow and Rao's approach and restoring an explicit element of Hogan and Warren's approach.

Specifying semivariance and semideviation carries the added benefit of generalizing conventional CAPM and reducing that model into a special case of mean-semivariance analysis. ${ }^{88}$ At a minimum, projections based on semivariance and semideviation can do no worse than those based on conventional CAPM as a special case. ${ }^{89}$

I have taken pains to extract upside as well as downside risk measures from the upper and lower partial moments. Much of the literature on downside risk omits this step. ${ }^{90}$ As we will see, upside semideviation can be analytically derived from the computation of downside semideviation alongside standard deviation, and vice versa, as long one takes care to retain the symmetry of covariance between specific assets and the market-wide portfolio. But full elaboration of upside as well as downside risk measures is so straightforward, and so potentially useful for testing hypotheses such as the existence and magnitude of an upside risk premium (or discount) or the behavior of investors during rising as well as falling markets, that I have made the marginal effort to specify the full arsenal of measures based on semideviation and semivariance.

We begin with the general definition of partial moments about the value $\tau:{ }^{91}$

$$
\begin{aligned}
& \mu_{n}^{+}=\int_{-\tau}^{\infty}(x-\tau)^{n} f(x) d x \\
& \mu_{n}^{-}=\int_{-\infty}^{\tau}(\tau-x)^{n} f(x) d x
\end{aligned}
$$

\footnotetext{
${ }^{87}$ See Galagedera, An Alternative Perspective, supra note 80, at 16 (concluding that beta as defined by Bawa \& Lindenberg, supra note 71 ,"appears to be a better measure of systematic risk" when "securities have abnormal returns" and that beta as defined by Harlow \& Rao, supra note 73, "is more suitable as a measure of systematic risk" in "markets whose returns distributions have high kurtosis"); Tsai, Chen \& Yang, supra note 79, at 446 (suggesting that definitions of beta based on Hogan \&Warren, supra note 69, and Harlow \& Rao, supra note 73, "had more explanatory power for the expected stock market compared with ... other" definitions of beta).

${ }^{88}$ See Estrada, Systematic Risk in Emerging Markets, supra note 5I, at 366; Bawa \& Lindenberg, supra note 7I, at 19I, I98.

${ }^{89}$ See Javier Estrada, Mean-Semivariance Behaviour:An Alternative Behavioural Model, 3 J. EMERGING MKT. FIN. 23 I, 242 (2004) (validating this analytical observation through empirical data).

${ }_{90}$ One salient exception is Andrew Ang, Joseph Chen \& Yuhang Xing, 19 Rev. FIN. STUD. I 191 , I $199-1200$ (2006) (introducing "two additional measures" beyond regular, unconditional beta: relative upside beta and relative downside beta).

91 See Fishburn, supra note 76, at II6. Partial moments are Lebesgue-Stieltjes integrals. See generally Paul R. Halmos, Measure Theory $\S \S$ I5.9, I8.II, 25.4, at 67,80, 106 (2d ed. 2013).
} 
As before, we set $\tau$ at mean returns for the portfolio in question, whether asset-specific or market-wide: $\tau=\mu_{p}$. We therefore speak again of central moments.

Translating partial upper and lower moments into upside and downside semideviation and semivariance parallels the elaboration of the central second moment of the distribution of returns into ordinary measures of volatility, variance, covariance, correlation, and beta. The primary difference lies in the use of conditional calculations. The conditional variance, or skedasticity, of variable $y$ given a certain value of $x=\tau$ is defined as:

$$
\operatorname{var}(y \mid x=\tau)=\left\langle(y-\langle y \mid x=\tau\rangle)^{2} \mid x=\tau\right\rangle
$$

In any of their manifestations, semivariance and semideviation merely represent special cases of conditional variance.

We define upside and downside covariance between two portfolios, $p$ and $q$, as conditional functions:

$$
\begin{aligned}
& \sigma_{+}(p, q)=\operatorname{cov}\left(p, q \mid x_{p}>\mu_{p}, x_{q}>\mu_{q}\right) \\
& \sigma_{-}(p, q)=\operatorname{cov}\left(p, q \mid x_{p}<\mu_{p}, x_{q}<\mu_{q}\right)
\end{aligned}
$$

In the case of downside covariance, risk increases only when both portfolios fail to meet their mean returns: $x_{p}<\mu_{p}, x_{q}<\mu_{q} \cdot{ }^{92}$ Downside covariance as a measure of risk increases only when asset-specific returns fall below their mean and returns on the market as a whole falls below the market-wide mean. This is perhaps the most significant difference between Javier Estrada's specification of semivariance and earlier efforts to measure downside risk. ${ }^{93}$

On the other hand, it may be easier to understand - and certainly easier to compute - these semicovariances in terms of expected values:

$$
\begin{aligned}
& \sigma_{+}(p, q)=\left\langle\max \left[\left(x_{p}-\mu_{p}\right), 0\right] \cdot \max \left[\left(x_{q}-\mu_{q}\right), 0\right]\right\rangle \\
& \sigma_{-}(p, q)=\left\langle\min \left[\left(x_{p}-\mu_{p}\right), 0\right] \cdot \min \left[\left(x_{q}-\mu_{q}\right), 0\right]\right\rangle
\end{aligned}
$$

Upside or downside semivariance within a single portfolio is merely a special case of the corresponding form of semicovariance:

$$
\begin{aligned}
& \sigma_{p,+}^{2}=\operatorname{var}\left(p \mid x_{p}>\mu_{p}\right)=\left\langle\max \left[\left(x_{p}-\mu_{p}\right), 0\right]^{2}\right\rangle \\
& \sigma_{p,-}^{2}=\operatorname{var}\left(p \mid x_{p}<\mu_{p}\right)=\left\langle\min \left[\left(x_{p}-\mu_{p}\right), 0\right]^{2}\right\rangle
\end{aligned}
$$

\footnotetext{
${ }^{92}$ See Estrada, Downside Risk and Capital Asset Pricing, supra note 79, at 173; Estrada, Systematic Risk in Emerging Markets, supra note 51, at 369-70.

${ }_{93}$ See Estrada, Systematic Risk in Emerging Markets, supra note 51, at 369-70 \& n.2.
} 
Taking the square root of these values immediately yields upside and downside semideviation:

$$
\begin{aligned}
& \sigma_{p,+}=\sqrt{\operatorname{var}\left(p \mid x_{p}>\mu_{p}\right)}=\sqrt{\left\langle\max \left[\left(x_{p}-\mu_{p}\right), 0\right]^{2}\right\rangle} \\
& \sigma_{p,-}=\sqrt{\operatorname{var}\left(p \mid x_{p}<\mu_{p}\right)}=\sqrt{\left\langle\min \left[\left(x_{p}-\mu_{p}\right), 0\right]^{2}\right\rangle}
\end{aligned}
$$

Upside and downside semicovariance between asset-specific and market-wide portfolios is another special case of general semicovariance:

$$
\begin{aligned}
& \sigma_{+}=(a, m)=\operatorname{cov}\left(a, m \mid x_{a}>\mu_{a}, x_{m}>\mu_{m}\right)=\left\langle\max \left[\left(x_{a}-\mu_{a}\right), 0\right] \cdot \max \left[\left(x_{m}-\mu_{m}\right), 0\right]\right\rangle \\
& \sigma_{-}=(a, m)=\operatorname{cov}\left(a, m \mid x_{a}<\mu_{a}, x_{m}<\mu_{m}\right)=\left\langle\min \left[\left(x_{a}-\mu_{a}\right), 0\right] \cdot \min \left[\left(x_{m}-\mu_{m}\right), 0\right]\right\rangle
\end{aligned}
$$

Dividing each form of semicovariance among asset-specific and market-wide portfolios by the product of the corresponding form of semideviation produces upside and downside semicorrelation:

$$
\begin{aligned}
& \rho_{+}(a, m)=\frac{\sigma_{+}(a, m)}{\sigma_{a,+} \sigma_{m,+}}=\frac{\operatorname{cov}_{+}(a, m)}{\sigma_{a,+} \sigma_{m,+}} \\
& \rho_{+}(a, m)=\frac{\left\langle\max \left[\left(x_{a}-\mu_{a}\right), 0\right] \cdot \max \left[\left(x_{m}-\mu_{m}\right), 0\right]\right\rangle}{\sqrt{\left\langle\max \left[\left(x_{a}-\mu_{a}\right), 0\right]^{2}\right\rangle \cdot\left\langle\max \left[\left(x_{m}-\mu_{m}\right), 0\right]^{2}\right\rangle}} \\
& \rho_{-}(a, m)=\frac{\sigma_{-}(a, m)}{\sigma_{a,-} \sigma_{m,-}}=\frac{\operatorname{cov}_{-}(a, m)}{\sigma_{a,-} \sigma_{m,-}} \\
& \rho_{-}(a, m)=\frac{\left\langle\min \left[\left(x_{a}-\mu_{a}\right), 0\right] \cdot \min \left[\left(x_{m}-\mu_{m}\right), 0\right]\right\rangle}{\sqrt{\left\langle\min \left[\left(x_{a}-\mu_{a}\right), 0\right]^{2}\right\rangle \cdot\left\langle\min \left[\left(x_{m}-\mu_{m}\right), 0\right]^{2}\right\rangle}}
\end{aligned}
$$

Squaring these values produces the coefficient of determination, or $r$-squared, above and below the mean return:

$$
\begin{aligned}
& r_{+}^{2}=\rho_{+}(a, m)^{2}=\frac{\left\langle\max \left[\left(x_{a}-\mu_{a}\right), 0\right] \cdot \max \left[\left(x_{m}-\mu_{m}\right), 0\right]\right\rangle^{2}}{\sqrt{\left\langle\max \left[\left(x_{a}-\mu_{a}\right), 0\right]^{2}\right\rangle \cdot\left\langle\max \left[\left(x_{m}-\mu_{m}\right), 0\right]^{2}\right\rangle}} \\
& r_{-}^{2}=\rho_{-}(a, m)^{2}=\frac{\left\langle\min \left[\left(x_{a}-\mu_{a}\right), 0\right] \cdot \min \left[\left(x_{m}-\mu_{m}\right), 0\right]\right\rangle^{2}}{\sqrt{\left\langle\min \left[\left(x_{a}-\mu_{a}\right), 0\right]^{2}\right\rangle \cdot\left\langle\min \left[\left(x_{m}-\mu_{m}\right), 0\right]^{2}\right\rangle}}
\end{aligned}
$$

And multiplying upside and downside semicorrelation by the ratio of upside or downside semideviation for the asset-specific portfolio to upside or downside semideviation for the entire market, as appropriate, produces upside and downside beta: 


$$
\begin{aligned}
& \beta_{+}=\frac{\sigma_{a,+}}{\sigma_{m,+}} \rho_{+}(a, m)=\frac{\sigma_{a,+}}{\sigma_{m,+}} \cdot \frac{\sigma_{+}(a, m)}{\sigma_{a,+} \sigma_{m,+}}=\frac{\operatorname{cov}_{+}(a, m)}{\sigma_{m,+}^{2}} \\
& \beta_{+}=\frac{\left\langle\max \left[\left(x_{a}-\mu_{a}\right), 0\right] \cdot \max \left[\left(x_{m}-\mu_{m}\right), 0\right]\right\rangle}{\left\langle\max \left[\left(x_{m}-\mu_{m}\right), 0\right]^{2}\right\rangle} \\
& \beta_{-}=\frac{\sigma_{a,-}}{\sigma_{m,-}} \rho_{-}(a, m)=\frac{\sigma_{a,-}}{\sigma_{m,-}} \cdot \frac{\sigma_{-}(a, m)}{\sigma_{a,-} \sigma_{m,-}}=\frac{\operatorname{cov}_{-}(a, m)}{\sigma_{m,-}^{2}} \\
& \beta_{-}=\frac{\left\langle\min \left[\left(x_{a}-\mu_{a}\right), 0\right] \cdot \min \left[\left(x_{m}-\mu_{m}\right), 0\right]\right\rangle}{\left\langle\min \left[\left(x_{m}-\mu_{m}\right), 0\right]^{2}\right\rangle}
\end{aligned}
$$

Each of these one-sided, conditional measures can be computed for discrete distributions. On the upside:

$$
\begin{aligned}
& \sigma_{p,+}=\sqrt{\frac{1}{n} \sum_{i=1}^{n} \max \left[\left(x_{p, i}-\mu_{p}\right), 0\right]^{2}} \\
& \sigma_{p,+}^{2}=\frac{1}{n} \sum_{i=1}^{n} \max \left[\left(x_{p, i}-\mu_{p}\right), 0\right]^{2} \\
& \operatorname{cov}_{+}(a, m)=\frac{1}{n} \sum_{i=1}^{n} \max \left[\left(x_{a, i}-\mu_{a}\right), 0\right] \cdot \max \left[\left(x_{m, i}-\mu_{m}\right), 0\right] \\
& \rho_{+}(a, m)=\frac{\sum_{i=1}^{n} \max \left[\left(x_{a, i}-\mu_{a}\right), 0\right] \cdot \max \left[\left(x_{m, i}-\mu_{m}\right), 0\right]}{\sqrt{\sum_{i=1}^{n} \max \left[\left(x_{a, i}-\mu_{a}\right), 0\right]^{2} \sum_{i=1}^{n} \max \left[\left(x_{m, i}-\mu_{m}\right), 0\right]^{2}}} \\
& r_{+}^{2}=\rho_{+}(a, m)=\frac{\left[\sum_{i=1}^{n} \max \left[\left(x_{a, i}-\mu_{a}\right), 0\right] \cdot \max \left[\left(x_{m, i}-\mu_{m}\right), 0\right]\right]^{2}}{\sum_{i=1}^{n} \max \left[\left(x_{a, i}-\mu_{a}\right), 0\right]^{2} \sum_{i=1}^{n} \max \left[\left(x_{m, i}-\mu_{m}\right), 0\right]^{2}} \\
& \beta_{a,+}=\frac{\sum_{i=1}^{n} \max \left[\left(x_{a, i}-\mu_{a}\right), 0\right] \cdot \max \left[\left(x_{m, i}-\mu_{m}\right), 0\right]}{\sum_{i=1}^{n} \max \left[\left(x_{m, i}-\mu_{m}\right), 0\right]^{2}}
\end{aligned}
$$

And the downside:

$$
\begin{aligned}
& \sigma_{p,-}=\sqrt{\frac{1}{n} \sum_{i=1}^{n} \min \left[\left(x_{p, i}-\mu_{p}\right), 0\right]^{2}} \\
& \sigma_{p,-}^{2}=\frac{1}{n} \sum_{i=1}^{n} \min \left[\left(x_{p, i}-\mu_{p}\right), 0\right]^{2}
\end{aligned}
$$




$$
\begin{gathered}
\operatorname{cov}_{-}(a, m)=\frac{1}{n} \sum_{i=1}^{n} \min \left[\left(x_{a, i}-\mu_{a}\right), 0\right] \cdot \min \left[\left(x_{m, i}-\mu_{m}\right), 0\right] \\
\rho_{-}(a, m)=\frac{\sum_{i=1}^{n} \min \left[\left(x_{a, i}-\mu_{a}\right), 0\right] \cdot \min \left[\left(x_{m, i}-\mu_{m}\right), 0\right]}{\sqrt{\sum_{i=1}^{n} \min \left[\left(x_{a, i}-\mu_{a}\right), 0\right]^{2} \sum_{i=1}^{n} \min \left[\left(x_{m, i}-\mu_{m}\right), 0\right]^{2}}} \\
r_{-}^{2}=\rho_{-}(a, m)=\frac{\left[\sum_{i=1}^{n} \min \left[\left(x_{a, i}-\mu_{a}\right), 0\right] \cdot \min \left[\left(x_{m, i}-\mu_{m}\right), 0\right]\right]^{2}}{\sum_{i=1}^{n} \min \left[\left(x_{a, i}-\mu_{a}\right), 0\right]^{2} \sum_{i=1}^{n} \min \left[\left(x_{m, i}-\mu_{m}\right), 0\right]^{2}} \\
\beta_{a,-}=\frac{\sum_{i=1}^{n} \min \left[\left(x_{a, i}-\mu_{a}\right), 0\right] \cdot \min \left[\left(x_{m, i}-\mu_{m}\right), 0\right]}{\sum_{i=1}^{n} \min \left[\left(x_{m, i}-\mu_{m}\right), 0\right]^{2}}
\end{gathered}
$$

\section{Pythagorean extensions of second-moment measures}

\subsection{Off center: triangulating deviation about a target not equal to the mean}

Thus far I have spoken exclusively of mean and variance as, respectively, the first and second central moments of the distribution of returns. But those values are merely special cases of moments about a value $\tau$. We can extend Part III's quantitative apparatus by relaxing the assumption that $\tau=\mu$. The generalization of this model is surprisingly easy and elegant. It also connects this elaboration of mean-variance analysis to a different set of mathematical tools: the Pythagorean theorem and trigonometry.

In certain circumstances, we may wish to set a benchmark return, or "target semivariance," 94 at some quantity other than mean return. ${ }^{95}$ Such a benchmark, also known as target return or minimum acceptable return, is "customized to the investor's tolerance for periodic losses" and "can be different than the mean return." designate the difference between $\tau$ and $\mu$ as $\kappa$. To wit: $\kappa=\mu-\tau$ and $\tau=\mu-\kappa$. The general definition of moments of a statistical distribution about $\tau$ yields formulas for the first and second moments about $\tau=\mu-\kappa$ :

$$
\begin{aligned}
& \tau=\mu-\kappa ; \kappa=\mu-\tau \\
& \sigma_{\tau}^{2}=\left\langle(x-\tau)^{2}\right\rangle=\left\langle(x-\mu-\kappa)^{2}\right\rangle \\
& \sigma_{\tau}^{2}=\left\langle x^{2}-2 \mu x+\mu^{2}+\kappa^{2}-2 \kappa x+2 \kappa \mu\right\rangle
\end{aligned}
$$

\footnotetext{
${ }^{94}$ Robert Libby \& Peter C. Fishburn, Behavioral Models of Risk Taking in Business Decisions, I5 J.AccountING RESEARCH 272, 277 (I 977 ); accord Harlow \& Rao, supra note 73, at 292.

${ }^{95}$ See, e.g., Bawa \& Lindenberg, supra note 7I, at 192 n.3 (acknowledging that portfolio optimization according to semivariance "can be solved for any fixed point"); Harlow \& Rao, supra note 73, at 286 (devising a "generalized Mean-Lower Partial Moment" model "consistent with any prespecified target rate of return" (emphasis in original)); id. at 287 (obtaining portfolio equilibrium "for arbitrary $\tau$ " as part of "a generalized ... asset pricing framework" making use of mean-lower partial lower moments to any order $n$ ).

${ }^{96}$ FEIBEL, supra note 76 , at 160 .
} 
This seemingly unruly series is easily reevaluated:

$$
\sigma_{\tau}^{2}=\left\langle\left(x^{2}-2 \mu x+\mu^{2}\right)-2 \kappa(x-\mu)+\kappa^{2}\right\rangle
$$

The foregoing rearrangement may be more intuitively understood if we see this relationship:

$$
\begin{aligned}
& \sigma_{\tau}^{2}=\left\langle(x-\tau)^{2}\right\rangle=\left\langle(x-\mu-\kappa)^{2}\right\rangle=\left\langle[(x-\mu)-\kappa]^{2}\right\rangle \\
& \left\langle[(x-\mu)-\kappa]^{2}\right\rangle=\left\langle(x-\mu)^{2}-2 \kappa(x-\mu)+\kappa^{2}\right\rangle
\end{aligned}
$$

The expectation operator, \langle\rangle , allows us to compress even further:

$$
\sigma_{\tau}^{2}=\sigma_{\mu-\kappa}^{2}=\left\langle(x-\mu)^{2}-2 \kappa(x-\mu)+\kappa^{2}\right\rangle=\left\langle(x-\mu)^{2}\right\rangle-\langle 2 \kappa(x-\mu)\rangle+\left\langle\kappa^{2}\right\rangle
$$

Since the expectation of the middle term, $\langle 2 \kappa(x-\mu)\rangle$, equals zero, we can simplify the entire expression:

$$
\sigma_{\mu-\kappa}^{2}=\left\langle(x-\mu)^{2}\right\rangle-\langle 2 \kappa(x-\mu)\rangle+\left\langle\kappa^{2}\right\rangle=\left\langle(x-\mu)^{2}\right\rangle+\left\langle(\mu-\tau)^{2}\right\rangle
$$

And ultimately:

$$
\sigma_{\mu-\kappa}^{2}=\left\langle(x-\mu)^{2}\right\rangle+\left\langle(\mu-\tau)^{2}\right\rangle=\sigma^{2}+\kappa^{2}
$$

A final exercise in rearrangement reveals the formula for the deviation of the distribution about $\tau=\mu-\kappa$, which is merely the square root of variance about that value about $\tau=\mu-\kappa$ :

$$
\sigma_{\mu-\kappa}=\sqrt{\sigma^{2}+\kappa^{2}}
$$

The relationship between standard variance and variance about a value $\tau=\mu-\kappa$, which in turn has been defined by reference to $\mu$ as the first central moment, is governed by the Pythagorean theorem. Having expressed mean, variance, and deviation relative to $\tau=\mu-\kappa$, it becomes a simple (if somewhat tedious) exercise to define covariance, correlation, the coefficient of determination, and beta for that benchmark.

The separation of each of these measures into upside and downside components is comparably straightforward. That exercise does more than extend the two-moment model for assessing portfolio risk to any benchmark besides mean return. The relationship between standard variance or deviation, on one hand, and these secondmoment measures' upside and downside components, lends itself to evaluation in Pythagorean and trigonometric terms. I now turn to that subject. 


\subsection{Triangulating semivariance and semideviation}

Among the many statistics generated by the complete specification of single-sided beta, upside and downside semideviation may be the simplest and easiest to deploy. In particular, downside semideviation, which "defines risks as volatility below [a market] benchmark," can be "articulated ... into a very simple asset pricing model." 97 Substituting "standard semideviation ... for standard deviation to measure portfolio risk" retains "the fundamental structure of the capital asset-pricing model." adaptation of the Sharpe ratio, ${ }^{99}$ Frank Sortino focuses on the ratio of reward (defined by returns exceeding some minimal acceptable benchmark) to downside risk, as expressed through target semideviation: $\frac{x_{a}-\tau}{\sigma_{a,-}} .{ }^{100}$ For good reason, all risk measurements represent a variation on the theme first struck by William Sharpe's original and still iconic transformation of standard scoring into a gauge of financial performance. ${ }^{101}$

To facilitate the proper use of semideviation as a risk measure, I will now elaborate the mathematical relationship between upside semideviation, downside semideviation, and standard deviation. Sources within the literature on single-sided risk sometimes err in describing this relationship as one of simple arithmetic, as though "the lower semideviation" were equal to "half the standard deviation" in a purely symmetrical distribution of returns. ${ }^{102}$ Proper mathematical evaluation of semivariance and semideviation contradicts this assertion. Rather, upside and downside semideviation are related to standard deviation according to the Pythagorean theorem.

Recall the general definitions of upside and downside semicovariance between two portfolios, $p$ and $q$ :

$$
\begin{aligned}
& \sigma_{+}(p, q)=\operatorname{cov}\left(p, q \mid x_{p}>\mu_{p}, x_{q}>\mu_{q}\right) \\
& \sigma_{-}(p, q)=\operatorname{cov}\left(p, q \mid x_{p}<\mu_{p}, x_{q}<\mu_{q}\right)
\end{aligned}
$$

It should be evident from this definition that upside and downside covariance are straightforwardly additive. In other words, overall covariance is the sum of upside and downside covariance:

\footnotetext{
${ }^{97}$ Javier Estrada, The Cost of Equity of Internet Stocks:A Downside Risk Approach, 10 EUR. J. Fin. 239, 241 (2004).

${ }^{98}$ Hogan \&Warren, supra note 69, at 10; accord James Chong \& G. Michael Philips, Measuring Risk for Cost of Capital:The Downside Beta Approach, 4 J. Corp. Treas. MGMt. 344, 347 (2012); see also Bawa \& Lindenberg, supra note 7I, at 197 (noting that a "mean-lower partial moment framework ... is identical in form to the traditional Capital Asset Pricing Model obtained in the mean-variance (MV) framework," with the substitution of conditional beta for beta across the full spectrum of returns).

${ }^{99}$ See William F. Sharpe, Mutual Fund Performance, 39 J. Bus. I 19, 123 (1966); William F. Sharpe, Adjusting for Risk in Portfolio Performance Measurement. I:2 J. PORTFOLIO MGMT. 29 (Winter 1975).

${ }^{100}$ See Frank A. Sortino \& Robert van der Meer, Downside Risk, 17:4 J. PortFolı MGMt. 27, 27-3I (Summer 199I).

101 See Li Chen, Simai He \& Shuzhong Zhang, When All Risk-Adjusted Performance Measures Are the Same: In Praise of the Sharpe Ratio, II QUANT. FIN. 1439 (201I).

${ }^{102}$ E.g., Chong \& Phillips, supra note 98, at 347. Other sources take pains to specify that it is semivariance rather than semideviation that is straightforwardly additive. See, e.g., Estrada, An Alternative Behavioural Model, supra note 89, at 23I, 237; Estrada, Downside Risk and Capital Asset Pricing, supra note 79, at 177 n.4.
} 


$$
\operatorname{cov}(p, q)=\sigma(p, q)=\sigma_{+}(p, q)+\sigma_{-}(p, q)
$$

Since the variance of a single distribution is merely a special case of covariance, where both variables are the same, the same additive relationship holds for upside and downside semivariance:

$$
\operatorname{cov}(p, p)=\sigma_{p}^{2}=\sigma_{p,+}^{2}=\sigma_{p,-}^{2}
$$

Volatility in any of its guises is the positive square root of the corresponding form of variance. This insight confirms what should be evident from the foregoing equation: The relationship between upside and downside semideviation is exactly that of the legs of a right triangle to the hypotenuse under the Pythagorean theorem. The sum of the squares of the upside and downside semideviation is equal to the square of standard deviation, or overall variance.

The same relationship can also be revealed through decomposition of variance as the second central moment of the distribution of returns:

$$
\begin{gathered}
\sigma^{2}=\int_{-\infty}^{\infty}(x-\mu)^{2} f(x) d x \\
\sigma^{2}=\int_{-\infty}^{\mu}(\mu-x)^{2} f(x) d x+\int_{\mu}^{\infty}(x-\mu)^{2} f(x) d x \\
\sigma=\sqrt{\int_{-\infty}^{\mu}(\mu-x)^{2} f(x) d x+\int_{\mu}^{\infty}(x-\mu)^{2} f(x) d x}
\end{gathered}
$$

Or more simply:

$$
\sigma=\sqrt{\sigma_{-}^{2}+\sigma_{+}^{2}}
$$

The applicability of the Pythagorean theorem to semideviation subjects one-sided measures of volatility to the entire apparatus of trigonometry. This property proves extremely useful for evaluating asymmetrical financial returns. In recognition of Frank Sortino's success in promoting the use of downside semideviation as a risk measure, ${ }^{103}$ many popular financial news sources report the so-called Sortino ratio alongside traditional modern portfolio theory measures such as mean return $(\mu)$, standard deviation $(\sigma)$, beta $(\beta)$, the Sharpe ratio, and $R^{2}$ (the coefficient of determination derived by squaring the correlation between the returns of an individual asset or an asset class and the returns on a benchmark portfolio). Whereas the Sharpe ratio is that of excess over mean return to standard deviation, the Sortino ratio is that of excess over mean

\footnotetext{
103 See, e.g., Frank A. Sortino, From Alpha to Omega, MANAGING Downside RISK IN FINANCIAL MARKETS, supra note 68, at 3; Sortino \& van der Meer, supra note 100; Sortino, van der Meer \& Plantinga, supra note 31. Others have also endorsed the use of downside semideviation as a risk measure. See, e.g., James Clash, Focus on the Downside, ForBES, Feb. 12, 1999, at 162-63; Estrada, Cost of Equity in Internet Stocks, supra note 97 , at 241 .
} 
return to downside semideviation. Although Morningstar does not report downside semideviation separately, $\sigma_{-}$is easily recovered from the interaction of the Sortino ratio with other traditional measures of portfolio risk and performance:

$$
\begin{aligned}
& \text { Sharpe }=\frac{x-\mu}{\sigma} ; \quad \text { Sortino }=\frac{x-\mu}{\sigma_{-}} \\
& \sigma_{-}=\sigma \cdot \frac{\text { Sharpe }}{\text { Sortino }}
\end{aligned}
$$

Even where financial news sources neglect to report upside volatility, that value awaits extraction by analytical means from any report that includes downside semideviation. Modest rearrangement, combined with the Pythagorean relationship of upside to downside semideviation, reveals a method for recovering upside semideviation from standard deviation and the Sharpe and Sortino ratios:

$$
\sigma_{+}=\sigma \cdot \sqrt{1-\left(\frac{\text { Sharpe }}{\text { Sortino }}\right)^{2}}
$$

The trigonometric manifestation of the Pythagorean theorem makes it possible, and arguably more desirable on strictly aesthetic grounds, to recover upside semideviation by treating either the arcsine or the arccosine of the ratio of the Sharpe to the Sortino ratio as an angle in radians:

$$
\begin{aligned}
& \sin ^{2} \theta+\cos ^{2} \theta=1 \\
& \sigma_{+}=\sigma \cdot \sin \left\lfloor\cos ^{-1}\left(\frac{\text { Sharpe }}{\text { Sortino }}\right)\right\rfloor
\end{aligned}
$$

Even more generally, the relationship between upside $\left(\sigma_{+}\right)$and downside $\left(\sigma_{-}\right)$semideviation may be evaluated in any number of ways. To the extent that financial returns are negatively skewed, ${ }^{104}$ we may expect downside semideviation to exceed its upside counterpart.

A simple stylized example illustrates the point in easily grasped graphic terms. Imagine a negatively skewed distribution in which downside semideviation exceeds upside semideviation by a ratio of 4 to 3 :

$$
\sigma_{-}=\frac{4}{3} \sigma_{+}
$$

Under the Pythagorean theorem, standard deviation would exceed downside semideviation by a ratio of 5 to 4 and upside semideviation by a ratio of 5 to 3 :

\footnotetext{
104 See generally sources cited supra note 15.
} 


$$
\begin{aligned}
& \sigma=\sqrt{\sigma_{-}^{2}+\sigma_{+}^{2}} \\
& \sigma=\frac{5}{4} \sigma_{-} \\
& \sigma=\frac{5}{3} \sigma_{+}
\end{aligned}
$$

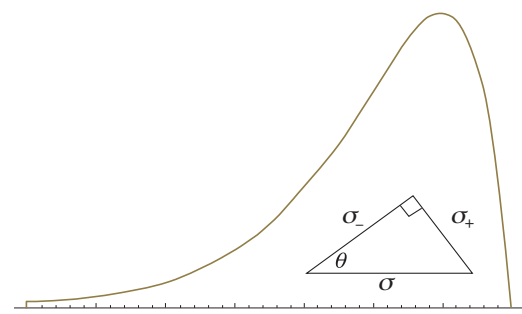

As this graphic shows, ${ }^{105}$ we may arrange upside and downside semideviation as the legs of a right triangle whose hypotenuse represents overall volatility.

On the foregoing assumptions, the ratio of upside to downside semideviation provides a crude gauge of asymmetry in volatility: $\sigma_{+} / \sigma_{-}$. To like effect, we could divide the ratio of the standard deviation to downside semideviation by $\sqrt{2}$, which is the expected ratio of standard deviation to either downside or upside semideviation where volatility on either side of expected return is perfectly symmetrical: $\frac{\sigma}{\sigma \sqrt{2}}$. This value reflects the assumption that perfectly symmetrical volatility would generate a standard deviation (hypotenuse) that is $\sqrt{2}$ times as large as either the upside or the downside semideviation. This follows from the trigonometric properties of an isosceles right triangle:

$$
\cos \left(\frac{\pi}{4}\right)=\frac{1}{\sqrt{2}} ; \sec \left(\frac{\pi}{4}\right)=\sqrt{2}
$$

Finally, the Pythagorean relationship between standard deviation and upside and downside semideviation enables us to express asymmetry in volatility according to angular terms. The angle that is formed by the downside semideviation and the standard deviation, $\theta$, can be derived from the ratio between semideviation and standard deviation:

$$
\begin{aligned}
& \cos \theta=\frac{\sigma_{-}}{\sigma} \\
& \theta=\cos ^{-1}\left(\frac{\sigma_{-}}{\sigma}\right)
\end{aligned}
$$

Equivalently, in terms making use of upside semideviation:

$$
\theta=\sin ^{-1}\left(\frac{\sigma_{+}}{\sigma}\right)=\tan ^{-1}\left(\frac{\sigma_{+}}{\sigma_{-}}\right)
$$

Comparing $\theta$ to the hypothetical angle formed by perfectly symmetrical measures of semideviation on either side of expected return gives us a final way to express asymmetrical volatility:

\footnotetext{
${ }^{105}$ Angela Caulley provided the graphic illustration of the Pythagorean interpretation of the relationship of standard deviation to upside and downside semideviation.
} 


$$
\frac{\theta}{\pi / 4}=\frac{4}{\pi} \cdot \cos ^{-1}\left(\frac{\sigma_{-}}{\sigma}\right)
$$

The following table summarizes these prospective measures of asymmetry in volatility in this stylized example:

\begin{tabular}{lll}
\hline Formula & Description & Value in this example \\
\hline$\sigma_{+} / \sigma_{-}$ & Ratio of upside to downside semideviation & $3 / 4=0.75$ \\
\hline$\frac{\sigma}{\sigma_{-} \sqrt{2}}$ & $\begin{array}{l}\text { Ratio of standard deviation to downside } \\
\text { semideviation, relative to } \sec (\pi / 4)\end{array}$ & $\frac{5}{4 \sqrt{2}} \approx 0.8839$ \\
\hline$\frac{\theta}{\pi / 4}=\frac{4}{\pi} \cdot \cos ^{-1}\left(\frac{\sigma_{-}}{\sigma}\right)$ & $\begin{array}{l}\text { Ratio of the semideviation angle, relative } \\
\text { to } \cos ^{-1}(1 / \sqrt{2})=\pi / 4\end{array}$ & $\frac{4}{\pi} \cos ^{-1}\left(\frac{4}{5}\right) \approx 0.8193$ \\
\hline
\end{tabular}

\section{Bifurcating beta:} relative volatility versus correlation tightening

\subsection{Two faces of single-sided beta: sinking, fast and slow}

Beta remains a popular albeit theoretically besieged risk measure. Measuring beta on either side of a target return offers the tantalizing prospect of rehabilitating this venerable risk measure within contemporary mathematical finance. Even Don Galagedera, a skeptic of the value of beta in any form, concedes that "the association between the CAPM beta and the downside beta depends on the standard deviation, skeweness and kurtosis of the market portfolio distribution" - in short, "that the choice of downside risk measure ... depend[s] on the distributive characteristics of the market being investigated."106

Beta as a composite measure reports both relative volatility across asset classes and correlation between those classes. ${ }^{107}$ Single-sided beta specifically reflects skewness as well as dispersion in returns. ${ }^{108}$ Consequently, single-sided beta is especially useful for assessing risk in asset classes whose returns deviate significantly from symmetry and other normal, Gaussian attributes. ${ }^{109}$ Emerging markets, embryonic industries, and

\footnotetext{
${ }^{106}$ Galagedera, An Alternative Perspective, supra note 80 , at 13.

107 See sources cited supra note 84 .

${ }^{108}$ See Estrada, Systematic Risk in Emerging Markets, supra note 5I, at 366; Campbell R. Harvey, John C. Liechty, Merrill W. Liechty \& Peter Müller, Portfolio Selection with Higher Moments, 10 QUANT. FIN. 469, 469 (2010) (describing the "us[e] [of] negative semi-variance in place of variance" as a "three moment optimization method[]").

${ }^{109}$ See Lakshman Alles \& Louis Murray, Rewards for Downside Risk in Asian Markets, 37 J. BANKING \& FIN. 250I, 250I (20I3) ("[T]here is evidence that asset returns [in emerging markets] exhibit very high volatility and are not normally distributed"); Estrada, The Cost of Equity of Internet Stocks, supra note 97, at 240 (emphasizing downside risk as the proper measure for the cost of equity in speculative securities, such as early Internet stocks); Don U.A. Galagedera \& Robert D. Brooks, Is Co-Skewness a Better Measure of Risk in the Downside Than Downside Beta?, I7 J. Multinat'L Fin. Mgmt. 214, 216 (2007); Campbell R. Harvey, Predictable Risk and Returns in Emerging Markets, 8 Rev. Fin. STud. 773, 779-80 (1995) (rejecting the null hypothesis of normal markets based on measures of skewness and excess kurtosis in 14 of 20 emerging markets and concluding that "returns in ... emerging markets depart from the normal distribution"). See generally Bekaert et al., supra note I5; Babak
} Eftekhari \& Stephen E. Satchell, International Investors' Exposure to Risk in Emerging Markets, 22 J. FIN. RESEARCH 83 (I999). 
micro-capitalized companies, among other categories, all fit this profile, ${ }^{110}$ as do commodity markets (especially for nonrenewable sources of energy). ${ }^{111}$

These are the markets where single-sided beta has made its mark as a risk measure. For example, Javier Estrada has found that downside betas in emerging markets exceeded their corresponding CAPM betas by roughly 50 percent, a gap that implied an annual increase of 300 to 640 basis points in the cost of capital in emerging markets. ${ }^{112}$ "These differential returns are simply too large ... to ignore." 113 Along similar lines, a survey of daily returns on the Russell 3000 index from 1985 through 2012 found a "positive and very significant risk premium on the downside $\beta$," worth "6.6\% per year." 114

Although Don Galagedera has suggested that downside beta's predictive power may be confined to emerging markets, ${ }^{115}$ other sources lend at least qualified support for downside beta as a risk measure in developed markets, ${ }^{116}$ including those of Great Britain, ${ }^{117}$ France, ${ }^{118}$ and Japan. ${ }^{119}$ One study of the American market concludes that consideration of downside risk in portfolio design would counsel a lower stock allocation. ${ }^{120}$ This finding is consistent with the provocative suggestion that downside

${ }^{110}$ See Soonsung Hwang \& Christian S. Pedersen, Asymmetrical Risk Measures When Modelling Emerging Markets Equities: Evidence for Regional and Timing Effects, 5 EMERGING MKTs. Rev. 109 (2004).

II' See José María Montero, Gema Fernández-Avilés \& María-Carmen García, Estimation of Asymmetrical Stochastic Volatility Models: Application to Daily Average Prices of Energy Products, 78 INT'L STAT. Rev. 330, 330-32 (2010). In Bilski v. Kappos, 56I U.S. 593, (2010), the Supreme Court of the United States invalidated a patent asserting a claim over a process for hedging against losses in energy commodities. On the economic impact of irreversible investments in energy, see generally Ben S. Bernanke, Irreversibility, Uncertainty, and Cyclical Investment, 97 Q.J. EcoN. 85 (1983); Robert S. Pindyck, Irreversibility, Uncertainty and Investment, 29 J. ECON. LIT. III0 (199I).

112 See Estrada, Systematic Risk in Emerging Markets, supra note 51, at 374.

${ }_{113}$ Id. at 375; accord Estrada, Downside Risk and Capital Asset Pricing, supra note 79, at 184.

114 Peter Xu \& Rich Pettit, No-Arbitrage Conditions and Expected Returns When Assets Have Different $\beta$ 's in Up and Down Markets, 15 J.Asset MGMT. 62,69 (2014); see also id. at 67 (justifying this study's use of the Russell 3000 "because it excludes the smallest and most illiquid names that may skew the results); cf. Nurjannah, Galagedera \& Brooks, supra note 49, at 274 (conceding that "increasing global investment flows into Indonesia provide a formidable challenge to equity evaluation due to considerable variation in market conditions and movement"). See generally Elroy Dimson, Risk Measurement When Shares Are Subject to Infrequent Trading, 7 J. FiN. EcoN. 197 (1977).

115 See Don U.A. Galagedera, Economic Significance of Downside Risk in Developed and Emerging Markets, 16 AppLIed ECON. LetTers 1627,1632 (2009) (concluding that conventional "CAPM beta clearly outperforms downside beta and downside co-skewness" in developed markets); Don U.A. Galagedera, Relationship Between Systematic Risk Measured in the Second-Order andThird-Order Co-Moments in the Downside Framework, 3 APPLIED FIN. ECON. LeTTERS I47, I52 (2007) (concluding that "variation in the difference between systematic risk measures in terms of cosemi-skewness and co-semi-variance is larger in emerging markets than in developed markets"). See generally Campbell R. Harvey, Predictable Risk and Returns in Emerging Markets, 8 REV. FIN. STUD. 773 (1995).

116 See Tsai, Chen \& Yang, supra note 79, at 447 (finding that downside betas as specified by Hogan \& Warren, supra note 69, and Harlow \& Rao, supra note 73 , "outperform[ed] ...other betas in explaining the expected stock market returns" in 23 developed countries).

$1{ }^{17}$ See Fletcher, supra note 42, at 220 (concluding that "there is a conditional relationship between beta and return in UK stock markets" and that "[b]eta seems to be a good indicator of how stocks react in periods of down market months"); David Morelli, Beta, Size, Book-to-Market Equity and Returns:A Study Based on UK Data, 17 J. MuLTINAT'L FIN. MGMT. 257,265 (2007) (finding "a statistically significant positive relationship" between conditional beta and "realised returns ... during up markets and a negative relationship during down markets"); $c$. Christian S. Pedersen \& Soosung Hwang, Does Downside Beta Matter in Asset Pricing?, 17 APPLIED FIN. ECON. 96I, 974 (2007) (concluding that CAPM explains 50 to $80 \%$ of variations in equity prices, leaving 15 to $15 \%$ for a lower partial moment version of the CAPM, but ultimately "not ... enough to construct a downside risk factor").

${ }^{118}$ See Nikolaos Artavanis, Goerge Diacogiannis \& John Mylonakis, The D-CAPM:The Case of Great Britain and France, 2 INT'L J. ECON. \& FIN. 25, 33 (2010) (concluding that "downside risk measures are better in explaining mean returns" in Great Britain "than the standard deviation and beta," but only for individual securities and not for portfolios, and concluding from French portfolio results that "downside beta is equivalent or better than the traditional beta in terms of explanatory power when beta and the downside beta are jointly considered").

${ }^{119}$ See Jiro Hodoshima, Xavier Garza-Gómez \& Michio Kunimura, Cross-Sectional Regression Analysis of Return and Beta in Japan, 52 J. EcoN. \& Bus. 515,532 (2000) (concluding that "the conditional relationship" between beta and positive or negative excess returns "is in general better fit in the down market than in the up market").

${ }^{120}$ See Henk Grootveld \&Winfried Hallerbach, Variance vs Downside Risk: Is There Really That Much Difference?, I 4 EUR.J. OPERATIONAL RESEARCH 304,315 (1999). 
risk aversion may be sufficiently large not merely to account for the maintenance of fixed-income positions to offset the greater downside exposure of value stocks, ${ }^{121}$ but also "to explain why a substantial fraction of investable wealth is invested in fixed income instruments, despite the sizeable equity premium." 122

Single-sided beta, particularly its downside variant, embodies two distinct aspects of market risk. As Javier Estrada has observed:

First, ..., investors do not dislike volatility per se; they only dislike downside volatility. Investors do not shy away from stocks that exhibit large and frequent jumps above the mean; they shy away from stocks that exhibit large and frequent jumps below the mean....

Second, aversion to the downside is consistent with both the theory and findings in the literature of behavioral finance. It is clearly consistent ... with the S-shaped utility function of prospect theory ....

Finally, the superiority of downside beta may be related to the contagion effect in financial markets.... [I]n the traditional [mean-variance] framework, the appropriate measure of risk is beta when markets are integrated, and standard deviation when markets are segmented. The superiority of the downside beta may then be explained by the fact that markets are more integrated on the downside than on the upside due to the contagion effect .... ${ }^{123}$

These insights put a methodological premium on the separate calculation and evaluation of beta's upside and downside components. Even more intriguingly, further analysis of upside and downside beta uncovers distinct elements of these single-sided measures. Emphasizing beta on the downside of mean returns reveals the distinct financial significance of beta's volatility and correlation components. Downside volatility, especially if it increases to a greater degree within a specific asset or asset class relative to the market as a whole, threatens to inflict the very sort of loss that humans fear most: losing ground relative to a fixed reference point. Humans subjectively measure their welfare in relative

\footnotetext{
${ }^{121}$ See Guido Baltussen, Thierry Post \& Pim Van Vliet, Downside Risk Aversion, Fixed Income Exposure, and the Value Premium Puzzle, $36 \mathrm{~J}$. BankING \& Fin. 3382 (20I2). But cf. Ralitsa Petkova \& Lu Zhang, Is Value Riskier Than Growth?, 78 J. Fin. EcoN. 187, 200 (2005) (concluding that a timevarying risk measure based on the difference between value betas and growth betas does point "in the right direction," but ultimately "is far too small to explain the observed magnitude of the value premium within the conditional CAPM").

${ }^{122}$ Baltussen, Post \& Van Vliet, supra note 121 . See generally Nicholas Barberis \& Ming Huang, Mental Accounting, Loss Aversion, and Individual Stock Returns, 56 J. FIN. 1247 (200I); Nicholas Barberis, Ming Huang \& Tano Santos, Prospect Theory and Asset Prices, II 6 Q.J. EcoN. I (200I); Bellelah, Bellelah, Ameur \& Hafsia, supra note 35; Shlomo Benartzi \& Richard H. Thaler, Myopic Loss Aversion and the Equity Premium Puzzle, II0 Q.J. EcoN. 73 (1995);Arjan B. Berkelaar, Roy Kouwenberg \& Thierry Post, Optimal Portfolio Choice Under Loss Aversion, 86 REv. EcoN. \& STAT. 973 (2005); Narayana R. Kocherlakota, The Equity Premium: It's Still a Puzzle, 34 J. EcoN. LiT. 42 (1996); N. Gregory Mankiw \& Stephen P.Zeldes, The Consumption of Stockholders and Nonstockholders, 29 J. Fin. EcoN. 97 (1991); Rajnish Mehra \& Edward C. Prescott, The Equity Premium:A Puzzle, I5 J. Monetary ECON. 145 (1985); Rajnish Mehra \& Edward C. Prescott, The Equity Premium Puzzle in Retrospect, in HANDBOOK OF THE ECONOMICS OF FINANCE 889 (George M. Constantinides, Milton Harris \& René M. Stulz eds., 2003).

${ }^{123}$ Estrada, Downside Risk and Capital Asset Pricing, supra note 86, at 183; Estrada, Systematic Risk in Emerging Markets, supra note 5I, at 375-76.The same passage appears in both articles; I have omitted Estrada's footnote crediting Mark Kritzer for the observation regarding contagion.
} 
rather than absolute terms. ${ }^{124}$ The choice of market-wide benchmarks is not merely rational, but deeply intuitive and naturally appealing.

Tightening correlation during market downturns creates a different, even insidious sort of peril. Correlations across asset classes, relatively stable under ordinary market conditions, tighten under stress. ${ }^{125}$ The very portfolios that are diversified to withstand volatility "might suffer greater damage" as correlations rise during "period[s] of severe market turmoil."126

Volatility per se poses a direct threat to financial expectations. By contrast, correlation tightening undermines diversification strategies adopted for the specific purpose of taming volatility. Unlike the instinctive and immediate fear of loss associated with volatility, comprehending the "surprising" or even "paradoxical" impact of correlation tightening on portfolio management requires "further reflection." 127 The contrast evokes Daniel Kahneman's distinction between the "fast" heuristics of human instinct and the "slow," deliberate processing of rational data. ${ }^{128}$ Loss aversion is fast, even instantaneous. Comprehending the indirect, insidious threat from correlation tightening takes greater effort and more time.

Having identified two sources of concern with sinking markets, one fast and the other slow, I will now specify the distinctive components of single-sided beta that measure changes in relative volatility and in correlation among assets as returns fall on either side of their expected value.

\subsection{Identifying distinct parameters that indicate relative volatility and correlation tightening}

Careful parsing of the ratio between ordinary beta and single-sided beta reveals two distinct parameters, each addressing the distinct emotional and rational responses to sinking, fast and slow. Recall the basic definition of beta as "correlated relative volatility": 129

$$
\beta_{a}=\frac{\sigma_{a}}{\sigma_{m}} \rho(a, m)=\frac{\sigma_{a}}{\sigma_{m}} \cdot \frac{\operatorname{cov}(a, m)}{\sigma_{a} \sigma_{m}}=\frac{\operatorname{cov}(a, m)}{\sigma_{m}^{2}}
$$

\footnotetext{
124 See, e.g., Gary Charness, David Masclet \& Marie Claire Villeval, The Dark Side of Competition for Status, 60 MGMT. SCI. 38 (20I4); Simon Dato \& Petra Kieken, Gender Differences in Competition and Sabotage, 100 J. Econ. BehAV. \& OrG. 64 (2014); Thomas Dohmen,Armin Falk, Klaus Flessbach, Uwe Sunde \& Bernd Weber, Relative Versus Absolute Income, Joy of Winning, and Gender: Brain Imaging Evidence 95 J.PUB. EcoN. 279 (20I I); Camellia M. Kuhnen \& Agnieszka Tymula, Feedback, Self-Esteem, and Performance in Organizations, 58 MGMT. SCI. 94 (20I2); Mark Sheskin, Paul Bloom \& Karen Wynn, Anti-Equality: Social Comparison in Young Children, I30 CogNITION I52 (20I4).

${ }^{125}$ See Malcolm P. Baker \& Jeffrey Wurgler, Comovement and Predictable Relations Between Bonds and the Cross-Section of Stocks, 2 Rev.AsSET PRICING STUD. 57 (2012).

${ }^{126}$ LIEBOWITZ, BOVA \& HAMMOND, supra note 29, at 265.

${ }^{127}$ Id.

${ }^{128}$ See generally KAHNEMAN, supra note 50 , at 19-105

129 See sources cited supra note 84 .
} 
Beta is a composite measure that combines two components. First, relative volatility is the ratio of asset-specific volatility to market-wide volatility: $\sigma_{a} / \sigma_{m}$. Second, beta reflects the correlation between an asset or asset class and the market as a whole: $\rho(a, m)$.

In comparing single-sided beta to its ordinary counterpart, let us focus on the downside variant - that is, beta contingent on the failure of the individual asset and the market-wide portfolio to meet their respective expected returns. Downside beta contains the same components as its general counterpart - beta as specified within the conventional capital asset pricing model. The key difference is that downside beta, unlike CAPM beta, relies entirely on partial moments, semideviation, and single-sided variants of correlation and covariance: ${ }^{130}$

$$
\beta_{a,-=}=\frac{\sigma_{a,-}}{\sigma_{m,-}} \rho_{-}(a, m)=\frac{\sigma_{a,-}}{\sigma_{m,-}} \cdot \frac{\operatorname{cov}_{-}(a, m)}{\sigma_{a,-} \sigma_{m,-}}=\frac{\operatorname{cov}_{-}(a, m)}{\sigma_{m,-}^{2}}
$$

With good reason, financial analysts often assume that beta increases when returns fall below their mean. "Periods of high volatility ... tend to coincide with downward market movements." ${ }^{131}$ Calculating downside beta alongside CAPM beta gives us a crude but very intuitive measure of "stress beta" - specifically, the ratio of downside beta to CAPM beta: $\beta_{a,-} / \beta_{a}$. But even this ratio contains further information, which awaits extraction by the simplest of mathematical expedients.

Recall that semivariance is a composite measure reporting elements of volatility alongside skewness. ${ }^{132}$ Beta likewise combines two financially meaningful statistics: correlation and relative volatility. "High downside beta can be produced by high downside correlation ... or by high downside volatility." ${ }^{133}$ Further dividing beta into its upside and downside components, and then comparing each side to the general value of beta, achieves (as it were) yet another feat of financial meiosis. The goal is to separate the volatility-based component of beta from its correlation-based component and to isolate each component within its own "haploid" measure. ${ }^{134}$ Just as the genetic makeup of a child reflects distinct contributions from each parent, beta as a measure of systematic risk communicates information about volatility as well as correlation.

\footnotetext{
${ }^{130}$ See Ang, Chen \& Xing, supra note 90, at 1227 (defining downside beta as $\beta_{-}=\rho_{-} \frac{\sigma_{a_{s}-}}{\sigma_{m_{-}-}}$).

${ }^{131}$ Andrew Ang, Robert J. Hodrick, Yuhang Xing \& Xiaoyan Zhang, The Cross-Section of Volatility and Expected Returns, 61 J. FIN. 259,260 (2006). See generally John Y. Campbell \& Ludger Hentschel, No News Is Good News: An Asymmetrical Model of Changing Volatility in Stock Returns, 3I J. FiN. EcoN. 28122 (1992); Kenneth R. French, G. William Schwert \& Robert F. Stambaugh, Expected Stock Returns and Volatility, 19 J. Fin. EcoN. 3 (1987).

132 See sources cited supra note 108.

${ }^{133}$ Ang, Chen \& Xing, supra note 90 , at 1228.

${ }^{134}$ For introductions to meiosis and ploidy, biological concepts that arise rarely, if at all, in the language or logic of finance, see Harris Bernstein \& Carol Bernstein, Evolutionary Origin of Recombination During Meiosis, 60 BIOSCIENCE 498 (2010); Laura Wegener Parfrey, Daniel J.G. Lahr \& Laura A. Katz, The Dynamic Nature of Eukaryotic Genomes, 25 MoleCULAR BIOL. \& Evol. 787 (2008); J.M. deWet, Origins of Polyploids, I3 BASIC LIFE SCIS. 3 (1979). In meiosis, a cell divides itself into two parts, each containing half of its chromosomes. Ploidy refers to the number of sets of chromosomes within a cell.A healthy haploid cell, usually a gamete (egg or sperm), contains a single copy of each chromosome. The typical somatic cell of a diploid species (such as humans) contains two complete haploid sets of chromosomes.
} 
A simple mathematical expedient enables us to distinguish changes in relative volatility from changes in correlation as markets move across critical boundaries such as mean return. ${ }^{135}$ Dividing downside beta by CAPM beta reveals the extent to which changes in beta, contingent upon declines in asset-specific returns and/or declines in marketwide returns, have hinged on changes in asset-specific volatility relative to the whole market, as opposed to correlation tightening:

$$
\begin{aligned}
& \beta_{a,-} / \beta_{a}=\frac{\sigma_{a,-}}{\sigma_{m,-}} \rho_{-}(a, m) / / \frac{\sigma_{a}}{\sigma_{m}} \rho(a, m) \\
& \frac{\beta_{a,-}}{\beta_{a}}=\left(\frac{\sigma_{a,-}}{\sigma_{m,-}} \cdot \frac{\sigma_{m}}{\sigma_{a}}\right)\left(\frac{\rho_{-}(a, m)}{\rho(a, m)}\right)
\end{aligned}
$$

The first of these factors in the full equation, relative asset volatility on the downside divided by relative asset volatility under all conditions, describes a parameter that measures the change in relative volatility on either side of the target return (presumably but not necessarily the mean return). Let us designate this parameter as $v$, as in volatility: ${ }^{136}$

$$
v=\frac{\sigma_{a,-}}{\sigma_{m,-}} \cdot \frac{\sigma_{m}}{\sigma_{a}}
$$

The second factor, the ratio of downside correlation to overall correlation, describes changes in correlation as returns fall below an asset-specific and/or market-wide mean. Because correlations are expected to tighten in falling markets, let us designate this ratio as $c$, our correlation tightening parameter: ${ }^{137}$

$$
c=\frac{\rho_{-}(a, m)}{\rho(a, m)}
$$

Multiplying the product of both parameters, $v c$, reveals the ratio of downside to CAPM beta:

$$
\frac{\beta_{a,-}}{\beta_{a}}=\left(\frac{\sigma_{a,-}}{\sigma_{m,-}} \cdot \frac{\sigma_{m}}{\sigma_{a}}\right)\left(\frac{\rho_{-}(a, m)}{\rho(a, m)}\right)=v c
$$

Equivalently, multiplying CAPM beta by $v c$ reveals downside beta:

$$
\beta_{a,-}=v c \beta_{a}
$$

\footnotetext{
135 See Andrew Ang \& Joseph Chen, Asymmetric Correlations of Equity Portfolios, 63 J. Fin. Econ. 443, 444 (2002); Longin \& Solnik, supra note 28, at 650-51.

${ }^{136}$ In naming this variable, I chose $v$ over $s$, the Roman alphabet's analogue of sigma $(\sigma)$, in order to avoid confusion with the statistical convention of designating estimated or sample values with Roman letters and true but unknown population values with Greek letters.

${ }^{137}$ Again, despite the intuitive appeal of $r$, the Roman alphabet's analogue of rho $(\rho)$, as the name for this variable, I chose the first letter of the English word correlation in order to avoid confusion with the notational conventions of statistics.
} 
Even better, identifying $v$ and $c$ isolates distinct relative volatility and correlation tightening parameters on either side of mean returns. Although other sources have identified these factors as a mathematical matter, ${ }^{138}$ this article proposes the use of these parameters to test hypotheses about changes in volatility and correlation under different market conditions.

The foregoing evaluation of downside beta according to relative volatility parameter $v$ and correlation tightening parameter $c$ can be performed with equal ease on the upside. In the interest of notational completeness and consistency, we should label the downside versions of these parameters as $v_{-}$and $c_{-}$, reserving $v_{+}$and $c_{+}$for evaluating market behavior on the upside. Thus:

$$
\begin{aligned}
& \beta_{a,-}=v_{-} c_{-} \beta_{a} \\
& \beta_{a,+}=v_{+} c_{+} \beta_{a}
\end{aligned}
$$

\subsection{Relative volatility and the beta quotient}

$v_{ \pm}$, the relative volatility component of single-sided beta, proceeds from the seemingly uncontroversial premise that "stocks ... have different sensitivities to innovations in market volatility."139 The history underlying this insight, however, is anything but placid. The science of portfolio management has long disputed the proper interpretation of relative volatility. In 1985, Robert Camp and Arthur Eubank advocated the displacement of beta by a direct measure of idiosyncratic risk. ${ }^{140}$ For portfolios whose correlation as measured by $R^{2}$ is less than or equal to 0.85 , the presence of "substantial amounts of unsystematic or diversifiable risk," Camp and Eubank recommended the ratio of market-wide beta to the correlation between an individual portfolio and the market at large as a more direct measure of the "total variation of return ... relative to overall market variation": ${ }^{141}$

$$
\beta_{a}^{*}=\frac{\beta_{m}}{\rho(a, m)}
$$

Although Camp and Eubank called this ratio the "beta quotient," this ratio of two standard deviations is just as readily - and perhaps more understandably - called "relative volatility" or the "volatility ratio." ${ }^{142}$ Mathematically, the beta quotient is

\footnotetext{
138 See LIEBOWITZ, BOVA \& HAMMOND, supra note 29, at 263, 267-69 (identifying a value called "stress beta" that is equal to "the original beta multiplied by" a quantity equivalent to $v_{-} c_{-}$); Ang \& Chen, supra note 135, at $46 \mathrm{I}$ (identifying "the ratio of upside portfolio volatility to market volatility" and its downside counterpart); Harvey, supra note 109, at 809 ("The correlation is related to beta by the ratio of .of the world and country standard deviations").

${ }^{139}$ Ang, Hodrick, Xing \& Zhang, supra note I3I, at 260.

140 See Robert C. Camp \& Arthur A. Eubank, Jr., The Beta Quotient:A New Measure of Portfolio Risk, 7:4 J. Portfolı MgMt. 53 (Summer I98I).

${ }^{141}$ Id. at 54. In terms of correlation, an $R^{2}$ value of 0.85 corresponds to $\rho \approx 0.922$.

${ }^{142}$ Chris Tofallis, Investment Volatility:A Critique of Standard Beta Estimation and a Simple Way Forward, 187 EUR.J. OPER. RESEARCH I358, I36I (2008).
} 
equivalent to the ratio of the volatility of an individual asset or asset class, relative to overall market volatility: ${ }^{143}$

$$
\beta_{a}^{*}=\frac{\beta_{m}}{\rho(a, m)}=\frac{\sigma_{a}}{\sigma_{m}} \cdot \operatorname{sgn}[\rho(a, m)]
$$

The beta quotient therefore dissolves into the ratio of "the volatility of an investment's rate of return [to] the volatility of the market's rates of return," times the sign of the correlation between the investment and the market. ${ }^{144}$

At least for nondiversified portfolios, ${ }^{145}$ Camp and Eubank argued that the beta quotient (or volatility ratio) should supplant beta as the gauge of the "return performance of a portfolio ... since it is bearing diversifiable risk in addition to its systematic or non-diversifiable risk." ${ }^{146}$ More recently, Chris Tofallis has advocated the use of the volatility ratio. Concerned that "low beta could actually represent a high relative volatility that is being masked by a low correlation," Tofallis urges direct reliance on relative volatility rather than a "formula for standard beta [that] confounds ... relative volatility and correlation." 147 Finally, Peter Butler and Keith Pinkerton, building on Aswath Damodaran's treatment of beta as a component of a company's cost of equity, ${ }^{148}$ aggressively tout the volatility ratio under the name "total beta." 149

Although the practitioner literature has forcefully rebutted Butler and Pinkerton's evident disregard for diversification, ${ }^{150}$ these authors' emphasis on the valuation of individual assets highlights the value of the $v$ parameter and its isolation of changes in relative volatility. Ironically, the utility of this measure lies not in its purported measure of "total" risk, but rather in narrowing the focus of financial analysis on idiosyncratic or company-specific factors. At a minimum, such a focus may illuminate two heretofore obscure corners of mathematical finance: the low-volatility anomaly and the precise relationship between moment-based models of financial risk (including the CAPM and the single-sided approaches highlighted here), on one hand, and the size, value, and momentum factors stressed in work by Eugene Fama and Kenneth French.

\footnotetext{
143 Id. at 1363.

144 Id. at |36|; see also id. at I363.

${ }^{145}$ Cf. Camp \& Eubank, supra note I40, at 54 (conceding that "the use of beta to measure [the] risk" of a "well-diversified" portfolio "is appropriate and adequate").

146 Id. at 56.

${ }^{147}$ Tofallis, supra note 142, at I36I.

148 See generally Aswath Damodaran, InVestment Valuation:Tools and TeChNiQues for Determining the VAlUe of ANy Asset I83-206 (3d ed. 2012).

149 See, e.g., Peter Butler \& Keith Pinkerton, Company Specific Risk - A Different Paradigm:A New Benchmark, 25:I Bus. VALUATION ReV. 22 (Spring 2006); Peter Butler \& Keith Pinkerton, There is a New "Beta" in Town, and It's Not Called Total Beta for Nothing!, I5:3 BUs. VALUATION UPDATE 7, I0 (March 2009). The notion of "total beta" is drawn from Camp and Eubank's assertion that the beta quotient measures "total risk," defined as "both systematic and unsystematic risk," as "contained in investment portfolios." Camp \& Eubank, supra note I40, at 56.

150 See, e.g., Larry Kasper, Fallacies of the Butler-Pinkerton Model and the Diversification Argument, VALUE EXAMINER, Jan.-Feb. 20I0, at 8; cf. Tony van Zijk, Beta Loss, Beta Quotient: Comment, II:4 J. PORTFOLIo Mgmt. 75 (Summer 1985).
} 
The relative volatility component of single-sided beta is akin to the book-to-market equity ratio, which defines what is now known as the "value" factor in Fama and French's three-factor asset pricing model. "[B]ook-to-market equity captures the relative corporate distress factor and is thus a risk variable that needs to be compensated." 151 If $v$ (especially $v_{-}$, its downside variant) measures some aspect of corporate distress and the risk premium commanded by investors willing to commit capital to undervalued, distressed firms, then this component of downside beta may explain the superior performance of low-beta portfolios. ${ }^{152}$

Such an explanation would address one of the most spectacular failures of traditional financial models relying upon raw volatility and traditional beta as measures of risk. The entire point of an efficient capital market is to reward the assumption of risk with returns. A "contemporaneous relationship between factor loadings and risk premia is the foundation of a cross-sectional risk-return relationship, and has been exploited from the earliest tests of the CAPM." ${ }^{153}$ Ceteris paribus, risky assets have high returns. Safe assets don't. "This simple empirical proposition has been hard to support on the basis of the history of U.S. stock returns." 154 Indeed, the "most widely used measures of risk point rather strongly in the wrong direction." 155 For instance, in a survey of stock returns from 1926 to 1971, Robert Haugen and James Heins concluded: "over the long run, stock portfolios with lesser variance in monthly returns have experienced greater average returns than their 'riskier' counterparts." 156

More recent studies confirm the presence of a low-volatility anomaly. Stocks exhibiting the highest levels of volatility have "abysmally low average returns." 157 The inversion of returns on low- versus high-volatility stocks has been confirmed across numerous historical periods and in markets around the world. ${ }^{158}$ "That low beta is high alpha is a robust historical pattern." 159 The presence of returns as low as negative $0.02 \%$ per month in the quintile of stocks exhibiting the highest levels of volatility is not merely "a puzzle." 160

\footnotetext{
${ }^{151}$ Morelli, supra note 213, at 267. See generally K.C. Chan \& Nai-Fu Chen, Structural and Return Characteristics of Small and Large Firms, 46 J. FiN. 1467 (1991).

152 See Malcolm Baker, Brendan Bradley \& Jeffrey Wurgler, Benchmarks as Limits to Arbitrage: Understanding the Low-Volatility Anomaly, 67:I FiN. ANALYSTS J. 40, 46 (Jan./Feb. 20II).

${ }^{153}$ Ang, Chen \& Xing, supra note 90 , at 1193.

${ }^{154}$ Baker, Bradley \&Wurgler, supra note 152, at 40.

155 Id. (emphasis in original).

156 Robert A. Haugen \& A. James Heins, Risk and the Rate of Return on Financial Assets: Some OldWine in New Bottles, 10 J. FIN. \& QUANT.ANALYSIS 775,782 (1975) (emphasis added).

${ }^{157}$ Ang, Hodrick, Xing \& Zhang, supra note 131, at 296; accord Baker, Bradley \& Wurgler, supra note I52, at 43; see also Andrew Ang, Robert J. Hodrick, Yuhang Xing \& Xiaoyan Zhang, High Idiosyncratic Volatility and Low Returns: International and Further U.S. Evidence, 91 J. FIN. EcoN. I (2009).

158 See, e.g., David C. Blitz \& Pim van Vliet, The Volatility Effect: Lower Risk Without Lower Return, 34:I J. PORTFOLIO MgmT. 102 (Fall 2007 ); Roger Clarke, Harindra de Silva \& Steven Thorley, Minimum-Variance Portfolios in the U.S. Equity Market, 33:I J. Portfolıo Mgmt. I0 (Fall 2006 );Andrea Frazzini \& Lasse Heje Pedersen, Betting Against Beta, I I I J. FIN. EcoN. I (20I4); Robert A. Haugen \& Nardin L. Baker, The Efficient Market Inefficiency of Capitalization-Weighted Stock Portfolios, 17:3 J. PoRTFOLIO MGMT. 35 (Spring 199I); cf. Estrada \& Serra, supra note 167, at 267 (finding, "counterintuitively," that "low risk portfolios" in emerging markets "outperform ... high-risk portfolios over 20 years," at least "when portfolios are rebalanced every 10 years").

159 Baker, Bradley \& Wurgler, supra note 152, at 43.

${ }^{160}$ Ang, Hodrick, Xing \& Zhang, supra note |3|, at 297.
} 
Abysmal returns in the most volatile quantile are the natural and predictable consequence of "a statistically significant negative price of risk of approximately $-1 \%$ per annum" charged against "innovations in aggregate volatility." 161 Because it so strikingly "challenges the basic notion of a risk-return tradeoff," the "long-term outperformance of low-risk portfolios" is quite possibly "the greatest anomaly in finance." 162

More generally, $v$ and $v_{-}$may reveal the relationship of single-sided beta (or at least its relative volatility component) to Fama and French's three-factor model, ${ }^{163}$ especially since the book-to-market ratio (value) and size (small-cap) are thought to correlate to higher volatility relative to the market as a whole. ${ }^{164} \mathrm{~A}$ similar connection may link single-sided risk measures to momentum in market returns. ${ }^{165}$ In due course, this article will address the extent to which "the extended Fama-French factors fully capture downside risk concerns." 166 For the moment, it suffices to organize competing models into three "families" of risk measures: (1) "the traditional family" of measures drawn from the conventional CAPM and modern portfolio theory, such as unconditional standard deviation and beta; (2) the "factor family" typified by Fama and French's emphasis on size and value; and (3) a "downside risk family" based on singlesided statistical moments and their derivations. ${ }^{167}$

\subsection{Correlation tightening}

Relative volatility (and, by extension, of the $v$ parameter in this article's evaluation of single-sided beta) focuses in laser-like fashion on changes in return on a single asset, against the backdrop of the overall market. This power comes at a price: disregarding the $c$ parameter and the information that it conveys regarding correlation. The most compelling reason to consider risk factors beyond relative volatility subsists in the fact that no owner of a financial asset can be an island, when markets operate as comprehensive, interactive ecosystems of prospective buyers and sellers. ${ }^{168}$ Taking account of the correlation component of beta ensures that the "[r] isk of an investment and its fair market value" are "based on the risks (and pricing) perceived by" the entire "pool of likely buyers," and not just "the diversification or nondiversification of the current

\footnotetext{
${ }^{161}$ Id. at 260 (emphasis added); see also id. ("If the price of aggregate volatility is negative, stocks with large, positive sensitivity should have low average returns.').

162 Baker, Bradley \& Wurgler, supra note 152, at 43.

163 See sources cited supra note 40.

${ }^{164}$ See Chong \& Phillips, supra note 98, at 351 (acknowledging that the connections between single-sided beta and the Fama-French three-factor model remain largely unexplored).

165 See sources cited supra note 22.

${ }^{166}$ Alles \& Murray, supra note 109, at 2508 (finding "no evidence" that Fama and French's factors fully capture - and therefore wholly supersede - downside risk concerns embodied in single-sided measures of volatility and correlation).

${ }^{167}$ Javier Estrada \& Ana Paula Serra, Risk and Return in Emerging Markets: Family Matters, I5 J. MuLtinAT'L Fin. MgMt. 257,259 (2004) (emphases in original).

${ }^{168}$ Cf. JOHn DONNE, Meditation I7, in DeVOtIONs UPON EMERGING OCCASIONs (I623) ("No man is an island, entire of itself; every man is a piece of the continent .... [T] herefore never send to know for whom the bell tolls; it tolls for thee.") (available at https://en.wikisource.org/wiki/Meditation_XVII).
} 
owner."169 The burden of tracking changes in correlation on either side of mean return therefore falls upon the $c$ parameter in this article's analysis of single-sided beta.

It is one thing to emphasize the beta quotient or relative volatility. It is treacherous, however, to ignore correlation. As I have just argued, changes in relative volatility on either side of mean return, as measured by the $v$ parameter, may reveal useful information about the undervaluation of individual assets. Relative volatility animates deeper connections between single-sided beta the three-factor model of Fama and French most often credited with deprecating the conventional capital asset pricing model and its conception of beta. But we should not ignore information on correlation, which after all lies at the heart of portfolio design and addresses risk management concerns distinct from those raised by volatility. Correlations between equities in a wide range of developed stock markets are known to be much higher in downside markets than in normal markets. ${ }^{170}$ Indeed, those "increase[s] in conditional correlation" do not appear to flow from "[h]igh volatility per se (i.e., large absolute returns)," but rather seem to be "mainly affected by the market trend." 171

Moreover, as with the derivation of upside semivariance and semideviation from its downside counterpart, information on correlation is readily extracted from explorations of volatility. The same mathematical maneuver that isolates relative volatility simultaneously reports correlation tightening. Having extracted relative volatility parameter $v$ (in its upside or downside incarnations, or both) from beta on either side of mean return, we should also put correlation tightening parameter $c$ to work.

An episode in economic history counsels us to fully exploit insights into changes in correlation under different market conditions. ${ }^{172}$ Just as the cotton boll comprises both fiber and seed, beta combines relative volatility with correlation. Preindustrial cotton cultivation emphasized retrieval of raw fiber. The seed was considered a nuisance. Though cottonseed in excess of planting needs had value as fertilizer, animal feed, and a source of oil, the developed economies of the nineteenth century wavered between treating cottonseed as an alternative to increasingly expensive animal fats (including whale oil) and severely regulating it because its utility as an additive to lard or olive oil undermined markets for these commodities and threatened to deceive consumers. But twentieth-century food science converted cottonseed into edible

\footnotetext{
169 PRATT \& GRABOWSKI, supra note 84, at 307 (criticizing the "total beta" technique advocated by Butler and Pinkerton in sources cited supra note 149). The notion of fair market value involves a market transaction between hypothetical, even idealized, buyers and sellers. See United States v. Cartwright, 4 I I U.S. 546, 55I (1973); Estate of Bright v. United States, 658 F.2d 999, $1005-06$ (5th Cir. I98I); PrATT \& GRABOWSKI, supra note 84 , at 307 n. 30

${ }_{170}$ See Ang \& Chen, supra note 135, at 444 ("on the downside, portfolios [in the United States] are much more likely to move together with the market”); Longin \& Solnik, supra note 28 (mature equity markets).

${ }^{171}$ Longin \& Solnik, supra note 28 , at 650 .

172 See generally Richard O’Brien, Lynn A. Jones, C. Clay King, Phillip J.Wakelyn \& Peter J.Wan, Cottonseed Oil, in 2 BaILEY'S EdIBLE OIL AND FAT ProdUCTS: EDIBLE OILS 173 (Fereidoon Shahidi ed., 6th ed. 2005); H.C. Nixon, The Rise of the American Cottonseed Oil Industry, 38 J. POL. ECON. 73 (1930). The information in this paragraph is derived from these sources.
} 
shortening and cooking oil (best known in the United States under the brand names Crisco and Wesson). The once-useless byproduct became a formidable, profitable commodity in its own right. That cottonseed has been eclipsed by other oilseeds, especially soybeans and corn, in no way diminishes this parable. Having isolated information on correlation in the process of "filtering" beta for information on changes in relative volatility, we should not discard the information we have simultaneously obtained on changes in correlation.

A simple comparison between developed and emerging markets illustrates the difference between volatility and correlation as indicators of investment risk. Almost indisputably, "[e]merging markets have higher average returns and volatility than developed markets." 173 Conventional mean-variance optimization compares returns from emerging markets with their volatility to assess the value of the tradeoff of higher volatility for higher return. At sufficiently high levels of volatility, an investor may not find it worthwhile to venture the risk from exposure to emerging markets. But "low correlations between emerging markets and developed markets" point with little ambiguity in the direction of "portfolio investment opportunities." 174 Consequently, the "inclusion of emerging market assets in a mean-variance efficient portfolio will significantly reduce portfolio volatility and increase expected returns."175

This is not to suggest that correlation tightening is uniquely confined to emerging markets. Quite the contrary. " $[T]$ he Normal distribution ... consistently underestimates the probability of (positive or negative) large returns. Therefore, booms and crashes in European [and other developed] markets are much more likely to occur than a Normal distribution would predict." 176 In their canonical study of correlation under extreme conditions in developed markets in France, Germany, the United Kingdom, and the United States, François Longin and Bruno Solnik discovered that "conditional correlation" among these markets "strongly increases," but only "in bear markets." 177 By contrast, "conditional correlation does not seem to increase in bull markets." 178

Although Longin and Solnik refrained from drawing firm normative conclusions, their "empirical distinction between bear and bull markets has potential implications for asset allocation and portfolio construction." 179 One such implication af-

\footnotetext{
${ }^{173}$ Harvey, supra note 109, at 780.

${ }^{174}$ Id. at 78I; see also Vihang R. Erruzna, Emerging Markets: New Opportunity for Improving Global Portfolio Performance, $39: 5$ FIN. ANALYSTS J. 5 I (Sept./Oct. 1983)

175 Harvey, supra note 109, at 811 .

${ }^{176}$ Aparicio \& Estrada, supra note 15, at 15-16. See generally, e.g., Joseph Chen, Harrison Hong \& Jeremy Stein, Forecasting Crashes:Trading Volume, Past Returns, and Conditional Skewness in Stock Prices, $6 \mathrm{I}$ J. FIN. Econ. 345 (200I); Eugene F. Fama, The Behavior of Stock Market Prices, 38 J. Bus. 34 (1965); Peiró, supra note 15; Michael A. Simkowitz \&William L. Beedles, Diversification in a Three-Moment World, I3 J. FIN. \& QUANT.ANALYSIS 927 (1978); J. Clay Singleton \& John Wingender, Skewness Persistence in Common Stock Returns, 2I J. FIN. \& QUANT.ANALYSIS 335 (I 986 ).

177 Longin \& Solnik, supra note 28 , at 650.

${ }^{178}$ Id. at 651 .

${ }^{179} \mathrm{Id}$.
} 
fects the impact of asymmetric correlation on extremely negative returns in otherwise weakly related markets. Where "the correlation structure of large returns is asymmetric," such that "[c]orrelation tends to decrease with the absolute size of the threshold for positive returns ... but tends to increase for negative returns," it necessarily follows that "the probability of having large losses simultaneously on two markets is much larger than would be suggested under the assumption of multivariate normality." 180 And actual evidence of differences in correlation on either side of mean returns reinforces the supposition that "[c]orrelation asymmetries are far greater for extreme downward moves." 181 Andrew Ang and Joseph Chen have found a swing exceeding 3 percentage points (from 8.48 to 11.61 percent) between (1) observed correlations between narrower, asset-class-based portfolios and the broader market, relative to correlations implied by a normal distribution of returns, and (2) "the average difference" between the same correlations "[c]onditional on just downside moves." 182

Effective diversification depends on low or even negative correlation between assets. Idiosyncratic risk, the phenomenon that propels both raw volatility and volatility relative to a broader benchmark, is the very reason for diversification. ${ }^{183}$ Inasmuch as "changes in market volatility ... represent[] a deterioration in investment opportunities," investors as "[r]isk-averse agents [will] demand stocks that hedge against that risk." ${ }^{184}$ For this reason, it is not return or volatility alone, but also correlation, that informs portfolio construction and asset allocation. If "[c]orrelations conditional on 'downside' movements" exceed "correlations implied by a normal distribution," or even correlations under other market conditions, such that "all stocks tend to fall together as the market falls, the value of diversification may be overstated" to the extent of the failure to "tak[e] the increase in downside correlations into account." 185

Because they undermine diversification, portfolio theory's standard response to idiosyncratic risk, changes in correlation under stressed market conditions inject a distinct and dangerous sort of risk in its own right, wholly apart from volatility. Correlation tightening can disrupt managerial strategies that assume lower levels of correlation among asset classes, or even negative correlation so that certain holdings can hedge against declines in others.

\footnotetext{
${ }^{180} / d$. at $669-70$.

${ }^{181}$ Ang \& Chen, supra note 135, at 469.

182 Id.

${ }^{183}$ See generally John Y. Campbell, Martin Lettau, Burton G. Malkiel \& Yexiao Xu, Have Individual Stocks Become More Volatile? An Empirical Exploration of Idiosyncratic Risk, 56 J. Fin. I (200I).

${ }^{184}$ Ang, Hodrick, Xing \& Zhang, supra note I3I, at 260. See generally John Y. Campbell, Intertemporal Asset Pricing Without Consumption Data, 83 AM. ECON. Rev. 487 (1993); Joseph Y. Campbell, Understanding Risk and Return, 104 J. POL. ECON. 298 (1996).

${ }^{185}$ Ang \& Chen, supra note 135, at 444 (reporting an II.6\% increase in downside correlation); see also id. at 450 (showing graphically the economic cost of ignoring or miscalculating downside correlation).
} 
In principle, this interest in diversification may, on its own, justify investments in highvolatility assets whose returns lag behind those of the broader universe of tradable instruments. A high-volatility component of a broader portfolio may lower risk by "provid[ing] insurance against bad events," especially by delivering returns during sharp downturns. ${ }^{186}$ Stocks "with high upside potential relative to downside risk tend[] to pay off more when an investor's wealth is already high." 187 Such stocks "are not as desirable as stocks that pay off when the market decreases." 188 If "assets with high sensitivities to market volatility risk" do indeed "provide hedges against market downside risk," then "higher demand for assets with high systematic volatility loadings" should "increase[] their price and lower[] their average return." 189 It is worth remembering that upside beta is the product of upside correlation and the ratio of upside asset-specific volatility to upside market-wide volatility; downside beta is similarly defined: ${ }^{190}$

$$
\begin{aligned}
& \beta_{+}=\rho_{+}(a, m) \frac{\sigma_{a,+}}{\sigma_{m,+}} \\
& \beta_{-}=\rho_{-}(a, m) \frac{\sigma_{a,-}}{\sigma_{m,-}}
\end{aligned}
$$

This relationship reminds us that "an asset [that] tends to move downward in a declining market more than it moves upward in a rising market ... is an unattractive asset to hold, because it tends to have very low payoffs precisely when the wealth of investors is so low."191

Actual evidence, however, sometimes points in the opposite direction. Once again, we confront the confounding effects of the low-volatility anomaly. High-volatility portfolios perform at their worst "in precisely those periods when an insurance payment would have been most welcome, such as the downturns of 1973-74 and 20002002, the crash of 1987, and the financial crisis that began in the fall of 2008."192 Rising correlation in stressed markets, the very phenomenon that tightening parameter $c_{-}$measures, poses an even greater threat to portfolios consciously designed to weather ordinary volatility. ${ }^{193}$

Poor performance by high-beta portfolios has been confirmed in studies of the ten months with the sharpest downward market movements in the six decades after $1932^{194}$

\footnotetext{
${ }^{186}$ Baker, Bradley \& Wurgler, supra note 152, at 43.

187 See Ang \& Chen, supra note 90 , at 1199.

188 Id.

${ }^{189}$ Ang, Hodrick, Xing \& Zhang, supra note 131, at 260. See generally Gurdip Bakshi \& Nikunj Kapadia, Delta-Hedged Gains and the Negative Market Volatility Risk Premium, I6 Rev. Fin. Stud. 527 (2003).

190 See Ang \& Chen, supra note 135, at 46I.

${ }^{191}$ Ang, Chen \& Xing, supra note 90 , at 1191 .

192 Baker, Bradley \& Wurgler, supra note 152, at 43.

193 See LeiBoWitZ, Bova \& HAMmOND, supra note 29, at 235, 265.

194 See Chan \& Lakonishok, supra note 38.
} 
and of all periods of market distress, defined as declines in the Standard \& Poor's 500 index exceeding 10 percent, in the quarter century preceding Fama and French's attack on beta. ${ }^{195}$ Replicating work on single-sided beta, especially the 1995 study by Pettengill, Sundaram, and Mathur, ${ }^{196}$ Malcolm Baker, Brendan Bradley, and Jeffrey Wurgler in 2011 not only found "the low-beta anomaly" across diverse market conditions, but also detected a meaningful difference between up and down markets. ${ }^{197}$ Although "the low-beta anomaly" persists in all market environments" on "a capital asset pricing model ... market-adjusted basis," it differs on either side of mean returns: "high-beta stocks earned higher (lower) total returns than did low-beta stocks in up (down) markets." 198

Further evaluation of beta according to its discrete components suggests that it is correlation tightening rather than downside volatility that drives the low-volatility anomaly. In a 2006 study by Andrew Ang, Joseph Chen, and Yuhang Xing, controlling for downside correlation showed that "stocks with high [downside] volatility, or $\bar{\sigma}$, tend to have low returns, which is exactly opposite to the high $\beta^{-}$, high average return effect" predicted by standard portfolio theory. ${ }^{199}$ These, after all, are the stocks with the highest levels of volatility and correspondingly "abysmal[]" returns. ${ }^{200}$ But holding downside volatility constant so that increases in downside beta are driven by downside correlation creates an average $5 \%$ annualized difference in returns on a month after month basis "between the tenth and first decile portfolios, sorted on past" downside correlation. ${ }^{201}$ At a minimum, an answer to beta's true significance begins with the bifurcation of beta on either side of mean return. If the upside risk premium fails to offset the negative risk premium on downside beta, as one might expect in negatively skewed markets, these results may explain, at least in part, the mechanics of the low-volatility anomaly.

The low-volatility anomaly has an unusual twist in banking, one that might be called the "curse of quality." Populating the trading book with lower-volatility, higher-quality investments does not necessarily lower a bank's market risk. Indeed, cautious investing, though seemingly prudent from the perspective of an individual bank, may exacerbate the systemic risk borne by the banking industry as a whole. This paradox sheds highlights the importance of correlation and changes in correlation - wholly apart from considerations of volatility - in risk management. Assets

\footnotetext{
195 See Grundy \& Malkiel, supra note 41.

196 See Pettengill, Sundaram \& Mathur, supra note 5.

${ }^{197}$ Baker, Bradley \&Wurgler, supra note I52, at 43.

198 Id.; cf. R. Burr Porter, Semivariance and Stochastic Dominance:A Comparison, 64 AM. EcoN. Rev. 260 (I974) (finding that portfolios with belowtarget semivariance showed statistic dominance over their benchmark, but that porfolios with below-mean semivariance did not).

${ }^{199}$ Ang, Chen \& Xing, supra note 90 , at 1228.

${ }^{200}$ See sources cited supra note 157.

${ }^{201}$ Ang, Chen \& Xing, supra note 90 , at 1228 n. 15.
} 
chosen specifically because they are less volatile under ordinary market conditions may face unique threats in when markets come under downward pressure. Systemic risk in banking, in short, arises at least in part from correlation tightening. The most highly rated assets, which effectively lower capital adequacy requirements, may expose banks to greater risk when markets come under stress, since the risk that inheres in highly rated assets is not the idiosyncratic, diversifiable risk associated with more speculative instruments. ${ }^{202}$ Stress-driven changes in correlation among asset classes and ineffectual flights to quality thus signal the elevation of systemic risk in global finance. ${ }^{203}$

Paradoxically, financial regulation may exacerbate the risk of simultaneous decline across markets that would otherwise be geographically and economically diverse. ${ }^{204}$ A coordinated financial system heeding the same rules is likelier to suffer from rising correlation across asset classes and from levels of systemic risk transcending the menace to any individual institution. By "promot[ing] coordination" within financial markets, uniformity in regulatory safeguards against market risk "can erode management tools premised on randomness and independent action and alter the dynamics that make risk management effective." 205

\subsection{Downside risk, upside reward}

The relationship between beta and returns is ultimately a function of market conditions. At least during rising markets, "[b]eta should have a positive relationship with investor returns." 206 By contrast, a "negative relationship is likely during downturns, as shares with greater exposure ... offer poorer returns," and "investors accepting high downside beta ... suffer relatively greater losses." 207 As a result, "high beta portfolios incur lower returns during down markets than low beta portfolios." 208 "Investors who are sensitive to downside losses, relative to upside gains, require a premium for holding assets that covary strongly with the market when the market declines." 209 Accordingly, "the cross-section of stock returns [should] reflect[] a premium for bearing downside risk."210

\footnotetext{
${ }^{202}$ See Markus Brunnermeier et al., The Fundamental Principles of Financial Regulation 8 (2009) (Geneva Reports on the World Economy, No. I I); Malcolm P. Baker \& Jeffrey Wurgler, Do Strict Capital Requirements Raise the Cost of Capital? Bank Regulation, Capital Structure and the Low Risk Anomaly, 105 AM. Econ. Rev. 315 (20I5).

${ }^{203}$ See Zeyu Zheng, Boris Podobnik, Ling Feng \& Baowen Li, Changes in Cross-Correlations as an Indicator for Systemic Risk, 2 SCI. RePORTS 888 (20I2).

${ }^{204}$ See lan Ayres \& Joshua Mitts, Anti-Herding Regulation, 5 HARv. Bus. L. Rev. I (20I5); Felix B. Chang, The Systemic Risk Paradox: Banks and Clearinghouses Under Regulation, 2014 COLuM. Bus. L. Rev. 747.

${ }^{205}$ Charles K.Whitehead, Destructive Coordination, 96 CoRNel. L. Rev. 323, 347 (20I I). See generally id. at 346-52.

${ }^{206}$ Alles \& Murray, supra note 109, at 2504.

207 Id.

${ }^{208}$ Pettengill, Sundaram \& Mathur, supra note 5 , at 110.

${ }^{209}$ Ang, Chen \& Xing, supra note 90 , at 1192.

${ }^{210} / d$.
} 
This "negative relation" between beta and returns when markets are down "provide[s] strong evidence that investors are paid for holding beta risk." 211 The "greater losses" borne by "investors accepting high downside beta" are precisely the sort of "risk exposure" that investors find "unattractive" and for which they demand "excess returns." 212 Put even more simply, "beta risk is rewarded in up markets for losses incurred in down markets." 213 "When upturn and downturn periods are combined, the overall relationship" between beta and returns "should [ultimately] depend on whether there are greater numbers of upturn or downturn periods."214 Although "investors clearly demand higher returns for stocks with larger downside $\beta$ 's," it is less clear whether a "negative risk premium on the upside $\beta$ indicates that investors are willing to accept lower returns for stocks with higher upside $\beta$ 's."215 This evidence is consistent with the behavioral insight that investors tend to be riskaverse toward losses, but risk-seeking vis-à-vis gains. ${ }^{216}$ The real trouble with the conventional capital asset pricing model's symmetrical version of beta lies in the typically negative skew of financial distributions: the presence "of a large number of negative market excess return periods" stretches the odds "against finding a systematic relationship" through "an unconditional positive correlation between beta and realized returns." 217

Emerging markets are typically treated as the canonical example of markets with negatively skewed returns. ${ }^{218}$ Variation among emerging markets arises from their failure to be fully integrated with global finance, due to "market liquidity, political risk," and other "[f]actors such as taxes." 219 These haphazard factors and mechanics have muddled the quest for "a model to beat" in emerging markets, comparable to the "role played by the CAPM" in developed markets. ${ }^{220}$ Risk variables as diverse as size, value, momentum, and single-sided and conventional measures of volatility and beta have "an impact on returns which varies from country to country." 221

\footnotetext{
211 Pettengill, Sundaram \& Mathur, supra note 5, at II5.

${ }^{212}$ Alles \& Murray, supra note 109 , at 2504.

${ }^{213}$ Morelli, supra note 117 , at 265.

${ }^{214}$ Alles \& Murray, supra note 109 , at 2504.

${ }^{215}$ Xu \& Pettit, supra note 114 , at 69.

${ }^{216}$ See, e.g., Haim Levy \& Moshe Levy, Prospect Theory and Mean-Variance Analysis, 17 Rev. Fin. STUD. 1015 (2004); Moshe Levy \& Haim Levy, Prospect Theory: Much Ado About Nothing?, 48 MGmT. SCl. 1334 (2002); Richard H.Thaler \& Eric J. Johnson, Gambling with the House Money and Trying to Break Event:The Effects of Prior Outcomes on Risky Choice, 36 MGMT. SCI. 643 (1990).

${ }^{217}$ Pettengill, Sundaram \& Mathur, supra note 5, at 105.

${ }^{218}$ See, e.g., C.J.Adcock \& K. Shutes, An Analysis of Skewness and Skewness Persistence in Three Emerging Markets, 6 EMERGING MKTS. REV. 396 (2005) (reporting significant skewness in daily returns on stocks in Kenya, Poland, and the Czech Republic); Hwang \& Pedersen, supra note II0.

${ }^{219}$ Harvey, supra note 109, at 787; see also id. at 801 (concluding that local information materially affects returns in emerging markets, while most of the variation in developed markets is "driven by global information variables" rather than "local information"); Geert Bekaert \& Campbell R. Harvey, Emerging Equity Market Volatility, 43 J. FIN. EcoN. 27 (1997); Geert Bekaert \& Campbell R. Harvey, Time-Varying World-Market Integration, 50 J. FiN. 403 (1995). On the impact of foreign exchange markets on stock prices, especially in emerging markets, see Geert Bekaert \& Robert J. Hodrick, Characterizing Predictable Components in Excess Returns on Equity and Foreign Exchange Markets, 47 J. FiN. 467 (I992); Richard Roll, Industrial Structure and the Comparative Behavior of International Stock Market Indexes, 47 J. FIN. 3 (1992). On the impact of foreign speculators, see Geert Bekaert \& Campbell R. Harvey, Foreign Speculators and Emerging Equity Markets, 55 J. FiN. 565 (2000).

${ }^{220}$ Estrada \& Serra, supra note 167 , at 268.

${ }^{221}$ Id.
} 
Evidence from emerging markets not only confirms the value of downside beta as a risk measure, but also suggests that it is correlation tightening that drives nearly all of the difference between downside beta and its conventional counterpart. In an illustrative 2002 study, Javier Estrada found that "average downside beta" in emerging markets was " $50 \%$ larger than average beta." 222 In other words, "emerging markets exhibit[ed] more downside volatility than relative volatility." 223 The following table reports the summary statistics for Estrada's original survey of emerging markets from January 1988 through December 2001,224 combined with a parallel survey of developed markets over the same 1988-2001 period (which Estrada published in 2007): 225

\begin{tabular}{|c|c|c|c|c|c|c|c|c|c|c|c|}
\hline Summary statistics & $\mu$ & $\sigma$ & $P$ & $\beta$ & $\sigma_{-}$ & $\rho_{-}$ & $\beta_{-}$ & $\gamma_{2}$ & $v_{-}$ & $c_{-}$ & $v_{-} c_{-}$ \\
\hline \multicolumn{12}{|c|}{ Developed countries } \\
\hline Australia & 0.86 & 5.63 & 0.57 & 0.77 & 3.94 & 0.70 & 0.89 & 0.24 & 0.94 & 1.23 & 1.15 \\
\hline Austria & 0.54 & 6.92 & 0.38 & 0.63 & 4.81 & 0.63 & 0.98 & 0.67 & 0.93 & 1.66 & 1.55 \\
\hline Belgium & 1.05 & 4.94 & 0.58 & 0.69 & 3.44 & 0.70 & 0.78 & 1.46 & 0.93 & 1.21 & 1.13 \\
\hline Canada & 0.83 & 5.15 & 0.72 & 0.89 & 3.86 & 0.79 & 0.98 & -3.28 & 1.00 & 1.10 & 1.10 \\
\hline Denmark & 1.17 & 5.37 & 0.59 & 0.76 & 3.81 & 0.72 & 0.89 & 0.13 & 0.95 & 1.22 & 1.16 \\
\hline Finland & 1.65 & 9.74 & 0.55 & 1.29 & 6.66 & 0.67 & 1.43 & 0.95 & 0.92 & 1.22 & 1.12 \\
\hline France & 1.13 & 5.66 & 0.69 & 0.94 & 4.01 & 0.79 & 1.02 & 0.12 & 0.95 & 1.14 & 1.09 \\
\hline Germany & 1.00 & 6.04 & 0.65 & 0.95 & 4.46 & 0.79 & 1.14 & -1.57 & 0.99 & 1.22 & 1.20 \\
\hline Greece & 1.55 & 11.34 & 0.27 & 0.72 & 6.67 & 0.60 & 1.28 & 8.63 & 0.79 & 2.22 & 1.75 \\
\hline Hong Kong & 1.44 & 8.45 & 0.59 & 1.19 & 5.80 & 0.67 & 1.26 & 1.37 & 0.92 & 1.14 & 1.05 \\
\hline Ireland & 0.99 & 5.69 & 0.66 & 0.90 & 3.98 & 0.75 & 0.96 & 0.53 & 0.94 & 1.14 & 1.07 \\
\hline Italy & 0.72 & 7.06 & 0.52 & 0.88 & 4.79 & 0.67 & 1.04 & 1.41 & 0.91 & 1.29 & 1.17 \\
\hline Japan & -0.01 & 7.06 & 0.76 & 1.29 & 4.71 & 0.80 & 1.21 & 2.14 & 0.89 & 1.05 & 0.94 \\
\hline Netherlands & 1.18 & 4.50 & 0.76 & 0.82 & 3.42 & 0.82 & 0.90 & -3.20 & 1.02 & 1.08 & 1.10 \\
\hline New Zealand & 0.35 & 7.08 & 0.49 & 0.84 & 4.86 & 0.68 & 1.06 & 1.59 & 0.92 & 1.39 & 1.28 \\
\hline Norway & 0.88 & 6.74 & 0.59 & 0.95 & 4.93 & 0.71 & 1.13 & -2.22 & 0.98 & 1.20 & 1.18 \\
\hline Portugal & 0.43 & 6.66 & 0.46 & 0.74 & 4.42 & 0.60 & 0.86 & 3.20 & 0.89 & 1.30 & 1.16 \\
\hline Singapore & 0.94 & 8.55 & 0.64 & 1.32 & 6.06 & 0.73 & 1.42 & 0.45 & 0.95 & 1.14 & 1.08 \\
\hline Spain & 0.96 & 6.36 & 0.70 & 1.07 & 4.48 & 0.83 & 1.19 & -0.33 & 0.94 & 1.19 & 1.12 \\
\hline Sweden & 1.39 & 7.37 & 0.72 & 1.27 & 5.33 & 0.81 & 1.40 & -1.29 & 0.97 & 1.13 & 1.09 \\
\hline Switzerland & 1.17 & 5.14 & 0.66 & 0.81 & 3.63 & 0.77 & 0.90 & -0.25 & 0.95 & 1.17 & 1.10 \\
\hline United Kingdom & 0.89 & 4.69 & 0.77 & 0.87 & 3.21 & 0.80 & 0.83 & 1.43 & 0.92 & 1.04 & 0.95 \\
\hline United States & 1.22 & 4.09 & 0.81 & 0.79 & 3.04 & 0.88 & 0.86 & -2.23 & 1.00 & 1.09 & 1.08 \\
\hline
\end{tabular}

\footnotetext{
${ }^{222}$ Estrada, Systematic Risk in Emerging Markets, supra note 5I, at 374.

${ }^{223} \mathrm{Id}$.

${ }^{224}$ See id. at 378 (table Al)

225 See Estrada, Downside Risk and Capital Asset Pricing, supra note 79, at 175-76 (exhibit I)
} 


\begin{tabular}{|c|c|c|c|c|c|c|c|c|c|c|c|}
\hline Summary statistics & $\mu$ & $\sigma$ & $P$ & $\beta$ & $\sigma_{-}$ & $\rho_{-}$ & $\beta_{-}$ & $\gamma_{2}$ & $v_{-}$ & $c_{-}$ & $v_{-} c_{-}$ \\
\hline \multicolumn{12}{|c|}{ Emerging markets } \\
\hline Argentina & 2.96 & 18.19 & 0.15 & 0.66 & 10.17 & 0.56 & 1.82 & 10.78 & 0.75 & 3.73 & 2.80 \\
\hline Brazil & 2.91 & 17.37 & 0.35 & 1.44 & 11.55 & 0.58 & 2.16 & 2.51 & 0.89 & 1.66 & 1.48 \\
\hline Chile & 1.74 & 7.56 & 0.32 & 0.57 & 5.27 & 0.56 & 0.95 & -0.42 & 0.93 & 1.75 & 1.64 \\
\hline China & -0.72 & 12.72 & 0.37 & 1.13 & 7.92 & 0.54 & 1.39 & 4.27 & 0.83 & 1.46 & 1.22 \\
\hline Colombia & 0.29 & 9.68 & 0.14 & 0.32 & 6.55 & 0.38 & 0.81 & 1.41 & 0.91 & 2.71 & 2.46 \\
\hline Czech Republic & 0.24 & 9.28 & 0.30 & 0.66 & 6.59 & 0.69 & 1.29 & 0.23 & 0.95 & 2.30 & 2.19 \\
\hline Egypt & 0.46 & 8.69 & 0.25 & 0.53 & 5.18 & 0.61 & 0.90 & 4.94 & 0.80 & 2.44 & 1.95 \\
\hline Hungary & 1.68 & 11.84 & 0.54 & 1.53 & 8.17 & 0.82 & 1.91 & 0.94 & 0.93 & 1.52 & 1.40 \\
\hline India & 0.42 & 8.88 & 0.26 & 0.54 & 6.04 & 0.56 & 1.10 & 1.09 & 0.91 & 2.15 & 1.96 \\
\hline Indonesia & 1.26 & 17.08 & 0.24 & 0.97 & 9.88 & 0.50 & 1.60 & 10.38 & 0.78 & 2.08 & 1.62 \\
\hline Israel & 0.76 & 7.13 & 0.37 & 0.63 & 5.42 & 0.49 & 0.87 & -2.01 & 1.02 & 1.32 & 1.35 \\
\hline Jordan & 0.16 & 4.45 & 0.11 & 0.11 & 3.11 & 0.32 & 0.32 & -0.80 & 0.94 & 2.91 & 2.73 \\
\hline Korea & 0.93 & 12.56 & 0.41 & 1.25 & 7.68 & 0.54 & 1.34 & 6.83 & 0.82 & 1.32 & 1.08 \\
\hline Malaysia & 0.95 & 10.09 & 0.42 & 1.02 & 6.87 & 0.60 & 1.33 & 3.16 & 0.91 & 1.43 & 1.30 \\
\hline Mexico & 2.40 & 10.41 & 0.45 & 1.12 & 7.67 & 0.60 & 1.47 & -2.23 & 0.99 & 1.33 & 1.32 \\
\hline Morocco & 0.70 & 4.95 & -0.10 & -0.12 & 3.35 & 0.41 & 0.39 & 1.62 & 0.91 & -4.10 & -3.72 \\
\hline Pakistan & -0.02 & 12.08 & 0.17 & 0.49 & 7.91 & 0.39 & 1.00 & 1.96 & 0.88 & 2.29 & 2.01 \\
\hline Peru & 0.97 & 9.47 & 0.33 & 0.74 & 6.55 & 0.56 & 1.19 & 0.76 & 0.93 & 1.70 & 1.57 \\
\hline Philippines & 0.71 & 10.36 & 0.44 & 1.10 & 6.94 & 0.63 & 1.40 & 2.78 & 0.90 & 1.43 & 1.29 \\
\hline Poland & 2.59 & 17.86 & 0.39 & 1.66 & 10.03 & 0.62 & 2.02 & 11.00 & 0.75 & 1.59 & 1.20 \\
\hline Russia & 3.59 & 22.22 & 0.50 & 2.69 & 15.27 & 0.65 & 2.85 & 0.56 & 0.92 & 1.30 & 1.20 \\
\hline South Africa & 0.78 & 8.20 & 0.56 & 1.10 & 6.02 & 0.68 & 1.33 & -1.90 & 0.98 & 1.21 & 1.20 \\
\hline Sri Lanka & 0.10 & 10.44 & 0.24 & 0.61 & 6.67 & 0.51 & 1.11 & 4.16 & 0.86 & 2.13 & 1.82 \\
\hline Taiwan & 1.27 & 12.47 & 0.29 & 0.87 & 8.19 & 0.57 & 1.49 & 2.44 & 0.88 & 1.97 & 1.73 \\
\hline Thailand & 0.72 & 12.73 & 0.46 & 1.41 & 8.80 & 0.62 & 1.75 & 1.25 & 0.93 & 1.35 & 1.25 \\
\hline Turkey & 2.34 & 18.90 & 0.23 & 1.04 & 11.86 & 0.56 & 2.13 & 4.47 & 0.84 & 2.43 & 2.05 \\
\hline Venezuela & 1.33 & 14.65 & 0.24 & 0.85 & 10.18 & 0.44 & 1.46 & -0.23 & 0.93 & 1.83 & 1.71 \\
\hline World averages & 0.78 & 4.17 & 1.00 & 1.00 & 3.11 & 1.00 & 1.00 & -2.14 & 1.00 & 1.00 & 1.00 \\
\hline
\end{tabular}

I have added columns reporting parameters $v_{-}$and $c_{-}$as defined in this article, which respectively describe changes in relative volatility and in correlation as returns fall below their mean. Closer examination of these parameters, and of their product, $v_{-} c_{-}$, reveals that nearly all changes in downside beta relative to conventional CAPM beta are attributable to $c$, the correlation tightening parameter. $v_{-} c_{-}$, it bears remembering, is the ratio of downside beta to conventional beta, or $\beta_{-} / \beta$. For the developed markets in Estrada's surveys, the correlation between $c_{-}$and $v_{-} c_{-}$is 0.965 ; for emerging markets, the correlation increases to 0.992 . The corresponding values of $R^{2}$ for developed and emerging markets, respectively, are 0.932 and 0.983 . By contrast, correlation between $v_{-} c_{-}$and $v$, the relative volatility parameter, is actually negative for 
both types of markets and close to zero for emerging markets: $\rho=-0.504$ for developed markets and -0.115 for emerging markets; $R^{2}=0.254$ for developed markets and and 0.013 for emerging markets.

It is also noteworthy that Estrada calculated standardized skewness for all markets in his surveys. Contrary to the usual characterization of emerging markets, most of the emerging markets in Estrada's 2002 and 2007 studies were positively skewed. ${ }^{226}$ Using the trigonometric techniques described in section IV.B., I computed implied upside volatility for all markets in Estrada's surveys. The $R^{2}$ statistic, or the coefficient of determination, for standardized skewness vis-à-vis the ratio of upside to downside volatility was 0.974 for developed markets and 0.936 for emerging markets. I derived $R^{2}$ from the ordinary correlation between the upside-downside volatility ratio and standardized skewness, which reported even more impressive values of $\rho=0.987$ for developed markets and $\rho=0.968$ for emerging markets.

The strength of downside beta's "explanatory power" in Estrada's 2007 survey, where this risk measurement "clearly outperform[ed] beta (and the other risk variables)," prompted Estrada to conclude that downside beta should "replace beta as the single explanatory variable of the cross section of stock returns." 227 Through an admittedly cursory meta-analysis, I have attempted to add a little nuance. I have shown that the explanatory power of downside beta resides predominantly in its correlation tightening component, or $c$. For its part, the $v$ parameter bears a very close kinship to skewness. Specifically, $v_{+}$, the upside relative volatility parameter, is almost perfectly correlated to standardized skewness, while $v_{-}$, its downside counterpart, exhibits values for $\rho$ close to -1 for both developed and emerging markets.

\section{Time-varying beta: autocorrelation and autoregressive time series}

This article thus far has focused on bifurcating beta in financial space - that is, on either side of mean rates of return or some other target. It has analyzed beta in recognition of two distinct but related departures from the conventions of modern portfolio theory, the capital asset pricing model, and the efficient capital markets hypothesis. Financial markets are both abnormal and irrational. They are abnormal in the sense that they violate the central limit theorem and other properties of the normal, Gaussian distribution. Furthermore, real investors respond to such abnormalities in ways that deviate from the neoclassical assumption of perfect rationality

\footnotetext{
${ }^{226}$ See Estrada, Systematic Risk in Emerging Markets, supra note 5I, at 378; Estrada, Downside Risk and Capital Asset Pricing, supra note 79, at I75-76. ${ }^{227}$ Estrada, Downside Risk and Capital Asset Pricing, supra note 79, at 177.
} 
and dispassionate maximization of individual or institutional welfare. Whether human behavior causes market abnormalities or vice versa lies well beyond our ken. It suffices to note that market abnormality and human irrationality travel together - that they are strongly correlated, even we cannot demonstrate a causal link.

As suggested by its subtitle, "Bifurcating Beta in Financial and Behavioral Space," this article consciously confines itself to the spatial dimensions of mathematical finance. It does so at the implicit expense of elaborating the temporal dimensions. Although a comprehensive analysis of beta (much less other aspects of capital asset pricing or portfolio theory) as a time series lies beyond the scope of this article, a brief interlude on time-varying beta is warranted.

This article has examined single-sided beta and its components without regard to serial correlation in beta or any other time-varying financial data. Until recently, most of the studies applying single-sided beta have taken no account of autocorrelation. Such studies have implicitly assumed that "investors in a hypothetical model-economy ... live for only one period." 228 In a "real world [where] investors live for many periods," however, it is not "particularly reasonable" to assume that "betas ... remain constant over time," instead of varying in response to changes in "financial leverage" or to "technological or taste shocks." 229

Since 2009, at least three studies have combined time-varying conditional heteroskedastic models with the calculation of downside beta. ${ }^{230} \mathrm{~A}$ fourth study, using the older, iterative model of Eugene Fama and James MacBeth ${ }^{231}$ to evaluate timevarying beta in Pakistani equities, tentatively "advocate[d] the replacement of variance by downside risk as a suitable risk measure in a single asset pricing model." 232 Contemporaneously, Taufiq Choudhry and Ranadeva Jayasekera have examined potentially asymmetric changes to beta in response to good and bad news. ${ }^{233}$

These articles emphasize asymmetry within the extensive literature on the so-called conditional capital asset pricing model, a modification of the CAPM that suspends the as-

\footnotetext{
${ }^{228}$ Jagannathan \& Wang, supra note 7 , at 4.

${ }^{229}$ Id. at 4-5. See generally Frank J. Fabozzi \& Jack Clark Francis, Beta as a Random Coefficient, I3 J. FIN. \& QUANT. ANALYSIS I0I (I978); George J. Alexander \& P. George Benson, More on Beta as a Random Coefficient, I7 J. FIN. \& QUANT.ANALYSIS 27 (I982).

${ }^{230}$ See Chong, Pfeiffer \& Phillips, supra note 32, at 75; Don U.A. Galagedera \& Asmah M. Mohd Jaapar, Modeling Time-Varying Downside Risk, 7 IUP J. FIN. ECON. 36 (2009); Tsai, Chen \& Yang, supra note 79, at 442.

${ }^{231}$ See Eugene F. Fama \& James MacBeth, Risk, Return and Equilibrium: Empirical Tests, I 3 J. PoL. EcoN. 607 (1973).

${ }^{232}$ Mohammad Tahir, Qaiser Abbas, Shahid Mehmmod Sargana, Usman Ayub \& Syed Kashif Saeed, An Investigation of Beta and Downside Beta Based CAPM - Case Study of Karachi Stock Exchange, 85 AM. J. SCI. ReSEARCH I I8, I 28 (201 I).

${ }^{233}$ Taufiq Choudhry \& Ranadeva Jayasekera, Comparison of Efficiency Characteristics Between the Banking Sectors of US and UK During the Global Financial Crisis of 2007-20I I, 25 INT'L REv. FIN.ANALYSIS I06, I08-II (20I2); accord Taufiq Choudhry \& Ranadeva Jayasekera, Level of Efficiency in the UK Equity Market: Empirical Study of the Effects of the Global Financial Crisis, 44 Rev. QUANT. FIN. AccountING 213, $219-20$ (20I5); Taufiq Choudhry \& Ranadeva Jayasekera, Market Efficiency During the Global Financial Crisis: Empirical Evidence from European Banks, 49 J. INT'L MoNEY \& FIN. 299, 30I-03 (2014). These articles extend earlier work by Choudhry on time-varying beta. See, e.g., Taufiq Choudhry, Lin Lu \& Ke Peng, Time-Varying Beta and the Asian Financial Crisis: Evidence from the Asian Industrial Sectors, 22 JAPAN \& WORLD ECON. 228 (2010); Taufiq Choudhry, Time-Varying Beta and the Asian Financial Crisis: Investigating the Malaysian and Taiwanese Firms, I3 PAC. BASIN FIN. J. 93 (2005).
} 
sumption of static, stable beta and explicitly models time-varying beta according to its lagged values. The conditional CAPM, which traces its origins to a 1991 article by James Bodurtha, Jr., and Nelson Mark, ${ }^{234}$ nearly coincided with Fama and French's celebrated attack on undermined the empirical underpinnings of conventional CAPM. In a trivial sense, finding that "betas remain constant over time" would "collapse[]" the conditional model back into "the familiar static CAPM." 235 On the other hand, if beta responds asymmetrically to positive and negative innovations, then a tractable explanation of beta's variability - not only across financial space but also as a predictable function of time may restore some measure of validity to the efficient capital markets hypothesis. ${ }^{236}$ Such a feat may also rehabilitate the rest of the CAPM, including beta as a measure of risk. ${ }^{237}$

Literature on single-sided beta and on time-varying beta ultimately shares the same mission: to test whether a more sophisticated understanding of covariances and correlations can better predict investor behavior and asset prices. Since the time series models that have been used to measure time-varying beta would warrant full specification and exacting application in their own right, I shall leave complete exploration of that subject for another time. In this article, I will make do a few observations on the harmonization of single-sided beta with time-varying beta.

Beta undoubtedly varies over time. "[M] any stocks' betas move randomly through time rather than remain stable." ${ }^{238}$ A 2001 study found that the correlation between current beta and beta from the previous year was 0.34 .239 In every instance, the question is whether beta exhibits serial correlation and, if so, whether a simpler autoregressive model or a conditionally heteroskedastic model supplies the appropriate technique for measuring conditional, time-varying beta. Tempting though it may be simply to assume autocorrelation within beta, we should proceed with a formal specification and application of the data's autocorrelation function.

Beta in any of its incarnations (including upside or downside beta, $\beta_{ \pm}$), may be rendered as a time series, $\left\{r_{t}\right\}$. ${ }^{240}$ This time series "is weakly stationary if both the mean of $r_{t}$ and the covariance between $r_{t}$ and $r_{t-l}$ are time invariant, where $l$ is an arbitrary integer." 241 Even more formally, time series $\left\{r_{t}\right\}$ is weakly stationary if both of these conditions are true: 242

\footnotetext{
${ }^{234}$ James N. Bodurtha, Jr. \& Nelson C. Mark, Testing the CAPM with Time-Varying Risks and Returns, 46 J. FIN. I485 (I99I); see also Tim Bollerslev, Robert F. Engle \& Jeffrey M.Wooldridge, A Capital Asset Pricing Model with Time-Varying Covariances, 96 J. POL. EcON. II6 (I988).

235 Jagannathan \&Wu, supra note 7, at 6.

236 See Ray Ball \& S.P. Kothari, Nonstationary Expected Returns: Implications for Tests of Market Efficiency and Serial Correlation in Returns, 25 J. FiN. ECoN. 5 I (1989); K.C. Chan, On the Contrarian Investment Strategy, 6 I J. Bus. 147 (1988); Young-Hye Cho \& Robert F. Engle, Time-Varying Betas and Asymmetric Effects of News: Empirical Analysis of Blue Chip Stocks, National Bureau of Economic Research Working Paper No. 7330 (Sept. 1999) (available at http://www.nber.org/papers/w7330).

${ }^{237}$ See Choudhry \& Jayasekera, Comparison of Efficiency Characteristics, supra note 237, at 106.

${ }^{238}$ Fabozzi \& Francis, supra note 229, at 101 .

239 MARK HIRSCHEY, INVESTMENTS:THEORY AND APPLICATIONS 54I (2000).

240 See Ruey S.TSAY,ANalysis Of FInANCIAL TIME Series $§ 2.1$, at 30 (3d ed. 2010).

${ }^{241}$ Id. (emphasis in original).

242 Id.
} 
1. $\left\langle r_{t}\right\rangle=\mu$, where $\mu$ is a constant

2. $\operatorname{cov}\left(r_{t}, r_{t-l}\right)=\gamma_{l} ; \gamma_{0}=\operatorname{var}\left(r_{t}\right)$ - i.e., the "lag-l autocovariance of $r_{t}$ " depends "only on on $l$ "

Weak stationarity, if established, "enables one to make inference concerning future observations." 243 In particular, one "version of the capital asset pricing model (CAPM) theory is that the return $\left\{r_{t}\right\}$ of an asset is not predictable and should have no autocorrelations." ${ }^{244}$ Accordingly, checking for zero autocorrelations provides a test of "the efficient market assumption." 245 On the other hand, if $\left\{r_{t}\right\}$ "has a statistically significant lag- $l$ autocorrelation," then "the lagged return $r_{t-l}$ might be useful in predicting $r_{t} . " 246$

Serial correlation in returns differ by market, sometimes dramatically. "[F]irst-order serial correlation coefficients are higher for ... emerging markets" than for developed markets. ${ }^{247}$ Many emerging markets "have serial correlation that is much higher than one would expect based on knowledge of the serial correlation in developed markets." 248 Whereas "first-order serial correlation averages less than 1 percent" for certain developed markets, Campbell Harvey in 1995 found serial correlation coefficients ranging from 10 or $20 \%$ to an "astonishing" $49 \%$ "first-order autocorrelation in Colombia." 249 These differences are sufficiently large so as to connect serial correlation in emerging market returns to the preeminence of local information over global market dynamics. ${ }^{250}$

Volatility clustering therefore appears to prevail in many (if not necessarily all) financial markets. ${ }^{251}$ "High volatility begets high volatility," 252 and sharp deviations from expected returns are disproportionately likely to be followed by comparably sharp deviations. ${ }^{253}$ Serially correlated returns should be expected to exhibit greater variance and greater kurtosis. ${ }^{254}$ Moreover, "[a] symmetry in volatility may also imply asymmetry in time-varying betas." 255

\footnotetext{
${ }^{243} / \mathrm{d}$.

${ }^{244}$ Id. $\$ 2.2$, at 34 .

${ }^{245} \mathrm{Id}$.

246 Id. $§ 2.4$, at 37 .

${ }^{247}$ Harvey, Predictable Risk and Returns, supra note 109, at 779.

248 Id. at 780.

${ }^{249}$ Id. at 779 .

${ }^{250}$ See id. at 801 .

${ }^{251}$ Clustering is a common scientific phenomenon. Among the first disciplines to observe and describe clustering was hydrology. See generally Harold Edwin Hurst, Long Term Storage Capacities of Reservoirs, I I6 TRANSACTIONS AM. SOC'Y CIVIL ENG'RS 776 (I95I); Demetris Koutsoyiannis, The Hurst Phenomenon and Fractional Gaussian Noise Made Easy, 47 HYDROLOGICAL SCIS. 573 (2002).

252 MILLER, supra note 84 , at 231 .

${ }^{253}$ See, e.g., TSAY, supra note $240, \S \S 3.4,3.5$, at I I6, 132 (describing how conditional heteroskedastic time series models address volatility clustering in financial returns).

${ }^{254}$ See Robert C. Blattberg \& Nicholas J. Gonedes, A Comparison of the Stable and Student Distributions as Statistical Models for Stock Pries, 47 J. Bus. 244, 275-76 (1974); Fama, The Behavior of Stock Market Prices, supra note 176.

${ }^{255}$ Choudhry \& Jayasekera, Comparison of Efficiency Characteristics, supra note 237, at 108.
} 
In principle, however, "stock volatility ... is not directly obervable." 256 The "unobservability of volatility makes it difficult to evaluate the forecasting performance" of models purporting to describe and predict this phenomenon. ${ }^{257}$ Conventional time series models in finance include the autoregressive (AR), autoregressive conditional heteroskedasticity $(\mathrm{ARCH})$, and generalized autoregressive conditional heteroskedasticity (GARCH) models. The AR(1) model, or the "autoregressive (AR) model of order 1," represents a "simple model that makes use of [the] predictive power" of the lagged return:

$$
r_{t}=\phi_{0}+\phi_{1} r_{t-1}+a_{t}
$$

"where $\left\{a_{t}\right\}$ is assumed to be a white noise series with mean zero and variance $\sigma_{a}^{2}$." An alternative specification of $\mathrm{AR}(1)$ expresses returns as the "weighted average of [the] mean and its lagged value": 259

$$
\begin{aligned}
& \theta=1-\phi_{1} \\
& \mu=\frac{\theta_{0}}{\theta}=\frac{\theta_{0}}{1-\phi_{1}} \\
& r_{t}=\theta \mu+(1-\theta) r_{t-1}+a_{t}
\end{aligned}
$$

The celebrated "random walk" model in finance "is a special case of the AR(1) model, where $\left[\phi_{0}\right]$ is 0 and $\left[\phi_{1}\right]$ is equal to $1 . " 260$

For its part, ARCH assumes "that (a) the shock $a_{t}$ of an asset return is serially uncorrelated but dependent, and (b) the dependence of $a_{t}$ can be described by a simple quadratic function of its lagged values." ${ }^{261} \mathrm{ARCH}(n)$ therefore takes the following form: ${ }^{262}$

$$
\begin{aligned}
& a_{t}=\sigma_{t} \varepsilon_{t} \\
& \sigma_{t}^{2}=\alpha_{0}+\alpha_{1} \alpha_{t-1}^{2}+\ldots+\alpha_{n} \alpha_{t-n}^{2}
\end{aligned}
$$

First-order $\mathrm{ARCH}$, or $\mathrm{ARCH}(1)$, implies that "the unconditional mean of $a_{t}$ remains zero" and that "the unconditional variance of $a_{t}$ " is equal to: ${ }^{263}$

$$
\operatorname{var}\left(a_{t}\right)=\alpha_{0}+\alpha_{1}\left\langle a_{t-1}^{2}\right\rangle
$$

\footnotetext{
256 TSAY, supra note $240, \S 3.1$, at II 0 .

${ }^{257}$ Id.

258 Id. $\$ 2.4$, at 37

259 MILLER, supra note 84 , at 220 .

${ }^{260}$ Id. at 218; cf. Choudhry \& Jayasekera, Comparison of Efficiency Characteristics, supra note 237, at 109 \& n.20 (declining to assign a "zero order [to]AR," which would "give[] ... beta extreme volatility implying complete stochastic behaviour analogous to a random walk," on the grounds that treating beta as a random walk "does not seem to be a realistic model" for beta as "a time-varying process").

261 TSAY, supra note 240, § 3.4, at II5. See generally Robert F. Engle, Autoregressive Conditional Heteroscedasticity with Estimates of the Variance of United Kingdom Inflation, 50 EconOMETRICA 987 ( 1 982);Tim Bollerslev, Ray Y. Chou \& Kenneth F. Kroner, ARCH Modeling in Finance, 52 J. EconOMETRICS 52 (1992).

262 See TSAY, supra note $240, \S 3.4$, at III

${ }^{263}$ Id. § 3.4.I, at II7.
} 
In other words, the volatility and the variance of the disturbance function, $\left\{a_{t}\right\}$, are both "influenced by the lagged value of the disturbance term," $a_{t-1} \cdot{ }^{264}$ As long as the coefficient " $\alpha_{1}$ is greater than zero," there will be "serial correlation in the disturbance term."265

$\mathrm{ARCH}$ models rely on "many parameters to adequately describe the volatility process of an asset return," such as the $\mathrm{ARCH}(9)$ process used to model "monthly excess returns [on an] S\&P 500 index." 266 The search for an "alternative model” gave rise to generalized autoregressive conditional heteroskedasticity $(\mathrm{GARCH}) .{ }^{267}$ Let the disturbance term $a_{t}=r_{t}-\mu_{t}$. In that event, " $a_{t}$ follows a $\operatorname{GARCH}(m, s)$ model if": 268

$$
\begin{aligned}
a_{t} & =\sigma_{t} \varepsilon_{t} \\
\sigma_{t}^{2} & =\alpha_{0}+\sum_{i=1}^{m} \alpha_{1} a_{t-i}^{2}+\sum_{j=1}^{s} \beta_{j} \sigma_{t-j}^{2}
\end{aligned}
$$

GARCH is well suited to modeling time series with volatility clustering. A large value for " $a_{t-1}^{2}$ or $\sigma_{t-1}^{2}$ gives rise to a large $\sigma_{t}^{2}$. " 269 "This means that a large $a_{t-1}^{2}$ tends to followed by another large $a_{t}^{2}$, generating ... the well-known behavior of volatility clustering in financial time series." 270 As long as disturbance term $a_{t}$ has a defined variance, "the multistep-ahead volatility forecasts of a $\operatorname{GARCH}(1,1)$ model converge to the unconditional variance of $a_{t}$ as the forecast horizon increases to infinity." 271

$\mathrm{ARCH}$ and GARCH models encounter the same weaknesses. ${ }^{272}$ Among other things, because they "depend[] on the square of previous shocks" to calculate volatility, $\mathrm{ARCH}$ and GARCH models "assume[] that positive and negative shocks have the same effects on volatility." 273 This is a particularly disturbing flaw in a time series model for a process whose time-invariant prices "respond[] differently to positive and negative shocks." ${ }^{274}$ What is said of beta in space applies with equal force to beta in time: Because investor "sensitivities to upside and downside" financial statistics "are not equal," the "use of double-sided moments incorporating both upside and downside in one measure are not a realistic representation of investor preferences and behaviour." 275

\footnotetext{
${ }^{264}$ MILLER, supra note 84 , at 231 .

${ }^{265}$ Id.

${ }^{266}$ TSAY, supra note 240, § 3.5, at I3I. See generally Debabrata Basu, On the Elimination of Nuisance Parameters, 77 J.Am. Stat. Ass'n 355 (1977); James C. Spall \& John P. Garner, Parameter Identification for State-Space Models with Nuisance Parameters, 26 IEEE TrANSACTIONS ON AEROSPACE \& ELECTRONIC SYS. 992 (1990).

${ }^{267}$ TSAY, supra note 240, $\$ 3.5$, at I3I. See generally Tim Bollerslev, Generalized Autocregressive Conditional Heteroskedasticity, 3 I J. ECONOMETRICS 307 (1986).

${ }^{268}$ TSAY, supra note $240, \S 3.5$, at 132

269 Id.

270 ld.

271 Id. $\$ 3.5$, at 133

${ }^{272}$ See id. $\$ 3.5$, at 134 .

${ }^{273}$ Id. \$ 3.4.2, at II9.

274 Id.

275 Balzer, supra note 68 , at 142 .
} 
ARCH and GARCH models may also be criticized for their propensity "to overpredict ... volatility because they respond slowly to large isolated shocks to the return series." ${ }^{276}$ Finally, these models "provide [no] new insight for understanding the source of variations of a financial time series." 277 Serving merely as "mechanical" tools for "describ[ing] the behavior of ... conditional variance," ARCH and GARCH models "give[] no indication about what causes such behavior to occur." 278

Accordingly, the application of a time series model for bifurcated beta should not be interpreted as a choice involving meaningful analysis beyond a strictly empirical effort to fit a model to data regarding volatility and correlation. Even the standard divide in financial econometrics between BEKK as the tool of choice for measuring conditional covariance ${ }^{279}$ and DCC (dynamic conditional correlation) ${ }^{280}$ as the default tool for measuring conditional correlation carries a certain arbitrariness. ${ }^{281}$ Given the characteristics that bifurcated beta is known to demonstrate on a time-invariant basis, a time series model should detect asymmetry (ideally in variance as well as correlation) without excessive sensitivity to outliers. Those are precisely the traits that José María Montero, Gema Fernández-Avilés, and María-Carmen García have demonstrated in their application of a threshold asymmetric autoregressive stochastic volatility (TAARSV) model to energy commodity prices. ${ }^{282}$

Another time series model sharing TA-ARSV's potential to capture differences in volatility on the upside and the downside of bifurcated financial returns is exponential GARCH (EGARCH). ${ }^{283}$ To "allow for asymmetric effects between positive and negative asset returns," EGARCH evaluates "the weighted innovation": ${ }^{284}$

$$
g\left(\varepsilon_{t}\right)=\theta \varepsilon_{t}+\gamma\left[\left|\varepsilon_{t}\right|-\left\langle\left|\varepsilon_{t}\right|\right\rangle\right]
$$

$\theta$ and $\gamma$ are real constants. Since both $\varepsilon_{t}$ and $\left|\varepsilon_{t}\right|-\left\langle\left|\varepsilon_{t}\right|\right\rangle$ "are zero-mean [independent and identically distributed] sequences with continuous distributions," $\left\langle g\left(\varepsilon_{t}\right)\right\rangle=0 .{ }^{285}$ Upon rewriting, the asymmetry of $g\left(\varepsilon_{t}\right)$ is readily seen: ${ }^{286}$

\footnotetext{
${ }^{276}$ TSAY, supra note $240, \S 3.4 .2$, at II 9 .

277 Id.

${ }^{278} \mathrm{Id}$.

${ }^{279}$ See generally Robert F. Engle \& Kenneth F. Kroner, Multivariate Simultaneous Generalized ARCH, II ECONOMETRIC THEORY I22 (I995). Because this work in draft included contributions from Yoshi Baba and Dennis Kraft, it came to be known by the acronym of all four original authors' names: BEKK. See id. at 122.

${ }^{280}$ See generally Robert F. Engle, Dynamic Conditional Correlation:A Simple Class of Multivariate Generalized Autoregressive Conditional Heteroskedasticity Models, 20 J. Bus. \& Econ. STAT. 339 (2002).

281 See generally Massimiliano Caporin \& Michael McAleer, Do We Really Need Both BEKK and DCC? A Tale of Two Covariance Models (Feb. 2009) (available at http://www.ssrn.com/abstract=1338190).

282 Montero, Fernández-Avilés \& García, supra note III, at 345.

${ }^{283}$ See generally Daniel B. Nelson, Condtitional Heteroskedasticity in Asset Returns:A New Approach, 59 ECONOMETRICA 347 (I99I).

284 TSAY, supra note $240, \S 3.8$, at I 43 .

285 Id.

${ }^{286}$ See id.
} 


$$
\begin{aligned}
& \text { If } \varepsilon_{t} \geq 0, g\left(\varepsilon_{t}\right)=(\theta+\gamma) \varepsilon_{t}-\gamma\left\langle\left|\varepsilon_{t}\right|\right\rangle \\
& \text { If } \varepsilon_{t}<0, g\left(\varepsilon_{t}\right)=(\theta-\gamma) \varepsilon_{t}-\gamma\left\langle\left|\varepsilon_{t}\right|\right\rangle
\end{aligned}
$$

Accordingly, "the use of $g\left(\varepsilon_{t}\right)$ enables the [EGARCH] model to respond asymmetrically to positive and negative lagged values of [disturbance term] $a_{t} . " 287$

Full treatment of modeling single-sided beta and its constituent parts, volatility and correlation, as time-varying phenomena will await another time. "[ $T]$ ime is the longest distance between two places." 288 Let us "find in motion what was lost in space." 289 I will therefore conclude this interlude on time series and return to a strictly spatial topic: using the behavior of single-sided beta to extrapolate a logical progression from the conventional two-moment specification of the capital asset pricing model to a four-moment CAPM. "For nowadays the world is lit by lightning! Blow out your candles ... - and so goodbye." 290

\section{A four-moment capital asset pricing model}

\subsection{From asymmetric beta to coskewness and cokurtosis: harbingers of a four- moment capital asset pricing model}

This entire enterprise has been driven by recognition of asymmetry in financial markets - whether expressed in terms of returns, volatility, correlation, or some combination of those factors - and the anticipation of asymmetrical responses to those imbalances. While it is trivially true that "[d]ownside risk is relevant only when the security returns distribution is skewed," 291 it is more persuasive to say that asymmetry and skewness give single-sided beta and related measures their significance. " $[A]$ s long as ... distributions do not vary significantly from normality," then beta in its conventional, two-tailed form "is the appropriate 'risk measure' for a single asset held in an efficient portfolio." 292 Within the mean-variance framework of modern portfolio theory and the conventional CAPM, "[t] he systematic risk of a security is measured as the contribution to the variance of a well-diversified portfolio."293

\footnotetext{
${ }^{287}$ Id. § 3.8, at 143-44. See generally Charles Cao \& Ruey S. Tsay, Nonlinear Time Series Analysis of Stock Volatilities, 7 J.APPLIED ECONOMETRICS sI 65 (1992).

288 Tennessee Williams, The Glass Menagerie 96 (New Direction Books, 1999) (Ist ed. 1945).

289 Id. at 97.

290 Id. at 97 .

${ }^{291}$ Galagedera \& Brooks, supra note 109, at 215.

${ }^{292}$ Timothy J. Nantell \& Barbara Price, An Analytical Comparison of Variance and Semivariance Capital Market Theories, I 4 J. FIN. \& QUANT. ANALYSIS 22I, 23I (1979).

${ }^{293}$ Campbell R. Harvey \& Akhtar Siddique, Conditional Skewness in Asset Pricing Tests, 55 J. FIN. I263, 1264 (2000).
} 
The history of bifurcated risk measures reflects rapid if grudging acceptance of abnormality in financial markets. In 1979, Timothy Nantell and Barbara Price declined to embrace single-sided variance. At least "for normal distributions of portfolio returns," they reasoned, "semivariance below the expected return is half the portfolio's variance, and, hence, the more familiar variance measure may as well be used to quantify risk." 294 In 1982, Nantell and Price rejected their prior assumption of equivalence between ordinary beta and beta conditional on failure to meet expected return, especially for samples where both risk measures exceeded $1.0 .{ }^{295}$ The case for bifurcating the constituent risk measures of the conventional CAPM can therefore be expressed in very simple mathematical terms: "If the ratio" of variance to below-mean return semivariance "is not equal to two, then there is evidence that the distribution is skewed or asymmetrical." 296 "When the skewness of an asset return distribution is negative, then the downside returns will have a larger magnitude of returns than the upside returns, i.e., losses when they occur will tend to be large losses."297

The "considerable evidence that the unconditional returns distribution cannot be adequately characterized by mean and variance alone" naturally "leads us to the next moment - skewness." 298 As I have already noted, single-sided beta and its constituents (including semivariance and semivolatility) reflect both skewness and dispersion in financial returns. ${ }^{299}$ And as we have just seen, evidence assembled by Javier Estrada reveals a close connection between skewness and measures of volatility on either side of mean returns. The strongest evidence that skewed markets behave differently on the upside and the downside may subsist in the link between correlation and skewness. Correlations between equities and bonds rise in downside markets relative to their normal levels. ${ }^{300}$ This asymmetrical "exceedence correlation" in equity and bond markets "is directly related to negative skewness and higher kurtosis."301

All of these considerations now pose a pivotal methodological question. We must now ask whether the bifurcation of beta across financial space adequately addresses questions of skewness, or whether skewness merits further elaboration through an expanded capital asset pricing model that addresses higher moments beyond mean and variance. In expounding a proper model for asset allocation or asset pricing, the broad methodological goal is to avoid "the acceptance of irrelevant sources of sys-

\footnotetext{
${ }^{294}$ Nantell \& Price, supra note 292, at 222.

295 See Kelly Price, Barbara Price \& Timothy J. Nantell, Variance and Lower Partial Moment Measures of Systematic Risk: Some Analytical and Empirical Results, 37 J. FiN. 843, 854 (1982). Note: be sure to consider Pp. 852-53 of this source in the discussion of (co)skewness.

${ }^{296}$ Nawrocki, supra note 75

297 Id.

${ }^{298}$ Harvey \& Siddique, supra note 293 , at 1264

299 See sources cited supra 108.

${ }^{300}$ See, e.g., Baker \& Wurgler, supra note 24; Longin \& Solnik, supra note 170

${ }^{301}$ James A. Xiong \& Thomas M. Idzorek, The Impact of Skewness and Fat Tails on the Asset Allocation Decision, 67:2 FIN.ANALYSTS J. 23,30 (March/April 20II).
} 
tematic risk." 302 This paper alone has presented the risk measures of the conventional CAPM, examined those measures on either side of mean returns, and made various efforts to reconcile these approaches with work by Fama, French, and others emphasizing the size, value, and momentum characteristics of individual securities. ${ }^{303}$ The proliferation of competing risk measures raises the distinct possibility that many proposed financial statistics not only fail to advance our true understanding of risk, but also clutter and retard analysis with useless factors. ${ }^{304}$ Although no firm formula provides a firm safeguard against useless factors, "a large increment in $R^{2}$ and the persistence of [the] sign and size of coefficients over time are most likely to be associated with truly priced factors." 305

Within contemporary literature on mathematical finance, Don Galagedera may be the most persistent critic of risk measures based on downside volatility and beta. Galagedera does acknowledge the usefulness of downside risk measures: "[ $T$ ] he relationship between the CAPM beta and downside beta is influenced by characteristics such as the standard deviation, skewness and kurtosis of the market portfolio returns distribution. The influence of these characteristics is more pronounced in the relationships derived in the downside framework." 306 Emphasizing the small "proportion of equities benefiting from downside beta" and the resulting limits on the utility of that risk measure, ${ }^{307}$ however, Galagedera has advocated the adoption of more direct measures of skewness or coskewness in financial returns. If "co-semi-variance and co-semi-skewness between security returns and market portfolio returns" are "alternative" and therefore interchangeable "measures of downside risk," then "it may be sufficient to include a measure that accounts for co-semi-skewness in the pricing model rather than a measure of cosemi-variance." 308 In spite of other scholars' conclusion that downside beta can explain the cross-section of returns, ${ }^{309}$ Galagedera treats "downside beta and downside coskewness [as] highly correlated measures of downside risk," whose joint inclusion "in a pricing model" would allegedly "produce misleading results." 310

Galagedera poses the choice between second- and third-moment risk measures as a methodological struggle to define what his frequent intellectual nemesis, Javier Estrada, has described as the race to define the "model to beat" in emerging markets,

\footnotetext{
${ }^{302}$ Barone Adesi, Gagliardini \& Urga, supra note 44, at 474.

${ }^{303}$ See Estrada \& Serra, supra note 167, at 259.

${ }^{304}$ See generally Raymond Kan \& Chu Zhang, GMMTest of Stochastic Discount Factor Models with Useless Factors, 54 J. FIN. EcoN. I03 (I999); Raymond Kan \& Chu Zhang, Two-Pass Tests of Asset Pricing Models with Useless Factors, 54 J. Fin. 203 (1999).

${ }^{305}$ Barone Adesi, Gagliardini \& Urga, supra note 44, at 474.

306 Galagedera, An Alternative Perspective, supra note 80 , at 16.

${ }^{307}$ Galagedera, Economic Significance, supra note II5, at 1627.

${ }^{308}$ Galagedera \& Brooks, supra note 109, at 215.

${ }^{309}$ Compare Thierry Post \& Pim Van Vliet, Downside Risk and Asset Pricing, 30 J. BANKING \& FiN. 823 (2006) (accepting downside beta as a risk measure) with Galagedera \& Brooks, supra note 109, at 215 (dismissing Post and Van Vliet's conclusions).

${ }^{310}$ Don U.A. Galagedera, Elizabeth A. Maharaj \& Robert Brooks, Relationship Between Downside Risk and Return: New Evidence Through a Multiscaling Approach, 18 ApPLIEd FIN. ECON. 1623, I63I (2008)
} 
akin to the iconic contribution of the conventional CAPM to developed markets. ${ }^{311}$ Galagedera frames "variation in the difference between systematic risk measured in terms of co-semi-skewness and co-semi-variance" as a contest between "two downside systematic risk measures" for evaluating emerging markets. ${ }^{312}$

Other sources likewise support the consideration of coskewness within portfolio theory and asset pricing models. In response to Andrew Ang and Joseph Chen's suggestion that correlation asymmetry tracks not only Fama and French's size and value factors, but also momentum in returns, ${ }^{313}$ Giovanni Barone Adesi, Patrick Gagliardini, and Giovanni Urga proposed coskewness as a unique, meaningful source of financial risk. They argued that the "negative (positive) coskewness" of "small (large) firms ... with market returns" implies that "small firm portfolios are exposed to a source of risk" - namely, "market coskewness, which is different from the usual market beta and arises from negative covariance with large absolute market returns." ${ }^{114}$ In short, "characteristics such as firm size [may] have no explanatory power ... once coskewness is taken into account." 315 Positive correlation between coskewness and firm size suggests that the otherwise "anomalous" and illusory "explanatory power of size in the cross-section of expected returns ... is a proxy for omitted coskewness risk." 316

By contrast, other sources suggest that single-sided beta and coskewness measure different sources or elements of risk. Ang and Chen's study of correlation asymmetry “captur[ed] [information] that [was] fundamentally differently from skewness or co-skewness." ${ }^{317}$ Close inspection of the precise mechanics at work suggests a truly nuanced relationship between single-sided beta and coskewness. In contemporaneous work with Yuhang Xing, Ang and Chen found that "past downside betas," in general, do "predict future expected returns. ${ }^{318}$ Ang, Chen, and Xing not only found a "contemporaneous relationship between realized downside beta and realized average returns"; they also discovered that "high past downside beta predicts high future returns over the [following] month." ${ }^{319}$ Consistent with the low-volatility anomaly, however, these researchers concluded that "this relation breaks down among stocks with very high volatility." 320 Past beta offered very little guidance on "the future downside covariation of very

\footnotetext{
${ }^{311}$ Estrada \& Serra, supra note 167, at 268.

${ }^{312}$ Galagedera, Downside Framework, supra note II 5, at I52; see also Galagedera, Economic Significance, supra note II 5, at I632 (urging "further investigation of co-skewness as ... a measure of risk in the downside especially in emerging markets").

${ }^{313}$ Ang \& Chen, supra note 135 , at 445.

${ }^{314}$ Barone Adesi, Gagliardini \& Urga, supra note 44, at 482.

${ }^{315} / d$. at 483 .

${ }^{316} / d$.

${ }^{317}$ Ang \& Chen, supra note 135, at 47I; see also id. at 469 ("we are not caputruing the same information in [correlation asymmetry] as skewness and co-skewness").

${ }^{318}$ Ang, Chen \& Xing, supra note 90 , at 1193.

${ }^{319}$ Id.

${ }^{320}$ Id. Compare id. at II 94 ("stocks with very high volatility exhibit anomalously low returns") with id. at I232 ("it remains to be explored why the cross-sectional relation for downside risk does not hold for stocks with very high levels of volatility").
} 
volatile stocks." 321 For example, the "average one-year auto-correlation of one-year betas for very volatile stocks is only $17.3 \%$ compared to $43.5 \%$ for a typical stock." 322

Although "the proportion of the market where past downside beta fail[ed] to predict future returns" was modest in Ang, Chen, and Xing's study - "less than 4\% in terms of market capitalization" - a possible explanation lies in in coskewness. ${ }^{323}$ Coskewness "represents the contribution of an individual share to the skewness of a broader portfolio." 324 Although "past coskewness [does] predict[] future returns," the "predictive power of past coskewness" does not arise from a putative relationship between "past coskewness" and "future exposure to downside risk." ${ }^{25}$ Coskewness and downside beta "capture[] separate aspects of an investor's risk exposure," unsurprisingly, because the two measures of risk are "constructed differently." ${ }^{226}$ Because "[n] egative co-skewness and downside beta remain priced" as though "investors consider them to be separate risk exposures," even when the two factors are "assessed together," 327 "past downside beta and past coskewness are different risk loadings." 328 "Downside risk is different from coskewness risk because downside beta explicitly conditions for market downside movements in a nonlinear fashion, [whereas] the coskewness statistic does not explicitly asymmetries across down and up markets, even in settings where coskewness may vary over time." 329

Of its own force, however, recognizing that "exposure to negative co-skewness does differ from exposure to downside beta" does not wholly address the low-volatility anomaly. ${ }^{330}$ The two concepts continue to overlap; each risk measure "is rewarded by excess returns during upturns, and is penalized by lower returns during downturns." 331 More precisely, "sizable exposure to either downside risk measure is associated with positive relationships between variance and return during upturns, and negative relationships during downturns." 332 Even if we must ultimately refrain from "offer[ing] a[] [complete] explanation for the variance-return puzzle" of the low-volatility anomaly, in-depth evaluation of downside beta vis-à-vis negative coskewness "reveal[s] the complexity of this relationship, and ... suggest[s] a partial explanation." 333

\footnotetext{
${ }^{321}$ Id. at 1193.

322 Id. at 1194 .

${ }^{323} \mathrm{Id}$.

${ }^{324}$ Alles \& Murray, supra note 109, at 2504.

${ }^{325}$ Ang, Chen \& Xing, supra note 90 , at 1194.

${ }^{326}$ Alles \& Murray, supra note 109, at 2504; see also Ang, Chen \& Xing, supra note 90, at II 99 ("Downside beta and coskewness may potentially capture different effects.")

${ }^{327}$ Alles \& Murray, supra note 109, at 2508; see also id. at 2509 (assigning a 12\% price premium to downside beta and a $7 \%$ price premium to negative coskewness).

${ }^{328}$ Ang, Chen \& Xing, supra note 90, at I 194; accord id. at 1227 ("the predictive pattern for cross-sectional returns from past coskewness is not picking up downside risk").

${ }^{329}$ Id. at II 93 . On time-varying cokewness, see generally Campbell R. Harvey \& Akhtar Siddique, Autoregressive Conditional Skewness, 34 J. FiN. \& QUANT.ANALYSIS 465 (1999).

${ }^{330}$ Alles \& Murray, supra note 109, at 2507.

${ }^{331}$ Id.

332 Id.

${ }^{333} \mathrm{Id}$.
} 
Applying their own version of a four-moment Taylor series expansion, researchers at the Federal Reserve Bank of St. Louis have found "evidence of two regimes in U.S. stock markets, namely a bear state with high volatility and low mean returns and a bull state with high mean returns and low volatility." 334 In turn, this insight has spurred Tobias Adrian and Joshua Rosenberg to divide the components of market risk into a short-run component driven by volatility and market skewness and a long-run component reflecting business cycle risk. ${ }^{335}$ Even in the absence of intertemporal effects of the sort posited by Adrian and Rosenberg, the existence of distinct bear and bull market states, with corresponding shifts in volatility, correlation, and skewness as the market moves across the boundary between those regimes, would unlock many mysteries, from the low-volatility anomaly to the interaction of odd- and even-numbered statistical moments in distributions of financial returns.

In short, "[i]f the world behaves according to" a capital asset pricing model that has been "augmented ... with skewness," then we should adopt analytical models and statistical techniques that address "both beta and coskewness" 336 - and, if theory and evidence so warrant, some measure of kurtosis as well. As is evident from the debates described here, and from the incorporation of skewness and kurtosis in cognate areas of economics, ${ }^{337}$ mathematical finance has begun to extend the conventional CAPM from a two-moment to a three- or four-moment model. At the dawn of modern portfolio theory, Harry Markowitz suggested that investor utility might be a function not just of mean and variance, but also of skewness. ${ }^{338}$ In the decades before Fama and French's assault on conventional beta threatened the primacy of two-moment CAPM, canonical works in the financial literature had already laid the foundations for three- and four-moment CAPM. ${ }^{339}$ Although "financial theory has been [historically] reluctant" to fully "incorporat[e] higher order moments," the bifurcation of the CAPM into single-sided measures of risk on either side of mean returns leads inexorably toward explicit consideration of skewness and kurtosis in asset allocation and pricing. ${ }^{340}$

\footnotetext{
${ }^{334}$ Massimo Guidolin \& Allan Timmermann, Optimal Portfolio Choice Under Regime Switching, Skewness and Kurtosis Preferences, Federal Reserve Bank of St. Louis Working Paper 2005-006A, at 2 (Jan. 2005) (available at http://research.stlouisfed.org/wp/2005/2005-006.pdf).

${ }^{335}$ See Tobias Adrian \& Joshua Rosenberg, Stock Returns and Volatility: Pricing the Long-Run Components of Market Risk, 63 J. FIN. 2997 (2008).

${ }^{336}$ Campbell R. Harvey, Drivers of Expected Returns in International Markets, I:I EMERGING MKTS. Q. 32, 46 (Fall 2000).

${ }^{337}$ See, e.g., Rohan Christie David \& Kukesh Chaudhry, Coskewness and Cokurtosis in Futures Markets, 8 J. EMPIRICAL FIN. 55 (200I); Kim Hiang Liow \& Lanz Chan, Co-Skewness and Co-Kurtosis in Global Real Estate Securities, 22 J. Prop. ReSEARCH I63 (2005).

${ }^{338}$ Harry Markowitz, Portfolio Selection, 7 J. FIN. 77, 91 (1952); accord Harvey, Liechty, Liechty \& Müller, supra note 108 , at 469.

339 See generally, e.g., Arditti, supra note 53; Robert F. Dittmar, Nonlinear Pricing Kernels, Kurtosis Preference, and Evidence from the Cross-Section of Equity Returns, 57 J. FiN. 368 (2002); Irwin Friend \& RandolfWesterfield, Co-Skewness and Capital Asset Pricing, 35 J. FIN. 897 (I980); Jonathan E. Ingersoll, Jr., Multidimensional Asset Pricing, 10 J. FIN. \& QUANT. ANALYsIS 785 (1975) Alan Kraus \& Robert L. Linzenberger, Skewness Preference and the Valuation of Risk Assets, 3 I J. FIN. 1085 (1976); Haim Levy, A Utility Function Depending on the First Three Moments, 24 J. FIN. 715 (I969); Kian-Guan Lim, A New Test of the Three-Moment Capital Asset Pricing Model, 24 J. Fin. \& QuANT.ANAlYSIs 205 (1989); Mark E. Rubinstein, The Fundamental Theorem of Parameter-Preference Security Valuation, 8 J. FIN. \& QUANT.ANALYSIS 6 I (1973); Paul Samuelson, The Fundamental Approximation Theorem of Portfolio Analysis in Terms of Means, Variances and Higher Moments, 37 Rev. Econ. STUD. 537 (1970).

${ }^{340}$ Gustavo M. de Athayde \& Renato G. Flôres, Jr., Finding a Maximum Skewness Portfolio — A General Solution to Three-Moments Portfolio Choice, 28 J. ECON. DYN. \& CONTROL I335, 1336 (2004).
} 
To facilitate proper discussion of a four-moment capital asset pricing model, I now turn to formal specifications of skewness and kurtosis as, respectively, third- and fourth-moment attributes of a statistical distribution.

\subsection{Skewness and kurtosis}

"Skewness is a measure of symmetry, or more precisely, the lack of symmetry." ${ }^{341}$ Formally, the skewness of a random variable is the third standardized moment:

$$
\gamma_{1}=\left\langle\left(\frac{x-\mu}{\sigma}\right)^{3}\right\rangle=\frac{\mu_{3}}{\sigma^{3}}
$$

where $\mu_{3}$ designates the third central moment. ${ }^{342}$ The addition of skewness as the third standardized moment to an asset pricing model permits the dramatic depiction of portfolio optimization in three dimensions, as illustrated by this plot of the meanvariance-skewness space of possible portfolios accompanying 2010 work by Campbell Harvey, John Liechty, Merrill Liechty, and Peter Müller: ${ }^{343}$

\section{Weights of portfolios} consisting of Carnival,

Starwood,

\section{L-3 Communications, and Raytheon}

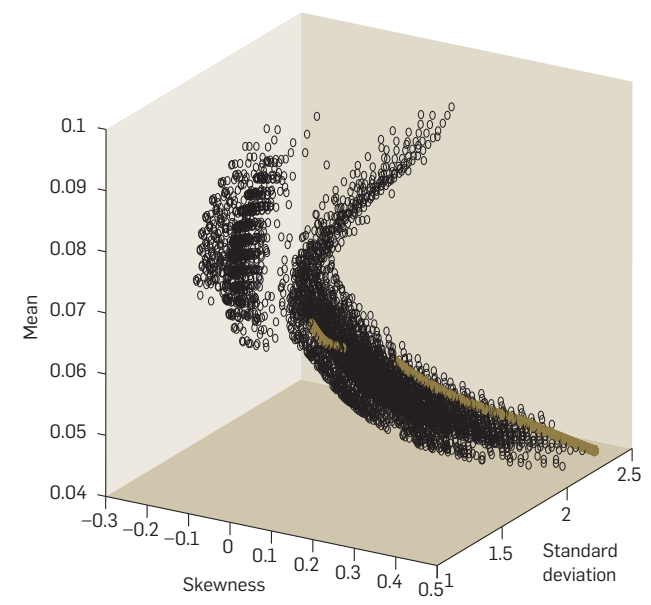

For its part, kurtosis "can be vaguely defined as the location- and scale-free movement of probability mass from the shoulders of a distribution into its center and tails." 344 A traditional (but rarely used) definition of kurtosis invokes the fourth standardized and central moments of a statistical distribution: ${ }^{345}$

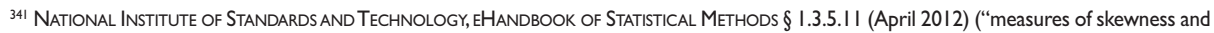
kurtosis") (available at http://www.itl.nist.gov/div898/handbook/eda/section3/eda35b.htm).

${ }^{342}$ https://en.wikipedia.org/wiki/Skewness. See generally Barry C.Arnold \& Richard A. Groeneveld, Measuring Skewness with Respect to the Mode, 49 Am. StATISTICIAN 34 (1995); Paul T. von Hippel, Mean, Median, and Skew: Correcting a Textbook Rule, 13:2 J. STAT. Educ. (July 2005); J.C.W. Rayner, D.J. Best \& K.L. Matthews, Interpreting the Skewness Coefficient, 24 CommUniCATIONS IN STAT.:THeORY \& Methods 594 (I995).

${ }^{343}$ Harvey, Liechty, Liechty \& Müller, supra note 108, at 482 (figure 9); see also id. at 476; Athayde \& Flôres, supra note 340, at I342; Harvey \& Siddique, supra note, at $127 \mathrm{I}$.

${ }^{344}$ Kevin P. Balanda \& H.L. MacGillivray, Kurtosis:A Critical Review, 42 AM. STATISTICIAN III, I I I (1988).

${ }^{345}$ https://en.wikipedia.org/wiki/Kurtosis.
} 


$$
\beta_{2}=\frac{\left\langle(x-\mu)^{4}\right\rangle}{\left\langle(x-\mu)^{2}\right\rangle^{2}}=\frac{\mu_{4}}{\sigma^{4}}
$$

The more familiar concept of excess kurtosis is formally "defined as the fourth cumulant divided by the square of the second cumulant, which is equal to the fourth moment around the mean divided by the square of the variance of the probability distribution minus $3 ": 346$

$$
\gamma_{2}=\frac{\kappa_{4}}{\kappa_{2}^{2}}=\frac{\mu_{4}}{\sigma^{4}}-3
$$

This understanding of the fourth moment more intuitively addresses the idea of kurtosis as the shape of "part of the distribution rather than" the shape of "the entire distribution." 347 In finance as in "the study of floods or pollution levels," it is "the tails (the extremes)" that "are of primary interest." 348

Skewness and kurtosis are closely related to each other. "The performance of skewness tests is ... very sensitive to the kurtosis of the underlying distribution." 349 Because "[d]ata sets containing extreme values" are not only "skewed, but also generally ... leptokurtic," it is impossible to "speak of non-normal skewness as if it were separable from non-normal kurtosis." 350 At best, "we can ... focus on the skewness statistic simply as one test for departure from the symmetric normal distribution." 351 "Although moments" - and in the case of kurtosis, "the value of the standardized fourth central moment $\beta_{2}$ " "play an important role in statistical inference, they are very poor indicators of distributional shape." 352 Financial theories often treat "kurtosis ... as a vague concept best formalized using partial orderings on distributions and measures that preserve them." 353

\subsection{Higher-moment CAPM as a Taylor series expansion}

The expansion of the capital asset pricing model to higher moments extends the intuition under conventional mean-variance optimization. If mean-variance optimization arises "from the idea that the investor prefers higher expected returns and lower risk," then higher-moment CAPM presumes, "ceteris paribus, investors prefer a high probability of an extreme event in the positive direction over a high probability of an extreme event in

\footnotetext{
${ }^{346}$ https://en.wikipedia.org/wiki/Kurtosis.

${ }^{347}$ Lawrence T. DeCarlo, On the Meaning and Use of Kurtosis, 2 PsYCH. Methods 292, 300 (1997).

${ }^{348}$ Id. See generally Thomas P. Hettmansperger \& Michael A. Keenan, Tailweight, Statistical Inference and Families of Distributions - A Brief Survey, in I A Modern Course on Statistical Distributions in SCientific Work: Models and Structures I6I (G.P. Patel, S. Kotz \& J.K. Ord eds., I975).

${ }^{349}$ Ronald L. Horswell \& Stephen W. Looney, Diagnostic Limitations of Skewness Coefficients in Assessing Departures from Univariate and Multivariate Normality, 22 COMMUNICATIONS IN STAT.: SIMULATION \& COMPUTATION 437, 437 (I993).

${ }^{350}$ David P. Doane \& Lori E. Seward, Measuring Skewness:A Forgotten Statistic?, I9 J. STAT. Educ. (July 20I I).

${ }^{351}$ Id. See generally Richard A. Groeneveld \& Glen Meeden, Measuring Skewness and Kurtosis, 33 J. RoYAL STAT. SOC'Y, SERIES D 39I (I984); D.N. Joanes \& C.A. Gill, Comparing Measures of Sample Skewness and Kurtosis, 47 J. RoYAL StAT. SOC'Y: SERIES D I83 (1998).

${ }^{352}$ Balanda \& MacGillivray, supra note 344 , at I I I.

${ }^{353}$ Id. at II 9; see also id. at III ('Like location, scale, and skewness, kurtosis should be viewed as a 'vague concept' that can be formalized in many ways.”). See generally Frederick MostelleR \& JOHN W.TUKey, DATA ANALYSIS AND REGRESSION, ch. I (I977)
} 
the negative direction." 354 On that assumption, mean-variance optimization under the conventional CAPM represents merely a special case of a more comprehensive model that accounts for asymmetry in returns (as expressed by skewness) and the relative probability of extreme events in the distribution of returns (as expressed by kurtosis). ${ }^{355}$ The goal, therefore, is to devise a theoretically coherent account of investor preferences with respect to at least the first four moments - mean, variance, skewness, and kurtosis.

One mathematically cogent "way of dealing with higher moments in the asset allocation is the use of the Taylor series expansion to derive an approximation of the expected utility function." "356 A higher-order Taylor series expansion can "simplify[] the asset allocation task" 357 and inform "optimal portfolio selection in the presence of ... higher-order moments and parameter uncertainty." 358 Specifically, to "[m]easure the effects of higher moments on ... asset allocation, we can "approximate the expected utility by a Taylor series expansion around the expected wealth."359

The Taylor series expansion for a function, $f(x)$, that is infinitely differentiable at value $a$ takes the form of a power series: ${ }^{360}$

$$
f(x)=f(a)+\frac{f^{\prime}(a)}{1 !}(x-a)+\frac{f^{\prime \prime}(a)}{2 !}(x-a)^{2}+\frac{f^{\prime \prime \prime}(a)}{3 !}(x-a)^{3}+\ldots
$$

Exploiting multiple mathematical identities - that $(x-a)^{0}$ and 0 ! both equal 1 , and the zeroth order derivative of $f(x)$ is $f(x)$ itself - enables us to express the Taylor series expansion in a more compact form:

$$
f(x)=\sum_{n=0}^{\infty} \frac{f^{(n)}(a)}{n !}(x-a)^{n}
$$

Accordingly, if an investor's "utility function is expressed in terms of the wealth distribution, so that":

$$
\langle U(w)\rangle=\int U(w) f(w) d w
$$

where $f(w)$ is "the probability distribution function of end-of-period wealth," contingent upon the multivariate distribution of returns" and the weights of the portfolio's components, then "the infinite-order Taylor series expansion of the utility function is":

$$
U(w)=\sum_{n=0}^{\infty} \frac{U^{(n)}(\bar{w})(w-\bar{w})^{n}}{n !}
$$

\footnotetext{
${ }^{354}$ Harvey, Liechty, Liechty \& Müller, supra note 108, at 47I.Athayde \& Flôres, supra note 340, at I342.

355 See Eric Jondeau \& Michael Rockinger, Optimal Portfolio Allocation Under Higher Moments, I2 EuR. Fin. MgMt. 29, 33 (2006).

356 Id. at 30

${ }^{357}$ Harvey, Liechty, Liechty \& Müller, supra note 108, at 470.

358 Id. at 469.

359 Jondeau \& Rockinger, supra note 355 , at 33.

${ }^{360}$ See https://en.wikipedia.org/wiki/Taylor_series. Unless otherwise noted, background information on the mathematics of the Taylor series expansion comes from this source. The special case of a Taylor series where $a=0$ is often designated a Maclaurin series.
} 
"where $\bar{w}=\langle w\rangle=1+\alpha$ ' $\mu$ denotes the expected end-of-period wealth," $\mu$ designates the vector of expected returns, and $\alpha$ designates the vector of portfolio weights. ${ }^{361}$

The application of this model to a simple set of financial returns is even more straightforward. "Let $R$ and $r$ denote simple (arithmetic) and logarithmic (continuously compounded) returns respectively." 362 By definition, $r=\ln (1+R) .{ }^{363}$ For the logarithmic function $\ln (1+x)$, the Taylor series expansion takes this form: ${ }^{364}$

$$
\ln (1+x)=\sum_{n=1}^{\infty}(-1)^{n+1} \frac{x^{n}}{n}
$$

Generalizing the Taylor series expansion to account for $\ln (1+x)$ at $x=\mu$ yields:

$$
\ln (1+\mu)+\frac{x-\mu}{1+\mu}-\frac{(x-\mu)^{2}}{2(1+\mu)}+\frac{(x-\mu)^{3}}{3(1+\mu)}-\frac{(x-\mu)^{4}}{4(1+\mu)}+o\left[(x-\mu)^{5}\right]
$$

where $o\left[(x-\mu)^{5}\right]$ represents remaining terms of order 5 and above. ${ }^{365}$ Inasmuch as time series also rely on logarithmic returns, a more elaborate third-order (or higher) Taylor series expansion may be derived by "relat[ing] the discount factor to the marginal rate of substitution between periods $t$ and $t+1$ in a two-period economy." 366

Somewhat optimistically, Javier Estrada leaps directly from this model to a Taylor series expansion that consists exclusively of alternative central statistical moments. He is partially correct - and almost entirely correct if we modify the definition of skewness and kurtosis. If we "let $\mu$ and $\sigma$ [represent] the mean and variance of $R$," then the conventional CAPM takes the form of a Taylor series expansion of expected returns: ${ }^{367}$

$$
\langle r\rangle=\langle\ln (1+R)\rangle=\ln (1+\mu)+\frac{x-\mu}{1+\mu}-\frac{1}{2} \cdot \frac{\sigma^{2}}{(1+\mu)^{2}}+R_{2}[\ln (1+R)]
$$

where $R_{n}(x)$ designates the remaining terms of the Taylor series expansion beyond order $n$ (which in this example is 2). ${ }^{368}$ Estrada omits the second term of the series, $\frac{x-\mu}{1+\mu}$, and takes no explicit account of the Taylor remainder. More critically, Estrada proposes to interpret the remainder term as direct implementations of skewness and kurtosis: ${ }^{369}$

$$
\langle r\rangle=\langle\ln (1+R)\rangle=\ln (1+\mu)-\frac{1}{2} \cdot \frac{\sigma^{2}}{(1+\mu)^{2}}+\frac{1}{3} \cdot \frac{\text { Skew }}{(1+\mu)^{3}}-\frac{1}{4} \cdot \frac{K u r t}{(1+\mu)^{4}}
$$

\footnotetext{
${ }^{361}$ Jondeau \& Rockinger, supra note 355 , at 33.

${ }^{362}$ Estrada, An Alternative Behavioural Model, supra note 89, at 241.

${ }^{363}$ See id.

${ }^{364}$ See https://en.wikipedia.org/wiki/Taylor_series.

${ }^{365}$ See http://www.wolframalpha.com/input/?i=taylor+series+for+ln\%281\%2Bx\%29+at+x\%3Dy.

${ }^{366}$ Harvey \& Siddique, supra note 293, at 1269.

${ }^{367}$ Estrada, An Alternative Behavioural Model, supra note 89, at 241.

${ }^{368}$ See https://en.wikipedia.org/wiki/Taylor\%27s_theorem.

${ }^{369}$ Estrada, An Alternative Behavioural Model, supra note 89, at 24I.
} 
And, likewise, for "[a]n approximate expected utility based on mean, variance, skewness and kurtosis ... for an investor who displays a logarithmic ... utility function": 370

$$
\langle r\rangle=\langle\ln (1+R)\rangle=\ln (1+\mu)-\frac{1}{2} \cdot \frac{\sigma^{2}}{(1+\mu)^{2}}+\frac{1}{3} \cdot \frac{\text { Skew }}{(1+\mu)^{3}}-\frac{1}{4} \cdot \frac{\text { Kurt }}{(1+\mu)^{4}}
$$

Estrada's interpretation of this Taylor series expansion is correct, but only if one defines skewness and kurtosis, respectively, as the third and fourth central moments rather than the third and fourth standardized moments. Potential confusion arises from other sources' adoption of the definition of skewness as the third standardized moment, $\gamma_{1}=\left\langle\left(\frac{x-\mu}{\sigma}\right)^{3}\right\rangle=\frac{\mu_{3}}{\sigma^{3}} \cdot{ }^{371}$ Note further that standard treatments of kurtosis subtract three from the fourth standardized moment in order to express excess kurtosis by reference to the kurtosis of a normal Gaussian distribution: $\gamma_{2}=\beta_{2}-3=\frac{\mu_{4}}{\sigma^{4}}-3$. In the interest of precision, we should restate Estrada's interpretation of the Taylor series expansion of log returns:

$$
\begin{aligned}
& \ln (1+x) \text { at }(x=\mu) \\
& =\ln (1+\mu)+\frac{x-\mu}{1+\mu}-\frac{(x-\mu)^{2}}{2(1+\mu)^{2}}+\frac{(x-\mu)^{3}}{3(1+\mu)^{3}}-\frac{(x-\mu)^{4}}{4(1+\mu)^{4}}+o\left[(x-\mu)^{5}\right] \\
& =\ln (1+\mu)+\frac{x-\mu}{1+\mu}-\frac{\sigma^{2}}{2(1+\mu)^{2}}+\frac{\mu_{3}}{3(1+\mu)^{3}}-\frac{\mu_{4}}{4(1+\mu)^{4}}+o\left(\mu_{5}\right)
\end{aligned}
$$

Therefore, this Taylor series expansion does correspond to definitions for skewness and kurtosis, ${ }^{372}$ but only if we define "skewness and kurtosis ... as central higher moments" in place of these terms' traditional "statistical definitions as standardised central moments." 373

If we insist, very modest rearrangement allows us to restate the Taylor series expansion in terms of more traditional interpretations of skewness and kurtosis - namely, $\gamma_{1}$, $\beta_{2}$, and $\gamma_{2}$ :

$$
\begin{aligned}
& \ln (1+x) \text { at }(x=\mu) \\
& =\ln (1+\mu)+\frac{x-\mu}{1+\mu}-\frac{\sigma^{2}}{2(1+\mu)^{2}}+\frac{\gamma_{1} \sigma^{3}}{3(1+\mu)^{3}}-\frac{\beta_{2} \sigma^{4}}{4(1+\mu)^{4}}+o\left(\mu_{5}\right) \\
& =\ln (1+\mu)+\frac{x-\mu}{1+\mu}-\frac{\sigma^{2}}{2(1+\mu)^{2}}+\frac{\gamma_{1} \sigma^{3}}{3(1+\mu)^{3}}-\frac{\left(\gamma_{2}+3\right) \sigma^{4}}{4(1+\mu)^{4}}+o\left(\mu_{5}\right)
\end{aligned}
$$

\footnotetext{
370 Id. at 246.

371 See, e.g., Balzer, supra note 68 , at 121 .

${ }^{372}$ Cf. Jondeau \& Rockinger, supra note 355 , at 34 (adopting a functionally equivalent definition of the Taylor series expansion of expected returns).

${ }^{373}$ Id. at 34 n.5. The abandonment of the statistical convention of defining skewness and kurtosis according to standardized central moments does separate more recent literature on three- and four-moment CAPM from the earliest works within this tradition. Compare sources cited supra note 339 (especially Friend \&Westerfield; Ingersoll; and Kraus \& Linzenberger) (relying on the traditional definition of skewness) with Harvey \& Siddique, supra note 293, at 1268 \& n.4 (relaxing the definition of skewness according to the third standardized central moment)
} 
The advantage of defining skewness and kurtosis in this Taylor series expansion as central moments, however, is the clarity with which the expression, $\ln (1+\mu)+\frac{x-\mu}{1+\mu}-\frac{\sigma^{2}}{2(1+\mu)^{2}}+\frac{\mu_{3}}{3(1+\mu)^{3}}-\frac{\mu_{4}}{4(1+\mu)^{4}}+o\left(\mu_{5}\right)$, demonstrates that the investor's "expected utility depends on all central moments of the distribution of end-of-period wealth." 374

Of even greater significance is what the Taylor series expansion implicitly says about the impact of skewness and kurtosis on investor welfare. Under rather modest assumptions - "positive marginal utility, decreasing risk aversion at all wealth levels," and a "strict consistency" in the investor's attitude toward a given statistical moment without regard to her or his wealth - "the following inequalities hold": ${ }^{375}$

$$
\begin{aligned}
& U^{(n)}(w)>0 \forall w, \text { if } n \text { is odd and } \\
& U^{(n)}(w)<0 \forall w, \text { if } n \text { is even. }
\end{aligned}
$$

Specifically, investors "have positive preference for positive skewness" and "negative

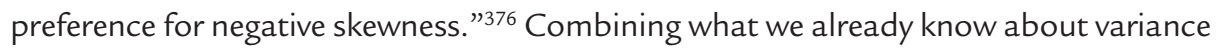
- that investors dislike it, at least on the downside - with this preference for positive skewness enables us to generalize to the next moment, kurtosis: "Consistent risk aversion, strict consistency of moment preference, and positive preference for positive skewness imply negative preference for the fourth statistical moment (kurtosis)." 377

Or, in simpler terms: "investors like mean return and positive skewness and dislike variance and kurtosis," since the even moments "produce a drag on expected compound return." 378 The alternating treatment of odd- and even-numbered mathematical moments represents a logical extension of "an essential non-linear feature of observed investor behavior" already "capture[d]" by the single-sided treatment of semivariance: "most investors perceive infrequent large losses or shortfalls [to be] far more risky than more frequent smaller losses or shortfalls." 379 As a result, investors generally "prefer high values for odd moments and low ones for even moments." 380 Whereas odd moments "can be seen as a way to decrease extreme values on the side of losses and increase them on the gains," even moments "measure dispersion, and therefore volatility, something undesirable that increases the uncertainty of returns." 381

\footnotetext{
${ }^{374}$ Jondeau \& Rockinger, supra note 355 , at 33.

375 Id. at 34.

${ }^{376}$ Robert C. Scott \& Philip A. Howath, On the Direction of Perference for Moments of Higher Order Than the Variance, 35 J. FiN. 915,917 (I980).

377 Id. at $917-18$.

${ }^{378}$ Estrada, An Alternative Behavioural Model, supra note 89, at 241.

${ }^{379}$ Balzer, supra note 68 , at 130 .

${ }^{380}$ Athayde \& Flôres, supra note 340 , at I 336.

${ }^{381}$ Id.
} 
Combining this insight with the basic, general definition of the Taylor series expansion as a function of differentials, factorials, and polynomials, $f(x)=f(a)+\frac{f^{\prime}(a)}{1 !}(x-a)+\frac{f^{\prime \prime}(a)}{2 !}(x-a)^{2}+\frac{f^{\prime \prime \prime}(a)}{3 !}(x-a)^{3}+\ldots$, enables an even simpler aproximation of expected returns or investor utility as a "preference function": 382

$$
\langle U(w)\rangle \approx U(\bar{w})+\frac{1}{2 !} U^{(2)}(\bar{w}) \sigma^{2}+\frac{1}{3 !} U^{(3)}(\bar{w}) S^{3}+\frac{1}{4 !} U^{(4)}(\bar{w}) k^{4}
$$

where $s$ and $k$ designate skewness and kurtosis, again defined as central moments. Consistent with our understanding of investor responses to odd and even moments, the actual expected utility approximated by this function "depends positively on expected return and skewness and negatively on variance and kurtosis." 383 In this view of the approximate preference function, the work of sorting expected return and skewness from variance and kurtosis is performed by the sign of the odd- and even-numbered derivatives of the utility function. Alternatively, if we insert the single-sided version of mean, variance, skewness, and kurtosis into the preference function, it becomes possible to frame downside risk as a sequence of "leakage sensitivit[ies]" to each moment. ${ }^{384}$ Leslie Balzer's version of the preference function thus extracts ordinary, quadratic, cubic, and quartic penalties, respectively tempered by 1 !, 2!, 3!, and 4!, for deviations in mean, variance, skewness, and kurtosis. ${ }^{385}$

Any Taylor series expansion of expected returns "is necessarily only an approximation," 386 and any model for asset allocation or pricing based upon it should be treated accordingly. To observe, as we have, that "expected utility depends on all central moments of the distribution of end-of-period wealth," is implicitly to commit to pursuing an infinite series expansion. 387 "[S] ince the infinite Taylor series expansion is not suitable for numerical implementation, [one] solution is to approximate the expected utility by truncating the infinite expression at a given" order. ${ }^{388}$ Just as the conventional CAPM omitted series elements above order 2, a four-moment expansion to kurtosis truncates a Taylor series remainder, albeit at a higher order.

Truncating a Taylor series expansion, however, is neither a trivial task, nor one with predictable, desirable outcomes. The Taylor series expansion does not invariably "converge to the expected utility"; it does so "under restrictive conditions only." 389 For example, although exponential series invariably converge, only some power series do. "Worse, the inclusion of an additional moment does not necessarily improve the qual-

\footnotetext{
${ }^{382}$ Jondeau \& Rockinger, supra note 355 , at 35.

${ }^{383}$ Id.

${ }^{384}$ Balzer, supra note 68 , at 141 .

385 See generally id. at 140-42, 150.

${ }^{386}$ Ang, Chen \& Xing, supra note 90 , at 1199

${ }^{387}$ Jondeau \& Rockinger, supra note 355 , at 33.

388 Id.

${ }^{389}$ Id. at 30.
} 
ity of the approximation." 390 In particular, "polynomial expansions ... may not be good global approximations" of a utility function that is kinked to reflect investor aversions toward risk and disappointment. ${ }^{391}$ As a result, there is "no general rule for selecting the order" at which a Taylor series expansion should be truncated. ${ }^{392}$ Indeed, some sources do not truncate the series, but rather omit terms according to empirical support for, say, the second and fifth order terms of a polynomial expansion, but not the first, third, or fourth. ${ }^{393}$

These limitations are ameliorated, if not fully overcome, through simplification. A Taylor series expansion that is truncated at a particular order can "provide[] an exact solution to the expected utility" as long as "utility is [defined] by a polynomial" of that order, as in a quadratic (Markowitz), cubic, or quartic utility function. ${ }^{394}$ Even without resorting to such definitional extremes, we can adopt "rather mild assumptions," such as continuity and infinite differentiability of our investor's utility function, so that "preference-weighted odd central moments are not dominated by their consecutive preference-weighted even central moments." 395 In other words, "including skewness and kurtosis" under these assumptions "always leads to a better approximation of the expected utility." 396

\subsection{Profusion and confusion over measures of coskewness and cokurtosis}

The implications of four-moment CAPM as elaborated through a Taylor series expansion are clear. "Everything else being equal, investors should prefer portfolios that are right skewed to portfolios that are left skewed.... [A]ssets that decrease a portfolio's skewness ... are less desirable and should command higher expected returns. Similarly, assets that increase a portfolio's skewness should have lower expected rates." 397 In addition, skewness should be priced apart from risk factors associated with lower-order moments. "Since the price of skewness should be negative, the implied risk premium for skewness should be positive.... [T] he implied risk premium for variance and skewness should be higher than that for variance alone ...."398

But it is not skewness as such, but rather the coskewness of an asset relative to the market portfolio, that does the real work of moving returns. High coskewness, which

\footnotetext{
${ }^{390} \mathrm{Id}$.

${ }^{391}$ Ang, Chen \& Xing, supra note 90 , at 1199.

${ }^{392}$ Jondeau \& Rockinger, supra note 355, at 30. See generally Patrick L. Brockett \& James R. Garven, A Reexamination of the Relationship Between Preferences and Moment Orderings by Rational Risk-Averse Investors, 23 GENEVA RISK \& INS. ReV. 127 (I998).

${ }^{393}$ See Ravi Bansal, David A. Hsieh \& S.Viswanathan, A New Approach to International Arbitrage Pricing, 48 J. FIN. I7I9, I733 (I993); Ronald Gallant, Peter E. Rossi \& George Tauschen, Stock Prices and Volume, 5 Rev. Fin. Stud. 199, 214 (1992).

${ }^{394}$ Jondeau \& Rockinger, supra note 355 , at 33.

395 Id. at 34.

$396 / d$.

${ }^{397}$ Harvey \& Siddique, supra note 293, at 1264.

${ }^{398}$ Id. at I29I.
} 
occurs when "an asset contributes positive skewness to a diversified portfolio," makes "that asset ... valuable" and will confer both "a high price" and "low expected return." 399 Negative coskewness, in the form of an "asset [that] contributes negative skewness" to the overall portfolio, drives a drop in price, and correspondingly "higher expected return," in order to induce purchases by investors. ${ }^{400}$ In even simpler terms: because "agents dislike stocks with negative coskewness, ... stocks with low coskewness tend to have high average returns." ${ }^{01}$

It therefore behooves us to distinguish carefully between skewness and coskewness. In the conventional capital asset pricing model, "it is only the beta that is rewarded, not the total volatility." 402 In order to "be consistent" and "analogous" with the CAPM's treatment of "beta and variance," we should structure higher-moment CAPM so that "only the systematic part of skewness (the coskewness) ... command[s] a reward." 403 This theoretically impeccable distinction between skewness and coskewness finds ample empirical support, as in a study by Andrew Ang and Joseph Chen concluding that "co-skewness monotonically increases with beta, while skewness has no discernable pattern." ${ }^{404}$ In short, "in the world of the augmented CAPM, coskewness should count, and skewness itself should not." ${ }^{405}$ Extending this logic rigorously to the fourth moment dictates the comparable inclusion of "the contribution to [the] kurtosis of a well-diversified portfolio," or cokurtosis, in a properly specified four-moment capital asset pricing model. ${ }^{406}$

At either the third or the fourth order of this higher-moment implementation of the CAPM, the distinction between simple, unconditional skewness or kurtosis, on one hand, and the appropriate, corresponding measure of coskewness or cokurtosis, on the other hand, parallels the distinction between variance and correlation. The distinction between those second moment concepts highlights the difference between a simple measure of dispersion and a measure of the extent to which dispersion in a specific source of returns moves alongside dispersion in the market as a whole.

Models approximating financial returns through Taylor series expansions, whether taken to two, three, or four orders, are just that: approximations. In the absence of a "utility function" with "an explicit form," "both downside beta and coskewness" must remain "approximations." 407 "Since [disappointment aversion] utility is kinked at an

\footnotetext{
${ }^{399}$ Harvey, supra note 336 , at 38.

400 Id.

${ }^{401}$ Ang, Chen \& Xing, supra note 90 , at 1193.

${ }^{402}$ Harvey, supra note 336 , at 38.

${ }^{403}$ Id.

${ }^{404}$ Ang \& Chen, supra note 135 , at 473.

${ }^{405}$ Harvey, supra note 336 , at 38.

${ }^{406} \mathrm{Id}$. at 46; see also id. (conceding the absence of an "attempt to measure ... cokurtosis" despite the presence of "a positive relation between kurtosis and returns" in emerging markets, albeit "not in developed markets").

${ }^{407}$ Ang, Chen \& Xing, supra note 90 , at II 99.
} 
endogenous certainty equivalent, skewness and other centered moments may not capture aversion to risk across upside and downside moments in all situations." 408 This insight embodies two prescriptions. First, having extended the CAPM from two to three or even four moments, we must move from central statistical moments to cross moments. Second, once we have properly specified cross moments for skewness and kurtosis, we need to measure them on either side of mean returns. These steps parallel those that we undertook in expounding upside and downside variants of volatility, variance, and beta.

The first of these steps is theoretically straightforward. Shifting from an extended CAPM based on central moments of an order greater than variance to a four-moment CAPM based on cross moments poses no serious conceptual problems. ${ }^{409}$ Like skewness, coskewness "can be motivated by a third-order Taylor expansion." 410 By extended analogy, so can its fourth-moment counterpart, cokurtosis. ${ }^{411}$

Rather, the immediate problem is one of choosing the right measure from a profusion of nontrivial measures of coskewness or cokurtosis. The formal statistical definition of coskewness suggests one possibility, ${ }^{412}$ which Andrew Ang and Joseph Chen (writing either in tandem ${ }^{413}$ or with Yuhang Xing $)^{414}$ and Campbell Harvey and Akhtar Siddique, ${ }^{415}$ have adopted:

$$
\gamma_{1}(a, m, m)=\frac{\left\langle\left(x_{a}-\mu_{a}\right)\left(x_{m}-\mu_{m}\right)^{2}\right\rangle}{\sqrt{\operatorname{var}\left(x_{a}\right)} \cdot \operatorname{var}\left(x_{m}\right)}=\frac{\left\langle\left(x_{a}-\mu_{a}\right)\left(x_{m}-\mu_{m}\right)^{2}\right\rangle}{\sigma_{a} \cdot \sigma_{m}^{2}}
$$

An obvious alternative to this definition is the other nontrivial formal measure of coskewness in statistics: ${ }^{416}$

$$
\gamma_{1}(a, m, m)=\frac{\left\langle\left(x_{a}-\mu_{a}\right)^{2}\left(x_{m}-\mu_{m}\right)\right\rangle}{\sigma_{m}^{2} \cdot \sigma_{m}}
$$

By contrast, in separate scholarship, Campbell Harvey has at least entertained the possibility that the definition of coskewness might include market-wide volatility, cubed, rather than some multiple of powers of asset-specific and market-wide volatility: ${ }^{417}$

\footnotetext{
${ }^{408}$ Id. (emphasis added).

${ }^{409}$ See generally MILLER, supra note 84, at 53-56.

${ }^{410}$ Ang, Chen \& Xing, supra note 90 , at 1197.

4II See Harvey, supra note 336, at 46.

${ }^{412}$ See https://en.wikipedia.org/wiki/Coskewness.

${ }^{413}$ See Ang \& Chen, supra note 135, at 469.

${ }^{414}$ See Ang, Chen \& Xing, supra note 90, at II 97.

${ }^{415}$ See Harvey \& Siddique, supra note 293, at 1276 (equation II) (defining $\beta_{S K D}$ as a "direct measure of coskewness"); see also id. ("As defined, standardized coskewness is unit-free and analogous to a factor loading.").

${ }^{416}$ See https://en.wikipedia.org/wiki/Coskewness.

${ }^{417}$ Harvey, supra note 336, at 33 (adopting this formulation as a "secondary measure of coskewness" to supplement the more traditional definition).
} 


$$
\beta_{S K D}=\frac{\left\langle\left(x_{a}-\mu_{a}\right)\left(x_{m}-\mu_{m}\right)^{2}\right\rangle}{\sigma_{m}^{3}}
$$

This measure appears to draw its inspiration from the definition of skewness as a special case of coskewness, where two otherwise random variables are in fact identical. ${ }^{418}$ In that event, the denominator also consists simply of volatility cubed.

Don Galagedera has evaluated two measures similar to Harvey's "secondary measure of coskewness." The first, named "E-gamma" after Javier Estrada, presents a possible "measure of systematic downside co-skewness risk": 419

$$
\frac{\left\langle\left(x_{a}-\mu_{a} \mid x_{a}<\mu_{a}\right)\left(x_{m}-\mu_{m} \mid x_{m}<\mu_{m}\right)^{2}\right\rangle}{\left\langle\left(x_{m}-\mu_{m} \mid x_{m}<\mu_{m}\right)\right\rangle^{3}}
$$

Galagedera appears to favor a second, similar measure he calls "downside gamma," which differs from E-gamma in the substitution of unconditional returns on an asset over the risk-free rate, $\left(x_{a}-x_{f}\right)$, for returns on that asset conditioned on their falling below their mean return, $\left(x_{a}-\mu_{a} \mid x_{a}<\mu_{a}\right)$ :420

$$
\frac{\left\langle\left(x_{a}-x_{f}\right)\left(x_{m}-\mu_{m} \mid x_{m}<\mu_{m}\right)^{2}\right\rangle}{\left\langle\left(x_{m}-\mu_{m} \mid x_{m}<\mu_{m}\right)\right\rangle^{3}}
$$

Galagedera touts his downside gamma measure as a "dominant" and "more appropriate explanatory variable" in pricing models that also include downside beta. ${ }^{421} \mathrm{Al}$ though "each component in the numerator of downside beta and downside gamma" is aligned so that "there is no loss of information" in switching between these measures, the difference in exponents "amplifies" the gamma measure's evaluation of "the contribution of excess market returns in the downside." ${ }^{22}$

Notably, we have not even contemplated kurtosis, let alone which among the three nontrivial measures of cokurtosis we might care to implement in extending the CAPM to four cross moments. ${ }^{423}$ The profusion of alternative definitions of coskewness alone makes it to easy to understand why "many standard risk models do not explicitly define coskewness or cokurtosis." 424 Despite the "obvious relevance" of coskewness and cokur-

\footnotetext{
${ }^{418}$ See https://en.wikipedia.org/wiki/Coskewness.

${ }^{419}$ Galagedera \& Brooks, supra note 109, at 217 (equation 6) (citing Estrada, Systematic Risk in Emerging Markets, supra note 51).

${ }^{420}$ Galagedera \& Brooks, supra note 109, at 217 (equation 2) (citing Hogan \& Warren, supra note 69); accord Galagedera, Downside Framework, supra note 115, at 147; Galagedera, Economic Significance, supra note 115, at 1627; Galagedera, Maharaj \& Brooks, supra note 310 , at I625.

${ }^{421}$ Galagedera \& Brooks, supra note 109, at 229.

422 Id. at 218.

${ }^{423}$ See generally https://en.wikipedia.org/wiki/Cokurtosis.

${ }^{424}$ MILLER, supra note 84, at 56.
} 
tosis "to risk management," "many models avoid these higher-order cross moments" for a very simple, practical reason." ${ }^{425}$ As the number of variables increases, the number of nontrivial cross moments increases rapidly." 426 For " $n$ random variables," the following formula reports "the number of nontrivial cross central moments of order $m$ ": 427

$$
k=\frac{(m+n-1) !}{m !(n-1) !}-n
$$

For a model with 10 variables - asset classes, geographic markets, individual securities - "there are 30 coskewness parameters and 65 cokurtosis parameters." 428 Once the number of variables reaches 100 , "these numbers increase," rather intractably, "to 171,600 " coskewness parameters "and over 4 million" cokurtosis parameters. ${ }^{429}$

\subsection{A way forward: relative lower partial moments}

Don Galagedera's emphasis on downside measures of coskewness suggests one way out of the thicket of proliferating cross moments. This entire article has rested a core premise of behavioral economics: since "investors are primarily concerned with downside risk," mathematical evaluation of financial risk "should concentrate on moments related to the downside tails of the return distributions." ${ }^{430}$ From this starting point, Leslie Balzer has devised a definition of "relative lower partial moments," whose orders are flexible enough to encompass all of the moments of interest to even an expanded version of the CAPM:

$$
R L P M^{n}=\left\langle\left|(x-b)^{n}\right| \mid x<b\right\rangle
$$

where $b$ designates the relevant benchmark return. This conditional definition implies that the value of a relative lower partial moment is unaffected by instances where $x \geq b$. Much of this article proceeds from the further premise that $b=\mu-$ that the relevant benchmark is mean return. But a regime of "personally relevant risk benchmarks" implies the definition of single-sided cross moments "relative to potentially random, rather than simply static, benchmarks."

Following Balzer's definition for orders 0 through 4 generates an entire family of relative lower partial moments that "provide[s] an elegant set of interesting information regarding returns which fall short of the benchmark": 431

\footnotetext{
${ }^{425} \mathrm{Id}$.

${ }^{426} \mathrm{Id}$.

${ }^{427}$ Id.

428 Id.

429 Id.

${ }^{430}$ Leslie A. Balzer, Measuring Investment Risk:A Review, 3:3 J. INVESTING 47, 57 (Fall 1994); accord Balzer, supra note 68, at 129. The balance of the information in this paragraph is derived from these sources.

43! Balzer, supra note 68 , at 129 .
} 
$R L P M^{0}$ is the probability of shortfall

$R L P M^{1}$ is the expected shortfall

$R L P M^{2}$ is the relative lower partial variance

$R L P M^{3}$ is related to the relative lower partial skewness

$R L P M^{4}$ is related to the relative lower partial kurtosis

Combining Balzer's relative lower partial moment framework with traditional mathematical definitions of the first four moments generates a comparably elegant family of financial statistics. Let $j=1$ to 4 serve as an indexing variable corresponding to the first four moments. A simple formula defines a risk measure, $r_{j}$, corresponding to each moment:

$$
r_{j}=\frac{\left\langle\left(x_{a}-\mu_{a}\right)\left(x_{m}-\mu_{a}\right)^{j-1}\right\rangle}{\sigma_{a} \sigma_{m}^{j-1}}
$$

For $j=1$ to 4 , this formula generates risk measures corresponding to very familiar financial statistics:

\begin{tabular}{llll}
\hline Order & Name & Symbol & Formula \\
\hline 1 & Sharpe ratio & $\mathrm{n} / \mathrm{a}$ & $r_{1}=\frac{\left\langle\left(x_{a}-\mu_{a}\right)\right\rangle}{\sigma_{a}}$ \\
\hline 2 & Correlation & $\rho(a, m)$ & $r_{2}=\frac{\left\langle\left(x_{a}-\mu_{a}\right)\left(x_{m}-\mu_{m}\right)\right\rangle}{\sigma_{a} \sigma_{m}}$ \\
\hline 3 & Coskewness & $\gamma(a, m, m)$ & $r_{3}=\frac{\left\langle\left(x_{a}-\mu_{a}\right)\left(x_{m}-\mu_{m}\right)^{2}\right\rangle}{\sigma_{a} \sigma_{m}^{2}}$ \\
4 & Cokurtosis & $\kappa(a, m, m, m)$ & $r_{4}=\frac{\left\langle\left(x_{a}-\mu_{a}\right)\left(x_{m}-\mu_{m}\right)^{3}\right\rangle}{\sigma_{a} \sigma_{m}^{3}}$ \\
\hline
\end{tabular}

The accommodation of cross moments greatly improves the potential performance of a four-moment capital asset pricing model. The elaboration of cross moments within an augmented CAPM would address concerns that returns hinge on coskewness between specific asset or asset classes and the broader market, and not simply on the skewness of one asset or asset class per se, evaluated without reference to the skewness of the rest of the portfolio. The recognition of this distinction parallels the inclusion of correlation within any consideration of variance or volatility.

This model also offers a simple solution to the problem of proliferation in plausible measures of higher cross moments. Unlike correlation, which consists of a single, symmetrical measure, coskewness and cokurtosis demand some choice between multiple nontrivial ways to measure higher cross moments. The $r_{j}$ model outlined above adopts measures of coskewness and cokurtosis, $\gamma(a, m, m)$ and $\kappa(a, m, m, m)$, that (respectively) square and cube differences between market-wide returns and the market-wide mean. It does so by analogy to the relationship between correlation and the 
Sharpe ratio. Other choices, of course, could be defended. For instance, we could define coskewness and cokurtosis by compounding differences between asset-specific returns and the asset-specific mean: $\gamma(a, a, m)$ and $\kappa(a, a, a, m)$. Or we could hew as closely to the middle as odd- and even-numbered cross moments permit. The last remaining nontrivial measure of cokurtosis, $\kappa(a, a, m, m)$ would be a natural candidate for such an approach. Within this symmetry-seeking framework, the corresponding third-moment measure could be based on the mean of the two nontrivial measures of coskewness, $\gamma(a, m, m)$ and $\gamma(a, a, m)$. Short of yielding to the proliferation of cross moments and calculating them all, however, we must make some choice.

This leaves the final question of elaborating these cross moments so that they reflect differences on either side of mean returns. Balzer's prescription for higher moments reflects the strategy explored in the balance of this article, which is bifurcation of a moment-based financial statistic into its upside and downside components. By analogy to semideviation, semivariance, and single-sided beta, we can specify each of these measures on either side of mean returns:

\begin{tabular}{llll}
\hline$r_{j}$ & Name & Symbol & Formula \\
\hline 1 & Downside Sharpe ratio & n/a & $r_{1,-}=\frac{\left\langle\left(x_{a}-\mu_{a} \mid x_{a}<\mu_{a}\right)\right\rangle}{\sigma_{a,-}}$ \\
\hline 2 & Downside correlation & $\rho_{-}(a, m)$ & $r_{2,-}=\frac{\left\langle\left(x_{a}-\mu_{a} \mid x_{a}<\mu_{a}\right)\left(x_{m}-\mu_{m} \mid x_{m}<\mu_{m}\right)\right\rangle}{\sigma_{a,-} \sigma_{m,-}}$ \\
\hline 3 & Downside coskewness & $\gamma_{-}(a, m, m)$ & $r_{3,-}=\frac{\left\langle\left(x_{a}-\mu_{a} \mid x_{a}<\mu_{a}\right)\left(x_{m}-\mu_{m} \mid x_{m}<\mu_{m}\right)^{2}\right\rangle}{\sigma_{a,-} \sigma_{m,-}^{2}}$ \\
\hline 4 & Downside Cokurtosis & $\kappa_{-}(a, m, m, m)$ & $r_{4,-}=\frac{\left\langle\left(x_{a}-\mu_{a} \mid x_{a}<\mu_{a}\right)\left(x_{m}-\mu_{m} \mid x_{m}<\mu_{m}\right)^{3}\right\rangle}{\sigma_{a,-} \sigma_{m,-}^{3}}$ \\
\hline
\end{tabular}

In sum, this expansion of a four-moment capital asset pricing model, from its origins as a Taylor series expansion of log returns, through an elegant implementation of relative lower partial moments for mean, variance, skewness, and variance, supplies tractable, mutually consilient single-sided moments for modeling risk across multiple dimensions of financial space.

\subsection{The practical implications of a spatially bifurcated four-moment capital asset pricing model}

Javier Estrada has argued that differences attributable to the bifurcation of beta on either side of mean returns, at least in emerging markets, are too substantial to ignore. ${ }^{432}$ We should likewise expect to find considerable differences in financial performance arising from the deployment of a four-moment capital asset pricing model,

${ }^{432}$ See sources cited supra note II3. 
the proper specification of this augmented CAPM according to cross moments, and the bifurcation of coskewness and cokurtosis along the upside and downside of mean returns. " $[\mathrm{A}]$ dopting sub-optimal investment strategies" in ignorance of higher-order moments undoubtedly inflicts "a large opportunity cost." 433 Eric Jondeau and Michael Rockinger have concluded that the "inability" of the conventional two-moment CAPM's "mean-variance criterion to cope with higher moments ... cost [s] more than 25 cents per dollar invested for all risk aversion levels." 434 They peg the "opportunity cost" of implementing higher-order variants of the CAPM at "significantly lower" levels: "about 10 cents" for a "three-moment strategy," plus an incremental "cost [for] the four-moment strategy ... not exceed[ing] 2.5 cents per dollar invested." 435

Even more intriguingly, a fully specified and properly implemented four-moment CAPM may unlock some of the deepest abiding mysteries in portfolio theory. Conventional mean-variance optimization is notorious for its "fail[ure] to [correctly] approximate the expected utility" for markets exhibiting "large departure[s] from normality." 436 "In such cases, ... three-moment or four-moment optimisation strategies may provide a good approximation of the expected utility." 437 Inasmuch as "[t]he failures of traditional asset pricing models often appear in specific groups of securities such as those formed on 'momentum' and small size stocks," the evaluation of "pricing errors" in those "asset pricing models" sheds light on the impact of skewness, kurtosis, and other statistical elements on asset pricing. ${ }^{438}$ Bifurcated four-moment CAPM therefore holds promise for better understanding of phenomena such as correlation asymmetry, the low-volatility anomaly, the persistence in differences between emerging and developed markets, and factor-based critiques of conventional asset pricing, including Fama and French's value and size factors and momentum trading.

\section{Correlation asymmetry}

As we have seen, the bifurcation of beta on either side of mean returns and the separate evaluation of the impact of volatility and correlation on single-sided beta suggest that correlation tightening may hold some of the answers to the low-volatility anomaly. Asymmetry in correlation, it turns out, is deeply connected to a wide range of anomalous phenomena in finance. In their foundational 2002 study of correlation, Andrew Ang and Joseph Chen did not merely "find that riskier stocks, as reflected in higher beta, have lower correlation asymmetry than lower beta stocks." 439 They also found that "greater correlation asymmetry" in "[r]eturns on portfolios of ... small

\footnotetext{
${ }^{433}$ Jondeau \& Rockinger, supra note 355 , at 50.

${ }^{434}$ Id.

${ }^{435} / \mathrm{ld}$.

${ }^{436} / \mathrm{ld}$.

${ }^{437} / d$.

${ }^{438}$ Harvey \& Siddique, supra note 293, at 1279.

${ }^{439}$ Ang \& Chen, supra note 135 , at 445.
} 
firms, value forms, or low past return firms." 440 "[S]ignificant correlation asymmetry" appears not only in speculative sectors such as international markets (where "correlations tend to increase on large negative, or 'bear market,' returns), ${ }^{441}$ but also in "traditional defensive sectors, such as petroleum and utilities." 442 This represents a comprehensive list of some of the most vexing problems in mathematical finance.

Among the conclusions of Ang and Chen's study, perhaps the most intriguing were those affecting evaluation of the low-volatility anomaly: "The portfolio of lowest beta stocks is the portfolio that exhibits the greatest correlation asymmetry. Lower risk firms exhibit more correlation asymmetry than higher risk firms." ${ }^{443}$ In light of evidence presented by Javier Estrada in 2007, which linked downside beta to correlation tightening, ${ }^{444}$ we might ponder whether skewness or coskewness bears on correlation tightening. Ang and Chen found no "pattern between past co-skewness and correlation asymmetry." 445 After "sorting stocks by coskewness" Ang and Chen concluded that coskewness was "not related to the degree of correlation asymmetry in [their] data." "466 They likewise discerned "no pattern in the skewness or co-skewness of portfolios formed by past conditional co-skewness." 447

The distinction between correlation tightening or asymmetry, on one hand, and skewness or coskewness, on the other hand, persisted in all market segments studied by Ang and Chen. Every portfolio in their study was "both negatively skewed and ... negatively co-skewed with the market." 448 This finding suggested "that there is some common component among all ... asymmetry statistics." 449 At the same time, however, Ang and Chen found low levels of correlation between (co)skewness and their measure of correlation asymmetry, indicated that they were "not capturing the same information" in correlation asymmetry "as skewness and co-skewness," but rather "capturing something that is fundamentally different" from those measures. ${ }^{450}$ This persistent failure to explain "correlation asymmetries in equity portfolios" through "traditional skewness and co-skewness measures," even for "small size, high bookto-market ratios, and low past return portfolios," confirms that "contemporaneous downside moves" by these asset classes "with the market" are "not reflected in measures that solely capture second moments, such as volatility." 451

\footnotetext{
${ }^{440} \mathrm{Id}$.

${ }^{44 I}$ Id. at 446

${ }^{442}$ Id. at 445 ; see also id. at 457 (table I) (presenting summary statistics on many of the foregoing categories); id. at 459 (figure 3 ) (illustrating downside correlation tightening between the broader market and defensive sectors, small and value stocks, and past losers). 


\section{Emerging markets}

The relationship between conventional, two-moment CAPM, bifurcated beta, and (co)skewness also sheds light on pricing anomalies in "emerging markets [that] are not fully integrated into world capital markets." ${ }^{452}$ Global capital markets continue to exhibit a striking difference between "emerging market returns," where "total variance can account for $52 \%$ of [the] variation," and "developed market returns," where total variance has "practically no[]" impact. ${ }^{453}$ In his 2000 evaluation of emerging markets, Campbell Harvey concluded that "semivariance measures," which "are all highly correlated with total variance," "account for a substantial part of the variation in ... emerging market returns." ${ }^{454}$ By contrast, semivariance had little impact in developed markets. ${ }^{455}$

Elaborating beyond considerations of semivariance and single-sided beta, Harvey linked the behavior of emerging markets to coskewness. Volatility and his measures of skewness showed "a positive relation for emerging markets but not developed markets." ${ }^{456}$ In "both developed and emerging markets," multiple measures of coskewness displayed "a negative relation," confirming the predictions of asset pricing theory "that more negative coskewness [should] get[] a higher expected return."457

In concert, these effects carry two significant implications for mathematical finance. The first of these lessons teaches more about imperfectly integrated markets in less developed parts of the world. The persistence of "total risk measures like variance and skewness" in "many emerging markets" is "consistent with their less-than-complete integration with world capital markets." 458 The second implication of Harvey's analysis, however, goes to the core of the four-moment capital asset pricing model and its explanatory power. "Risk measures implied by asset pricing pricing theory, in particular world beta and coskewness, work reasonably well in capturing the crosssection of average return in world markets." 459 Accordingly, a global implementation of the "CAPM with coskewness appears to have some ability to explain average returns in both developing and emerging markets." ${ }^{460}$ Bifurcated beta has already exhibited some value for modeling emerging markets. Enhancing that model, and extending it to the third and fourth moments of the distribution of returns, may yet rehabilitate the CAPM in emerging and developed markets around the world.

\footnotetext{
${ }^{452}$ Harvey, supra note 336 , at 45 .

${ }^{453}$ Id. at 35 .

${ }^{454}$ Id. at 38

455 See id.

$456 / d$.

${ }^{457}$ Id. at 45 .

458 Id. at 48.

459 Id.

${ }^{460} / d$. at 47.
} 


\section{Size, value, and momentum}

Finally, a bifurcated, four-moment approach to asset pricing may provide good answers to the anomalous market segments and trading strategies that have most persistently vexed the conventional CAPM. It is now received wisdom that "the standard CAPM" fails to "explain[] the returns of ... the smallest market-capitalized deciles" and stocks with low book-to-market ratios, as well as "returns for specific [trading] strategies such as ... momentum." 461 Those are also the "assets ... with the most skewed returns." 462 Devising an explanation for these anomalies in terms of all four cross moments and the bifurcated nature of an augmented CAPM would go a long way toward reconciling conventional approaches to portfolio theory with Fama and French's size and value factors and with momentum trading.

The leading study of these relationships remains Campbell Harvey and Akhtar Siddique's canonical 2000 article, Conditional Skewness in Asset Pricing Tests. Consistent with contemporaneous work by Harvey alone, the ultimate emphasis should fall not on skewness as such, but on coskewness between disputed asset or asset classes and the overall market. ${ }^{463}$ To be sure, overall skewness does matter in the sense that "[n]onincreasing absolute risk aversion implies that ... increases in total skewness are preferred." ${ }^{464}$ But changes in total skewness do not take place in the abstract or in a financial vacuum. Instead, they arise from the coskewness of individual components of the overall porfolio. "Since adding an asset with negative coskewness ... makes [a] portfolio more negatively skewed, ... assets with negative coskewness must have higher expected returns than assets with identical risk-characteristics but zero-coskewness." 465 Asset-specific differences in coskewness assume heightened signficance in market conditions where "unconditional skewness is negative" for baseline portfolios in "both U.S. and world" markets. ${ }^{466}$

Harvey and Siddique found, "as expected," a "negative correlation between [their] direct measures of coskewness and ... mean returns" for all test portfolios. ${ }^{467}$ For "three-way (size, book-to-market, and momentum) sorted portfolios," which combined Fama and French's size and value factors with momentum trading strategies, Harvey and Siddique found "a remarkably sharp relation between the direct measure of skewness, and ... mean returns ( -0.71 correlation)." ${ }^{468}$

Using a "full-information maximum likelihood (FIML) method that [did] not allow time-series variation in the betas" and therefore "explicitly assume[d] that the betas

\footnotetext{
${ }^{461}$ Harvey \& Siddique, supra note 293 , at 1264.

462 Id. at 47.

${ }^{463}$ Cf. Harvey, supra note 336, at 38 ("in the world of the augmented CAPM, coskewness should count, and skewness itself should not").

464 Harvey \& Siddique, supra note 293 , at 1269.

465 Id. at $1269-70$.

466 Id. at $129 \mid$

467 Id. at 1278

${ }^{468}$ /d. at I 279 .
} 
[were] constant over time," 469 Harvey and Siddique reported $R^{2}$ values linking the following test portfolios: ${ }^{470}$

\begin{tabular}{lccc}
\hline $\begin{array}{l}\text { Portfolios (vertical axis) versus } \\
\text { pricing models (horizontal axis) }\end{array}$ & $\begin{array}{c}\text { Fama and French's } \\
\text { 3-factor pricing model }\end{array}$ & $\begin{array}{c}\text { CAPM with negative } \\
\text { coskewness }\end{array}$ & $\begin{array}{c}\text { CAPM alone } \\
\text { ("one-factor CAPM") }\end{array}$ \\
\hline Size and book-to market (value) & $71.8 \%$ & $68.1 \%$ & $11.4 \%$ \\
\hline Momentum & $89.1 \%$ & $61.0 \%$ & $3.5 \%$ \\
\hline
\end{tabular}

Although Fama and French's "three-factor model always" outperformed "the onefactor CAPM," adding "a skewness factor makes the single-factor strikingly more competitive." 471 Combining negative coskewness with Fama and French's three-factor pricing model increased the asset pricing model's explanatory power to 95 percent. ${ }^{472}$

At a minimum, this analysis demonstrated that Fama and French's size and value factors, "to some extent, capture[d] information similar to that captured by skewness." 473 Even more "[i]mportantly, the addition of the skewness factor add[ed] something over and above the three-factor model." 474 Adding skewness "raise[d] the expalantory power in all ... portfolio groups with the exception of the size portfolios" - where "the explanatory power of the CAPM plus skewness" was already "slightly higher than that of the three-factor model." 475

Harvey and Siddique found similar results for momentum trading. ${ }^{476}$ "Momentum or relative strength [trading] strategies have posed the greatest challenge for asset pricing models," since "the strategy of buying [past] winners and selling losers ... produce[s] abnormal returns," even to the point of constituting "a large component of ... abnormal returns" overall. 477 Surveying momentum in equity markets from 1992 through 1997, Harvey and Siddique found that "winners have substantially lower skewness than losers": 478 "For every momentum definition, the skewness of the loser portfolio [was] higher than that of the winner portfolio... The higher mean strategy is associated with lower skewness." 479 Indeed, as Andrew Ang and Joseph Chen concluded in parallel research, " $[\mathrm{m}]$ omentum strategies are more profitable than they first appear, because in times of market distress, loser stocks ... are more likely to fall with the market than past winners." 480

\footnotetext{
${ }^{469} \mathrm{Id}$. at 1282

$470 \mathrm{Id}$. at 1283 .

${ }^{471}$ Id.

${ }^{472}$ See id.

${ }^{473} \mathrm{Id}$.

${ }^{474} \mathrm{Id}$.

${ }^{475} \mathrm{Id}$.

${ }^{476}$ See id.

${ }^{477}$ Id. at 1288 .

${ }^{478} \mathrm{Id}$.

${ }^{479} / \mathrm{ld}$.

${ }^{480}$ Ang \& Chen, supra note I35, at 475.
} 
These conclusions carry deep "implications for asset allocation and portfolio analysis." 481 The presence of a skewness premium across all market conditions, "higher than what one should expect from variance alone," could help "explain the market risk premium" for equities over all other asset classes. ${ }^{482}$ Better understanding of the bifurcated nature of coskewness, on either side of mean returns, could help clarify "the asymmetrical variance phenomenon," whereby conditional variance increases when returns are negative. ${ }^{483}$ Suffice it to say that the elaboration of capital asset pricing beyond its conventional "mean-variance framework," and outward in financial space to the consideration of higher-order cross moments on either side of mean return, and their relationship to known anomalies involving emerging markets, size and value factors, and momentum trading, promises to enhance portfolio theory through the rise of "a richer conditional mean-variance-skewness [and -kurtosis] framework." 484

\section{Finance as a romance of many moments ${ }^{485}$}

Eugene Fama and Kenneth French's demolition of beta in 1992 heralded the scholarly embrace of multifactor asset-pricing models at the expense of the conventional capital asset pricing model. Over the past generation, finance has likewise acknowledged however grudgingly and belatedly - the economic impact of investor behavior. Finance nevertheless remains a mathematical romance, one in which the ultimate quest is that of finding the asset-pricing formula, the statistical distribution, and the set of equations that best explain the behavior of capital markets. But the simplicity and elegance of mathematical finance in its modern incarnation have yielded to the anomalies and abnormalities of a more nuanced age. ${ }^{486}$ Asymmetry, autocorrelation, and aleatory uncertainty have taken center stage in a new financial drama. Extensions of the CAPM's classic toolkit enable us to evaluate, perhaps even to master, the new quantitative landscape.

In its grandest manifestations, portfolio theory is a pattern of timeless moments. Despite their shortcomings, modern portfolio theory and mathematical models derived from it continue to wield considerable influence. A wide range of policy judgments continue to rest on the assumption that market returns and risks follow the visually supple and analytically pliable curves of the standard normal distribution. Indeed, the metaphysical arc of modern portfolio theory and its intellectual successors ex-

\footnotetext{
${ }^{481}$ Harvey \& Siddique, supra note 293 , at 1292.

${ }^{482}$ Id. at I29I-92. On the equity premium puzzle, see generally sources cited supra note.

${ }^{483}$ Harvey \& Siddique, supra note 293 , at 1292.

${ }^{484}$ Id.

${ }^{485}$ Cf. EdWIn AbBott AbBott, Flatland:A Romance of Many Dimensions (I884).

${ }^{486}$ Cf. Baker, Bradley \& Wurgler, supra note 152, at 43 (noting the "considerable energy" and "newer models" that have driven mathematical finance "[f]or the past few decades," which "make the mathematics of the CAPM look quaint").
} 
hibits the seductive symmetry of "beauty supreme - a beauty cold and austere, like that of sculpture, without any appeal to any part of our weaker nature, without the gorgeous trappings of painting or music, yet sublimely pure, and capable of a stern perfection such as only the greatest art can show." 487 The attraction in law and finance to formal elegance reflects a love affair with the Gaussian mathematics that dominates the culture of contemporary business and science. ${ }^{488}$

In this period of scientific transition, mathematical finance often finds that it "can no longer understand [itself] because the theories ... of [its] former age no longer work and the theories of the new age are not yet known." 489 We have exactly one path forward: to "start afresh as if [we] were newly come into a new world." ${ }^{490}$ We have no choice but to subject the comforting mirage of modern portfolio theory to a withering postmodern critique. The law's preference for ordered liberty must give way to pragmatic exigencies. When at last we grasp the uncomfortable truth that Gaussian models of risk and return belong to "a system of childish illusions," our affair with the seductive symmetry of traditional risk modeling shall pass "like first love ... into memory." 491

\section{Acknowlegments}

Christian Diego Alcocer Argüello provided very capable research assistance. I appreciate comments by Jagoda Kaszowska, Daniel Martin Katz, Othmar Lehner, José-María Montero Lorenzo, Merav Ozair, Jeffrey A. Sexton, Jurica Šimurina, and Gal Zahavi. Special thanks to Heather Elaine Worland Chen.

\footnotetext{
${ }^{487}$ Bertrand Russell, The Study of Mathematics, in Mysticism AND LogiC,AND Other Essays 58, 60 (I988); accord Jim Chen, Truth and Beauty:A Legal Translation, 4I U.TOLEDO L. Rev. 26 I, 265 (2010).

${ }^{488}$ See TALEB, supra note 9, at 278.

${ }^{489}$ Walker Percy, The Delta Factor, in The Message in the Bottle 3, 3 (1986).

${ }^{490}$ Id. at 7.

491 DAVID BERLINSKI,A TOUR OF THE CALCULUS 239 (1995).
} 
